MILENE GALETI

\title{
ESTUDO TEÓRICO-EXPERIMENTAL DO TRANSITÓRIO DA CORRENTE DE DRENO E DO TEMPO DE VIDA DE GERAÇÃO EM TECNOLOGIAS SOI MOSFETS
}

São Paulo 


\section{MILENE GALETI}

\section{ESTUDO TEÓRICO-EXPERIMENTAL DO TRANSITÓRIO DA CORRENTE DE DRENO E DO TEMPO DE VIDA DE GERAÇÃO EM TECNOLOGIAS SOI MOSFETS}

Tese apresentada à Escola Politécnica da Universidade de São Paulo para obtenção do título de Doutor em Engenharia.

São Paulo 


\section{MILENE GALETI}

\section{ESTUDO TEÓRICO-EXPERIMENTAL DO TRANSITÓRIO DA CORRENTE DE DRENO E DO TEMPO DE VIDA DE GERAÇÃO EM TECNOLOGIAS SOI MOSFETS}

Tese apresentada à Escola Politécnica da Universidade de São Paulo para obtenção do título de Doutor em Engenharia.

Área de Concentração:

Engenharia Elétrica

Orientador:

Prof. Dr.

João Antonio Martino

São Paulo 
Este exemplar foi revisado e alterado em relação à versão original, sob responsabilidade única do autor e com a anuência de seu orientador.

São Paulo, de de 2008.

Assinatura do autor

Assinatura do orientador

\section{FICHA CATALOGRÁFICA}

\section{Galeti, Milene}

Estudo teórico-experimental do transitório da corrente de dreno e do tempo de vida de geração em tecnologias SOI MOSFETs / M. Galeti. -ed.rev.-- São Paulo, 2008. $148 \mathrm{p}$.

Tese (Doutorado) - Escola Politécnica da Universidade de São Paulo. Departamento de Engenharia de Sistemas Eletrônicos.

1. Transistores 2.Simulação 3.Modelos analíticos 4.Dispositivos eletrônicos I.Universidade de São Paulo. Escola Politécnica. Departamento de Engenharia de Sistemas Eletrônicos II.t. 
Este trabalho foi realizado com o apoio das seguintes entidades:

- Conselho Nacional de Desenvolvimento Científico e Tecnológico - CNPq.

- Laboratório de Sistemas Integráveis - LSI/EPUSP. 


\section{DEDICATÓRIA}

À Marlene Andreuccetti “in memorian”

Tenho razão de sentir saudades, mãe, daquelas noites em que sentia seu beijo sobre a minha testa, suas mãos alisando meus cabelos, ajeitando o cobertor e depois saindo do meu quarto nas pontas dos pés. Era bom ouvir seus passos vindo para perto da minha cama ... Sinto saudades ainda, mãe, das brincadeiras no quintal, das nossas aventuras e do seu afago depois. Em meio a essas lembranças, me sinto sozinha, mas não infeliz. Apenas sinto saudades ... Muitas saudades... Sinto falta de você ao meu lado.

Hoje sou o seu fruto maduro, e dedico esta conquista a você com todo o meu amor. Em nome do nosso pacto implícito: "Nunca desistir”. 


\section{AGRADECIMENTOS}

Agradeço aos meus queridos filhos, Giulia e Pedro, por fartarem a minha vida com tantas alegrias e fazerem da minha luta a sua luta, acomodando em suas vidas a minha ausência.

Devo agradecer com fervor ao meu pai, aos meus irmãos e aos meus avós pelo exemplo, formação e apoio indispensável. Porque estas pessoas, sem sombra de dúvida, formaram a melhor sala de aula que já tive a oportunidade de freqüentar.

Ao Prof. Dr. João Antonio Martino não só pela orientação cuidadosa e confiança depositada, mas pelo constante incentivo, sempre indicando a direção a ser tomada nos momentos de maior dificuldade.

Aos grandes amigos do grupo SOI-CMOS que me deram a oportunidade de convivência e assim contribuíram de forma imprescindível com o meu crescimento pessoal e profissional.

Aos jovens e talentosos pesquisadores do LSI que muitas vezes se confundiram com a minha família, pois muitas vezes tudo o que precisei foi de uma mão para segurar e um coração para me entender.

Ao Laboratório de Sistema Integráveis da Escola Politécnica da Universidade de São Paulo pela disponibilidade da infra-estrutura necessária para a realização deste trabalho.

Ao CNPq pelo apoio financeiro que possibilitou esta atividade de pesquisa.

A tantas outras pessoas, que de alguma forma colaboraram para a realização deste trabalho e que, de forma involuntária, foram aqui omitidos. 
“Ninguém pode construir em meu lugar as pontes que precisarei passar, para atravessar o rio da vida. Ninguém, exceto eu, só eu. Existem, por certo, atalhos sem números, e pontes, e semideuses que se oferecerão para levar-me além do rio; mas isso me custaria a minha própria pessoa; eu me hipotecaria e me perderia. Existe no mundo um único caminho por onde só eu posso passar. Onde leva? Não perguntei, segui-o.”

Nietzsche. 


\section{RESUMO}

Este trabalho apresenta um estudo sobre o transitório da corrente de dreno e métodos de extração de tempo de vida de geração em transistores SOI MOSFETs parcialmente depletados de porta simples, porta dupla e FinFETs de porta tripla. Este estudo foi baseado tanto em simulações numéricas bidimensionais como em dados experimentais extraídos a partir de transistores fabricados no IMEC (Interuniversity Microelectronics Center), que fica na Universidade Católica de Leuven (KUL) na Bélgica.

Inicialmente foi analisada a influência da espessura do óxido de porta e da temperatura na extração do tempo de vida de geração dos portadores utilizando o transitório da corrente de dreno. Nesta análise, além do tempo de vida de portadores, outros parâmetros elétricos também foram estudados, como a tensão de limiar, o potencial de superfície na primeira interface e a energia de ativação para criação de um par elétron-lacuna. Com o estudo da influência dos parâmetros de processo no método de determinação do tempo de vida de geração foi possível propor um modelo simples para estimar o tempo de geração dos portadores em função da temperatura. Este modelo foi aplicado experimentalmente e comparado com resultados obtidos através de simulações apresentando um erro máximo de $5 \%$.

Fez-se uma análise detalhada do impacto da presença da região de implantação de HALO na extração do tempo de vida de geração baseando-se no transitório da corrente de dreno. Os resultados obtidos através deste estudo possibilitaram a proposta de um novo modelo. O modelo proposto considera tanto o impacto da lateralidade não uniforme da dopagem do canal no efeito de corpo flutuante, devido à presença das regiões de implantação de HALO, como também as cargas controladas pelas junções de fonte e dreno, o que até então não havia sido alvo de estudo na literatura. Com as novas considerações tornou-se possível à análise do transitório da corrente de dreno com a redução do comprimento de canal. A sensibilidade do novo modelo foi ensaiada com a variação de $\pm 20 \%$ nas concentrações da região de canal e de implantação de HALO resultando em um erro máximo de 9,2\%. 
A maior eficiência do acoplamento da porta nos dispositivos de porta dupla, comparando com os de porta única, foi observada através do estudo do comportamento do potencial de corpo destas estruturas. Esta análise resultou na inserção de um parâmetro dependente da espessura do filme de silício, possibilitando a extrapolação do modelo proposto neste trabalho também para os dispositivos de porta dupla. Os resultados obtidos apresentaram um ajuste bastante satisfatório com a variação do comprimento de canal, temperatura e com a variação das concentrações de dopantes da região de canal e da região de implantação de HALO.

Por fim, é apresentado um estudo sobre o transitório da corrente de dreno em dispositivos FinFETs de porta tripla, com e sem a região de implantação de HALO, considerando a variação da largura de canal. Através da análise da tensão de limiar, transcondutância e do transitório da corrente de dreno foi possível observar que os dispositivos sem a presença da região de implantação de HALO são mais susceptíveis a influência dos efeitos de corpo flutuante. 


\section{ABSTRACT}

This work presents a study of drain current switch-off transients and extraction methods of the generation lifetime in partially depleted SOI nMOSFET transistors of single gate, double gate and triple gate FinFETs. This study is accomplished through two-dimensional numerical simulations and compared with experimental data of devices fabricated in the IMEC (Interuniversity Microelectronics Center), which is in the Catholic University of Leuven (KUL) in Belgium.

Initially, it was analyzed the gate oxide thickness and temperature influences on the carrier generation lifetime extraction using the drain current transient. Beyond the generation lifetime, other electric parameters were also analyzed, such as the threshold voltage, the surface potential and the activation energy. Based on process parameter influence study in the determination method of the generation lifetime, it was possible to propose a simple model in order to estimate the carrier generation lifetime as a function of the temperature. This model was experimentally applied and compared to simulated results and it presented a maximum error of $5 \%$.

A detailed analysis of the effect of HALO implanted region in the generation lifetime extraction was based on the drain current transient. The results obtained through this study made possible the proposal of a new model. The proposed model considers not only the laterally non-uniform channel profile due to the presence of a HALO implanted region but also the amount of charge controlled by drain and source junctions, a never-before-seen topic in the literature. The new model sensitivity was tested with $a \pm 20 \%$ variation of the doping concentration of the channel and implanted HALO region resulting in a maximum error of $9.2 \%$.

Taking the obtained results into consideration, it was possible to analyze the drain current as a function of the channel length reduction. The great efficiency presented by the gate in double gate devices, compared to the single gate ones, was observed through the study of the body potential behavior in this structure. This analysis resulted in the inclusion of a silicon film thickness dependent parameter that made possible the adaptation of the proposed model in this work also for double gate devices. The obtained results presented a good agreement with the channel length 
variation, temperature and with the doping concentration variation in the channel and HALO implanted region.

Finally, it was presented a study about the drain current transient in triple gate FinFET devices, with and without the HALO implanted region, taking the geometric parameter variation into consideration. Through the analysis of the threshold voltage, the transconductance and the drain current transient of the devices, it was possible to observe that the devices without HALO are remarkably more susceptible to the floating body effects influence. 


\section{LISTA DE FIGURAS}

Figura 2-1-Diagramas de faixas de energia para transistores MOS convencional (A), SOI parcialmente depletado (B) e SOI totalmente depletado $(C)^{29}$ 30

Figura 2-2 - Perfil do transistor SOI modo enriquecimento 31

Figura 2-3 - Perfil do transistor SOI modo acumulação. 32

Figura 2-4 - Variação da tensão de limiar em função da tensão aplicada no substrato ${ }^{29}$.

Figura 2-5 - Esquemático do acoplamento capacitivo em um PD SOI MOSFET. 36

Figura 2-6 - Distribuição das cargas de depleção em um dispositivo MOS convencional (A) e em um dispositivo SOI nMOSFET (B), de canal longo (esquerda) e de canal curto (direita). 38

Figura 2-7 - Tensão de limiar em função do comprimento de canal em um dispositivo MOS convencional e um SOI MOSFET totalmente depletado ${ }^{29}$. 39

Figura 2-8 - Perfil da concentração de dopantes ao longo do canal de um dispositivo MOSFET convencional com Halo: (A) Corte transversal e (B) Perfil bidimensional 47

Figura 2-9 - Seção transversal de um transistor SOI nMOSFET com as notações usadas nesta seção.

Figura 2-10 - Variação da tensão de limiar, do MOS convencional e do SOI totalmente depletado, com a temperatura ${ }^{29}$

Figura 2-11 - Curvas experimentais, simuladas e calculada através do modelo clássico de um dispositivo SOI MOSFET com L $=20 \mu \mathrm{m}$ e $\mathrm{W}=20 \mu \mathrm{m}{ }^{59}$.

Figura 2-12 - Variação de $\mu_{0}$ em função da temperatura, em um SOI MOSFET canal-n $(\bullet)$ e em um SOI MOSFET canal-p (o) ${ }^{62}$

Figura 2-13 - Extração do $\theta$ (contínuo) e $\alpha_{R}$ (tracejado) em função da temperatura, para dispositivos SOI MOSFET canal-n com L $=20 \mu \mathrm{m}(\bigcirc), 10 \mu \mathrm{m}(\bullet), 5 \mu \mathrm{m}(\square), 3 \mu \mathrm{m}(\mathbf{\square})$ e $2 \mu \mathrm{m}(\triangle)^{62}$. .56

Figura 3-1 - Recombinação Shockley-Read-Hall (SRH) ou por multifonon ${ }^{74}$. 64

Figura 3-2 - Recombinação radiativa ${ }^{74}$. .66 
Figura 3-3 - Recombinação Auger ${ }^{74}$......

Figura 3-4 - Geração Shockley-Read-Hall ${ }^{74}$

Figura 3-5 -SOI MOSFET submetido a um degrau na porta, os pares elétron-lacuna estão representados pelos círculos cheios e vazios. Mecanismo de geração 1 - no corpo, 2 - junto ao dreno/fonte, 3 - na primeira interface e 4 - na segunda interface.

Figura 3-6 - Desenho esquematizado do degrau negativo de tensão aplicado na porta do transistor, juntamente com a corrente de dreno após variação de tensão na porta.

Figura 3-7 - Transistor SOI submetido a um degrau no substrato, os pares elétronlacuna estão representados pelos círculos cheios e vazios. Mecanismo de geração 1 - no corpo, 2 - junto ao dreno/fonte, 3 - na primeira interface e 4 - na segunda interface.

Figura 4-1 - O transitório da corrente de dreno obtida experimentalmente (sólida) e por simulação bidimensional (tracejada) depois de aplicar um degrau negativo na porta com $V_{D S}=25 \mathrm{mV}$ para um PD nMOSFET com $\mathrm{L}=\mathrm{W}=10 \mu \mathrm{m}$. .79

Figura 4-2 - Simulações MEDICI da distribuição de potencial através do filme de silício para diferentes tempos, em um PD SOI com $t_{\text {oxf }}=2,5 \mathrm{~nm}, \mathrm{~N}_{\mathrm{a}}=5,510^{17} \mathrm{~cm}^{-3} \mathrm{e}$ temperatura de $30^{\circ} \mathrm{C}$.

Figura 4-3 - Fator $F$ e $n_{i}$ calculados teoricamente e $T_{0}$ obtidos experimentalmente e por simulações em função da temperatura.

Figura 4-4 - Fator F calculado em função da temperatura para varias espessuras de óxidos de porta $\left(\mathrm{t}_{\mathrm{oxf}}\right)$. 83

Figura 4-5- Fator $F$ calculado em função da temperatura para várias concentrações de dopantes na região do canal $\left(\mathrm{N}_{\mathrm{a}}\right)$.

Figura 4-6 - Curva de Arrhenius para 1/To variando a espessura do óxido de porta......84 Figura 4-7 -Curva de Arrhenius para 1/ $T_{0}$ variando a concentração de dopantes no filme de silício.

Figura 4-8 - Tempo de vida de geração experimental e simulado em função da temperatura, obtidos a partir do método proposto na ref. ${ }^{82}$ e estimado pelo modelo descrito pela eq. (95). 
Figura 4-9 - Transitório da corrente de dreno para transistores SOI nMOSFETs parcialmente depletados com diferentes comprimentos de canal $(L)$. .89

Figura 4-10 - Distribuição de potencial através do filme de silício em um PD SOI MOSFET com $\mathrm{t}_{\mathrm{oxf}}=2,5 \mathrm{~nm}, \mathrm{~N}_{\mathrm{a}}=5,510^{17} \mathrm{~cm}^{-3}$ com a variação do tempo. 90

Figura 4-11 - Potencial ao longo do dispositivo, a uma profundidade de $80 \mathrm{~nm}$ em relação a $1^{\mathrm{a}}$ interface, variando o comprimento de canal

Figura 4-12 - Tensão de limiar e o potencial no corpo em função do tempo para diferentes comprimentos de canal $(L)$.

Figura 4-13 - Transitório da corrente de dreno normalizado pelo comprimento de canal $(L)$ em função do tempo, variando $L$ dos dispositivos. .93

Figura 4-14 - Taxa de geração em função da profundidade do filme de silício, antes e depois da aplicação do degrau negativo de tensão, variando o comprimento de canal. 94

Figura 4-15 - Densidade de corrente de elétrons em função do comprimento do dispositivo, logo após a aplicação do degrau negativo de tensão $\left(t=0^{+} s\right)$.

Figura 4-16 - Densidade de corrente de lacunas em função do comprimento do dispositivo, para dispositivos com e sem HALO, logo após a aplicação do degrau negativo de tensão $\left(\mathrm{t}=0^{+} \mathrm{s}\right)$. .96

Figura 4-17 - Tempo de transitório $T_{0}$ em função do comprimento de canal (L)..... 97

Figura 4-18 - Seção transversal do dispositivo com o perfil de dopagem ao longo do canal....... 100

Figura 4-19 - O comportamento da largura da região de depleção normalizada pela largura da região de depleção máxima em função do tempo. 102

Figura 4-20 - Transitório da corrente de dreno para transistores PD SOI nMOSFETs com diferentes comprimentos de canal. 103

Figura 4-21 - Tempo de transitório em função do comprimento de canal. 104

Figura 4-22 - Transitório da corrente de dreno, para um PD SOI nMOSFET de $L=0,3 \mu \mathrm{m}$, $\mathrm{N}_{\mathrm{a}}=5,510^{17} \mathrm{~cm}^{-3}$ e $\mathrm{N}_{\mathrm{h}}=110^{18} \mathrm{~cm}^{-3}$, com a variação da temperatura. 106

Figura 4-23 - Tempo de vida de geração $\left(\tau_{g}\right)$ em função do comprimento de canal. ..107 Figura 4-24 - Secção transversal do dispositivo de porta dupla com o perfil de dopagem ao longo do canal. 
Figura 4-25 - Simulações numéricas da distribuição do potencial de corpo através do filme de silício, para $L=0,2 \mu \mathrm{m}$ e $\mathrm{L}=5 \mu \mathrm{m}$ em dispositivos de porta simples e dupla, antes $(t<0 s)$ e depois $\left(t=0^{+} s\right)$ da aplicação do degrau negativo de tensão.

Figura 4-26 - Transitório da corrente de dreno de um PD SOI nMOSFET com diferentes comprimentos de canal. (A) Comparação entre as curvas experimentais e simuladas de dispositivos SG. (B) Comparação entre as curvas simuladas de dispositivos SG e DG 113

Figura 4-27- Transitório da corrente de dreno normalizado pelo comprimento de canal em função do tempo, para dispositivos SG e DG PD SOI nMOSFET com diferentes comprimentos de canal. 114

Figura 4-28 - Tempo de transitório em função do comprimento de canal. 115

Figura 4-29 - Tempo de transitório do DG PD SOI nMOSFET em função do comprimento de canal, com a variação da espessura do filme de silício. 115

Figura 4-30 - Tempo de vida de geração $\left(\tau_{g}\right)$ em função do comprimento de canal. ..116

Figura 4-31 - Esquema de um dispositivo FinFET de porta tripla, destacando seus parâmetros geométricos. 118

Figura 4-32 - Segunda derivada da corrente de dreno em função da tensão na porta com a variação do potencial no substrato, em dispositivos com (A) e sem (B) HALO.

Figura 4-33 - Tensão de limiar em função da polarização aplicada ao substrato, para dispositivos com e sem HALO.

Figura 4-34 - Tensão de limiar em função da largura do canal $\left(W_{\text {fin }}\right)$, com polarização do substrato de 0 e $-20 \mathrm{~V}$, em dispositivos FinFETs com e sem região de implantação de HALO.

Figura 4-35- Transcondutância de dreno normalizada pela largura de canal em função da polarização de porta, para dispositivos com e sem a região de HALO, variando $W_{\text {fin }}$.....

Figura 4-36 - Transitório da corrente de dreno normalizado pela corrente de dreno no

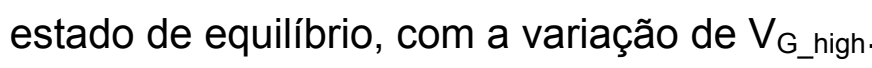
125

Figura 4-37- Corrente de dreno normalizada por $\mathrm{W}_{\text {fin }}+2 \mathrm{H}_{\text {fin }}$ em função da tensão aplicada à porta, com a variação de $W_{\text {fin }}$, em dispositivos com e sem HALO. ......126 
Figura 4-38 - Transitório da corrente de dreno normalizado por $\mathrm{W}_{\text {fin }}+2 \mathrm{H}_{\text {fin }} \ldots \ldots \ldots \ldots \ldots . .127$ Figura 4-39 - Transitório da corrente de dreno normalizado pela corrente no estado de equilíbrio,com a variação de $W_{\text {fin }},(A)$ com HALO e (B) sem HALO. .....................128 


\section{LISTA DE TABELA}

Tabela 1 - Valores pré-definidos pelo simulador para o modelo ANALYTIC . ...............58

Tabela 2 - Valores pré-definidos pelo simulador para o silício no modelo PRPMOB. ....59

Tabela 3 - Valores pré-definidos pelo simulador para o modelo BGN..........................60

Tabela 4 - Valores pré-definidos pelo simulador para o modelo CONSRH....................60

Tabela 5 - Tempo de transitório extraídos a partir de simulação numérica, do modelo proposto e dados experimentais em função do comprimento de canal. ...............105

Tabela 6 - Tempo de transitório extraídos a partir de simulação numérica e do modelo proposto para diferentes concentrações no canal e na região de HALO. ..............105

Tabela 7 - Tempo de vida de geração extraído para três diferentes tempos de vida de alimentação da equação (99), com a variação do comprimento de canal. 107

Tabela 8 - Tempo de vida de geração extraído para diferentes espessuras do filme de silício e comprimentos de canal. 


\section{LISTA DE SÍMBOLOS}

A Área da junção pn $\left[\mu \mathrm{m}^{2}\right]$

ALPHAN Expoente da razão entre as concentrações, usado no modelo de mobilidade ANALYTIC do simulador para elétrons

ALPHAP Expoente da razão entre as concentrações, usado no modelo de mobilidade ANALYTIC do simulador para lacunas

AN Constante usada no modelo CONSRH do simulador para o cálculo do tempo de vida de elétrons

AP Constante usada no modelo CONSRH do simulador para o cálculo do tempo de vida de lacunas

B Coeficiente de recombinação radiativa

BETAN Expoente usado no modelo de mobilidade FLDMOB do simulador para elétrons

BETAN Expoente usado no modelo de mobilidade FLDMOB do simulador para lacunas

BN Coeficiente do termo linear do modelo CONSRH do simulador para o cálculo do tempo de vida de elétrons

BP Coeficiente do termo linear do modelo CONSRH do simulador para o cálculo do tempo de vida de lacunas

$C_{D} \quad$ Capacitância da região de depleção por unidade de área $\left[\mathrm{F} / \mathrm{cm}^{2}\right]$

$\mathrm{C}_{\text {Dtot }} \quad$ Capacitância total do corpo considerando a variação da densidade de portadores livres $\left[\mathrm{F} / \mathrm{cm}^{2}\right]$

Cox Capacitância do óxido de porta do transistor MOS convencional por unidade de área $\left[\mathrm{F} / \mathrm{cm}^{2}\right]$

$\mathrm{C}_{\text {oxb }} \quad$ Capacitância do óxido enterrado por unidade de área $\left[\mathrm{F} / \mathrm{cm}^{2}\right]$

$\mathrm{C}_{\text {oxf }} \quad$ Capacitância do óxido de porta do transistor SOI por unidade de área $\left[\mathrm{F} / \mathrm{cm}^{2}\right]$

$\mathrm{C}_{\mathrm{si}} \quad$ Capacitância da camada de silício por unidade de área $\left[\mathrm{F} / \mathrm{cm}^{2}\right]$

$\mathrm{CN}$ Coeficiente do termo exponencial do modelo CONSRH do simulador para o cálculo do tempo de vida de elétrons 
CP Coeficiente do termo exponencial do modelo CONSRH do simulador para o cálculo do tempo de vida de lacunas

CON.BGN Parâmetro constante usado no modelo BGN do simulador [eV]

$D_{n} \quad$ Coeficiente de difusão para elétrons $\left[\mathrm{cm}^{2} / \mathrm{s}\right.$ ]

$D_{p} \quad$ Coeficiente de difusão para lacunas $\left[\mathrm{cm}^{2} / \mathrm{s}\right]$

$\mathrm{E}_{\mathrm{a}} \quad$ Energia de ativação [eV]

E $\quad$ Nível de energia inferior da faixa de condução $[\mathrm{eV}]$

ECN.MU Campo elétrico crítico usado no modelo de mobilidade PRPMOB para elétrons $[\mathrm{V} / \mathrm{cm}]$

ECP.MU Campo elétrico crítico usado no modelo de mobilidade PRPMOB para lacunas $[\mathrm{V} / \mathrm{cm}]$

$E_{\text {eff }} \quad$ Campo elétrico efetivo na primeira interface $[\mathrm{V} / \mathrm{cm}]$

$\mathrm{E}_{\mathrm{F}} \quad$ Nível de Fermi do semicondutor [eV]

$\mathrm{E}_{\mathrm{FM}} \quad$ Nível de Fermi do metal [eV]

$\mathrm{E}_{\mathrm{g}} \quad$ Faixa proibida do silício $[\mathrm{eV}]$

Ei Nível de Fermi intrínseco [eV]

EN Expoente usado no modelo CONSRH do simulador para elétrons

EP Expoente usado no modelo $\mathrm{CONSRH}$ do simulador para lacunas

$\mathrm{E}_{\mathrm{SF}} \quad$ Campo elétrico na primeira interface $[\mathrm{V} / \mathrm{cm}]$

$\mathrm{E}_{\mathrm{V}} \quad$ Nível de energia superior da faixa de valência $[\mathrm{eV}]$

$\mathrm{E}_{\mathrm{I}, \mathrm{n}} \quad$ Componente do campo elétrico transversal à direção da corrente para elétrons $[\mathrm{V} / \mathrm{cm}]$

$\mathrm{E}_{\mathrm{l}, \mathrm{p}} \quad$ Componente do campo elétrico transversal à direção da corrente para lacunas $[\mathrm{V} / \mathrm{cm}]$

$\mathrm{E}_{\|, \mathrm{n}} \quad$ Componente do campo elétrico paralelo à direção da corrente para elétrons $[\mathrm{V} / \mathrm{cm}]$

$\mathrm{E}_{\|, \mathrm{n}} \quad$ Componente do campo elétrico paralelo à direção da corrente para lacunas $[\mathrm{V} / \mathrm{cm}]$

ETRAP Nível energético de armadilhas usado no cálculo da taxa de recombinação de Shockley-Read-Hall [eV]

G Taxa de geração $\left[\# / \mathrm{cm}^{3} \mathrm{~s}\right]$ 
$\mathrm{G}_{\mathrm{s}} \quad$ Taxa de geração superficial $\left[\# / \mathrm{cm}^{3} \mathrm{~s}\right]$

GSURFN Fator de redução para baixo campo elétrico na superfície usado no cálculo de mobilidade de elétrons

GSURFP Fator de redução para baixo campo elétrico na superfície usado no cálculo de mobilidade de lacunas

gD Condutância de dreno [S]

gm Transcondutância de saída do transistor [S]

$\mathrm{gm}_{\text {,max }} \quad$ Máxima transcondutância do transistor [S]

h Constante de Planck [eV.s]

$J_{\mathrm{nb}} \quad$ Densidade de corrente de difusão de elétrons no corpo $\left[\mathrm{A} / \mathrm{cm}^{2}\right]$

$J_{\mathrm{ps}} \quad$ Densidade de corrente de difusão de lacunas na região da fonte $\left[\mathrm{A} / \mathrm{cm}^{2}\right]$

IDS Corrente entre Dreno e Fonte $[A]$

IDsat Corrente de saturação [A]

$\mathrm{I}_{\mathrm{DS}}(\mathrm{t}) \quad$ Transitório da corrente de Dreno $[\mathrm{A}]$

$I_{G} \quad$ Corrente de tunelamento pela porta $[A]$

l leak $\quad$ Corrente de fuga através de uma junção [A]

Ion Corrente de ligamento $[A]$

$\mathrm{I}_{\text {off }} \quad$ Corrente de desligamento [A]

k Constante de Boltzmann $\left[1,38066 \times 10^{-23} \mathrm{~J} / \mathrm{K}\right]$

L Comprimento de canal do transistor $[\mu \mathrm{m}]$

$\mathrm{L}_{\mathrm{ch}} \quad$ Comprimento de canal do transistor $[\mu \mathrm{m}]$

$L_{p} \quad$ Comprimento da região de implantação de HALO $[\mu \mathrm{m}]$

$L_{\text {eff }} \quad$ Comprimento efetivo de canal do transistor $[\mu \mathrm{m}]$

$\mathrm{L}_{\mathrm{h}} \quad$ Largura da região de implantação de HALO [nm]

MUN.MIN Mobilidade mínima de elétrons usada no modelo de mobilidade ANALYTIC do simulador [ $\left.\mathrm{cm}^{2} / \mathrm{V} . \mathrm{s}\right]$

MUN.MAX Mobilidade máxima de elétrons usada no modelo de mobilidade ANALYTIC do simulador [ $\left.\mathrm{cm}^{2} / \mathrm{V} . \mathrm{s}\right]$

MUP.MIN Mobilidade mínima de lacunas usada no modelo de mobilidade ANALYTIC do simulador $\left[\mathrm{cm}^{2} / \mathrm{V} . \mathrm{s}\right]$ 
MUP.MAX Mobilidade máxima de lacunas usada no modelo de mobilidade ANALYTIC do simulador $\left[\mathrm{cm}^{2} / \mathrm{V} . \mathrm{s}\right]$

$\eta \quad$ Fator de correção da inclinação de sublimiar

$\mathrm{n} \quad$ Densidade de elétrons $\left[\mathrm{cm}^{-3}\right.$ ]

$\mathrm{Na}_{a} \quad$ Concentração de dopantes na região do corpo [ $\left.\mathrm{cm}^{-3}\right]$

$\mathrm{N}_{\mathrm{h}} \quad$ Concentração de dopantes na região do HALO $\left[\mathrm{cm}^{-3}\right]$

$\mathrm{N}_{\mathrm{ab}} \quad$ Concentração do substrato do transistor SOI MOSFET [ $\mathrm{cm}^{-3}$ ]

$\mathrm{N}_{\text {Deff }} \quad$ Concentração efetiva de dopantes na região de fonte $\left[\mathrm{cm}^{-3}\right]$

$\mathrm{N}_{\mathrm{it}} \quad$ Densidade de armadilhas de interface [1/eVcm$\left.{ }^{2}\right]$

$\mathrm{n}_{\mathrm{i}} \quad$ Concentração intrínseca de portadores $\left[\mathrm{cm}^{-3}\right]$

$\mathrm{n}_{\mathrm{ie}} \quad$ Concentração intrínseca de portadores efetiva $\left[\mathrm{cm}^{-3}\right]$

$\mathrm{N}_{\text {subP }} \quad$ Concentração de dopantes na região de HALO $\left[\mathrm{cm}^{-3}\right]$

$\mathrm{N}_{\text {subC }} \quad$ Concentração de dopantes na região do canal $\left[\mathrm{cm}^{-3}\right]$

$\mathrm{N}_{\text {subeff }} \quad$ Concentração efetiva de dopantes na região do canal $\left[\mathrm{cm}^{-3}\right]$

$\mathrm{N}_{\text {total }} \quad$ Concentração total de impurezas $\left[\mathrm{cm}^{-3}\right]$

$\mathrm{N}_{\text {total }}(\mathrm{x}, \mathrm{y}) \quad$ Concentração total de impurezas local $\left[\mathrm{cm}^{-3}\right]$

$\mathrm{N}_{\text {eff }} \quad$ Média das dopagens no interior do canal $\left[\mathrm{cm}^{-3}\right]$

$\mathrm{N}_{\mathrm{QD}} \quad$ Média das dopagens no interior do canal dos dispositivos de porta simples, considerando a influência das junções de fonte e dreno $\left[\mathrm{cm}^{-3}\right]$

$\mathrm{N}_{\mathrm{QD}(\mathrm{DG})} \quad$ Média das dopagens no interior do canal dos dispositivos de porta dupla, considerando a influência das junções de fonte e dreno $\left[\mathrm{cm}^{-3}\right]$

NREFN Concentração de impurezas de referência usada no modelo de mobilidade ANALYTIC do simulador para elétrons $\left[\mathrm{cm}^{-3}\right]$

NREFP Concentração de impurezas de referência usada no modelo de mobilidade ANALYTIC do simulador para lacunas $\left[\mathrm{cm}^{-3}\right]$

NSRHN Parâmetro de concentração usado no modelo CONSRH do simulador para elétrons $\left[\mathrm{cm}^{-3}\right]$

NSRHP Parâmetro de concentração usado no modelo CONSRH do simulador para lacunas $\left[\mathrm{cm}^{-3}\right]$

NUN Expoente da temperatura normalizada do numerador usado no modelo de mobilidade ANALYTIC do simulador para elétrons 
NUP Expoente da temperatura normalizada do numerador usado no modelo de mobilidade ANALYTIC do simulador para lacunas

N0.BGN Parâmetro de concentração usado no modelo BGN do simulador $\left[\mathrm{cm}^{-3}\right]$

$\mathrm{p} \quad$ Densidade de lacunas $\left[\mathrm{cm}^{-3}\right]$

$\mathrm{p}_{\mathrm{b}}(\mathrm{x}=0) \quad$ Concentração máxima de lacunas no corpo do transistor $\left[\mathrm{cm}^{-3}\right]$

q

Carga elementar do elétron $\left[1,6.10^{-19} \mathrm{C}\right]$

$Q_{\text {dep }}$

Densidade de carga de depleção no silício $\left[\mathrm{C} / \mathrm{cm}^{2}\right]$

$Q_{\text {dep1 }}$

Qinv1

Densidade de carga de depleção na camada de silício $\left[\mathrm{C} / \mathrm{cm}^{2}\right]$

Qox

Densidade de carga de inversão na primeira interface $\left[\mathrm{C} / \mathrm{cm}^{2}\right]$

$Q_{0 \times 1}$

Densidade de carga fixa no óxido de porta $\left[\mathrm{C} / \mathrm{cm}^{2}\right]$

$Q_{0 \times 2}$

Densidade de cargas fixas na primeira interface $\left[\mathrm{C} / \mathrm{cm}^{2}\right]$

QS2

Densidade de cargas fixas na segunda interface $\left[\mathrm{C} / \mathrm{cm}^{2}\right]$

Densidade de carga de acumulação $\left(Q_{\mathrm{S} 2}>0\right)$ ou inversão

$\left(\mathrm{Q}_{\mathrm{S} 2}<0\right)$ na $2^{\mathrm{a}}$ interface $\left[\mathrm{C} / \mathrm{cm}^{2}\right]$

$Q_{i t} \quad$ Densidade de carga de armadilha de interface $\left[\mathrm{C} / \mathrm{cm}^{2}\right]$

$R_{S D} \quad$ Resistência série de fonte e dreno

Profundidade da junção de fonte e dreno [nm]

S Inclinação de Sublimiar [V/dec]

$\mathrm{S}_{\mathrm{r}} \quad$ Velocidade de recombinação na superfície

$\mathrm{S}_{\mathrm{g}} \quad$ Velocidade de geração superficial

T Temperatura absoluta $[\mathrm{K}]$

$\mathrm{T}_{\mathrm{K}} \quad$ Temperatura crítica $\left[{ }^{\circ} \mathrm{C}\right]$

$\mathrm{T}_{0} \quad$ Tempo de Transitório [s]

$t_{\text {oxb }}$

Espessura do óxido enterrado [nm]

$t_{\text {oxf }}$

$t_{\mathrm{si}}$

Espessura do óxido de porta [nm]

Espessura da camada de silício [nm]

$t_{\text {rel }}$

Parâmetro de ajuste dependente da espessura do filme de silício

TAUNO Tempo de vida de elétrons no modelo de Shockley-Read-Hall [s]

TAUPO Tempo de vida de lacunas no modelo de Shockley-Read-Hall [s]

$\mathrm{U}_{\mathrm{SRH}} \quad$ Taxa de recombinação de Shockley-Read-Hall [\#/cm $\left.{ }^{3} \mathrm{~s}\right]$

$\mathrm{U}_{\mathrm{s}} \quad$ Taxa de recombinação superficial $\left[\# / \mathrm{cm}^{3} \mathrm{~s}\right]$ 


\begin{tabular}{|c|c|}
\hline $\mathrm{V}_{\mathrm{BS}}$ & Potencial de corpo [V] \\
\hline$V_{D S}$ & Tensão entre Dreno e Fonte [V] \\
\hline $\mathrm{V}_{\text {DSsat }}$ & Tensão de saturação [V] \\
\hline $\mathrm{V}_{\mathrm{FB}}$ & Tensão de faixa plana da estrutura MOS [V] \\
\hline $\mathrm{V}_{\mathrm{G}}$ & Tensão aplicada à porta do transistor MOS [V] \\
\hline $\mathrm{V}_{\mathrm{GB}}$ & Tensão aplicada ao substrato do transistor SOI MOSFET[V] \\
\hline $\mathrm{V}_{\mathrm{GB}, \mathrm{acc} 2}$ & $\begin{array}{l}\text { Tensão aplicada ao substrato do transistor SOI MOSFET para acumular a } \\
\text { segunda interface }[\mathrm{V}]\end{array}$ \\
\hline$V_{\mathrm{GB} \_ \text {high }}$ & Nível alto do degrau de tensão aplicado ao substrato [V] \\
\hline $\mathrm{V}_{\mathrm{GB} \_ \text {low }}$ & Nível baixo do degrau de tensão aplicado ao substrato [V] \\
\hline $\mathrm{V}_{\mathrm{GF}}$ & Tensão aplicada à porta do transistor SOI MOSFET[V] \\
\hline $\mathrm{V}_{\mathrm{GT}}$ & Sobretensão de limiar [V] \\
\hline$V_{G_{-} \text {high }}$ & Nível alto do degrau de tensão aplicado à porta [V] \\
\hline$V_{G \_l o w}$ & Nível baixo do degrau de tensão aplicado à porta [V] \\
\hline$v_{n}^{\text {sat }}$ & Velocidade de saturação para elétrons $[\mathrm{cm} / \mathrm{s}$ ] \\
\hline$v_{p}^{\text {sat }}$ & Velocidade de saturação para lacunas [cm/s] \\
\hline $\mathrm{V}_{\text {th }}$ & Tensão de limiar da porta do transistor MOS convencional [V] \\
\hline$V_{\text {th0 }}$ & Tensão de limiar da porta do transistor MOS convencional para $V_{B S}=0[V]$ \\
\hline $\mathrm{Vth}_{\mathrm{F}}$ & Tensão de limiar da porta do transistor SOI MOSFET [V] \\
\hline $\mathrm{V}_{\text {th1, acc2 }}$ & $\begin{array}{l}\text { Tensão de limiar da porta do transistor SOI MOSFET, com a segunda } \\
\text { interface acumulada [V] }\end{array}$ \\
\hline $\mathrm{V}_{\text {th1,inv2 }}$ & $\begin{array}{l}\text { Tensão de limiar da porta do transistor SOI MOSFET, com a segunda } \\
\text { interface invertida [V] }\end{array}$ \\
\hline$V_{\text {th1,depl2 }}$ & $\begin{array}{l}\text { Tensão de limiar da porta do transistor SOI MOSFET, com a segunda } \\
\text { interface depletada [V] }\end{array}$ \\
\hline V0.BGN & Parâmetro de tensão usado no modelo BGN do simulador [V] \\
\hline W & Largura de canal do transistor $[\mu \mathrm{m}]$ \\
\hline$x_{1}$ & Profundidade de depleção [nm] \\
\hline$X_{\text {dmáx }}$ & Profundidade de depleção máxima [nm] \\
\hline$d$ & Profundidade de depleção [nm] \\
\hline
\end{tabular}




\begin{tabular}{|c|c|}
\hline$x_{d \infty \infty}$ & Profundidade de depleção no estado de equilíbrio [nm] \\
\hline XIN & $\begin{array}{l}\text { Expoente da temperatura normalizada do denominador usado no modelo } \\
\text { de mobilidade ANALYTIC do simulador para elétrons }\end{array}$ \\
\hline XIP & $\begin{array}{l}\text { Expoente da temperatura normalizada do denominador usado no modelo } \\
\text { de mobilidade ANALYTIC do simulador para lacunas }\end{array}$ \\
\hline$\alpha$ & $\begin{array}{l}\text { Parâmetro resultante da associação das capacitâncias do transistor } \\
\text { MOSFET }\end{array}$ \\
\hline$\alpha_{R}$ & Fator de variação da resistência série $\left[\mathrm{V}^{-1}\right]$ \\
\hline$\varepsilon_{\mathrm{Si}}$ & Permissividade do silício $\left[1,06 \times 10^{-12} \mathrm{~F} / \mathrm{cm}\right]$ \\
\hline$\varepsilon_{\mathrm{ox}}$ & Permissividade do óxido de silício $\left[3,45 \times 10^{-13} \mathrm{~F} / \mathrm{cm}\right]$ \\
\hline$\phi_{\mathrm{MS}}$ & $\begin{array}{l}\text { Diferença de função trabalho entre metal de porta e semicondutor no } \\
\text { transistor MOS [V] }\end{array}$ \\
\hline$\phi_{\mathrm{MS} 1}$ & $\begin{array}{l}\text { Diferença de função trabalho entre metal de porta e semicondutor no } \\
\text { transistor SOI MOSFET[V] }\end{array}$ \\
\hline$\phi_{\mathrm{MS} 2}$ & $\begin{array}{l}\text { Diferença de função trabalho entre o substrato e a camada de silício no } \\
\text { transistor SOI MOSFET[V] }\end{array}$ \\
\hline$\phi_{\mathrm{SB}}$ & Potencial de superfície da segunda interface [V] \\
\hline$\phi_{\mathrm{SF}}$ & Potencial de superfície da primeira interface [V] \\
\hline$\phi_{F}$ & Potencial de Fermi [V] \\
\hline$\phi_{\mathrm{Ff}}$ & Potencial de Fermi da camada de silício [V] \\
\hline$\phi_{0 \times 1}$ & Potencial através do óxido de porta [V] \\
\hline$\phi_{0 \times 2}$ & Potencial através do óxido enterrado [V] \\
\hline$\mu_{n}$ & Mobilidade efetiva dos elétrons na camada de silício $\left[\mathrm{cm}^{2} / \mathrm{V} \cdot \mathrm{s}\right]$ \\
\hline$\mu_{p}$ & Mobilidade efetiva das lacunas na camada de silício $\left[\mathrm{cm}^{2} / \mathrm{V} \cdot \mathrm{s}\right]$ \\
\hline$\mu_{\mathrm{S}, n}$ & $\begin{array}{l}\text { Mobilidades de elétrons para baixo campo elétrico incluindo o mecanismo } \\
\text { de espalhamento }\left[\mathrm{cm}^{2} / \mathrm{V} \cdot \mathrm{s}\right]\end{array}$ \\
\hline$\mu_{S, p}$ & $\begin{array}{l}\text { Mobilidades de lacunas para baixo campo elétrico incluindo o mecanismo } \\
\text { de espalhamento }\left[\mathrm{cm}^{2} / \mathrm{V} \cdot \mathrm{s}\right]\end{array}$ \\
\hline$\mu_{\text {máx }}$ & Mobilidade máxima dos elétrons na camada de silício $\left[\mathrm{cm}^{2} / \mathrm{V} \cdot \mathrm{s}\right]$ \\
\hline$u_{0}$ & Mobilidade para baixo campo elétrico $\left[\mathrm{cm}^{2} / \mathrm{s} \cdot \mathrm{s}\right]$ \\
\hline
\end{tabular}




$\begin{array}{ll}\mu_{0 n} & \text { Mobilidade de elétrons para baixo campo elétrico }\left[\mathrm{cm}^{2} / \mathrm{V} \cdot \mathrm{s}\right] \\ \mu_{0 p} & \text { Mobilidade de lacunas para baixo campo elétrico }\left[\mathrm{cm}^{2} / \mathrm{V} \cdot \mathrm{s}\right] \\ v & \text { Freqüência }\left[\mathrm{s}^{-1}\right] \\ \omega_{\mathrm{s}} & \text { Distância entre a junção fonte-canal e o contato de fonte }[\mu \mathrm{m}] \\ \theta & \text { Fator de degradação da mobilidade }\left[\mathrm{V}^{-1}\right] \\ \gamma & \text { Efeito de corpo }\left[\mathrm{V}^{1 / 2}\right] \\ \tau_{\mathrm{n}} & \text { Tempo de vida de elétrons [s] } \\ \tau_{\mathrm{n}(\mathrm{x}, \mathrm{y})} & \text { Tempo de vida de elétrons local [s] } \\ \tau_{\mathrm{p}} & \text { Tempo de vida de lacunas [s] } \\ \tau_{\mathrm{p}(\mathrm{x}, \mathrm{y})} & \text { Tempo de vida de lacunas local [s] } \\ \tau_{\mathrm{e}} & \text { Tempo de vida efetivo [s] } \\ \tau_{\mathrm{g}} & \text { Tempo de vida de geração[s] } \\ \tau_{\mathrm{SRH}} & \text { Tempo de vida de Shockley-Read-Hall [s] } \\ v_{\mathrm{th}} & \text { Velocidade térmica dos portadores [cm/s] } \\ \sigma_{\mathrm{n}} & \left.\text { Secção transversal de captura de elétrons [cm }{ }^{2}\right] \\ \sigma_{\mathrm{ns}} & \text { Secção transversal de captura de elétrons superficial }\left[\mathrm{cm}^{2}\right] \\ \sigma_{\mathrm{p}} & \text { Secção transversal de captura de lacunas }\left[\mathrm{cm}^{2}\right] \\ \sigma_{\mathrm{ps}} & \text { Seç̧ão transversal de captura de lacunas superficial }\left[\mathrm{cm}^{2}\right]\end{array}$




\section{SUMÁRIO}

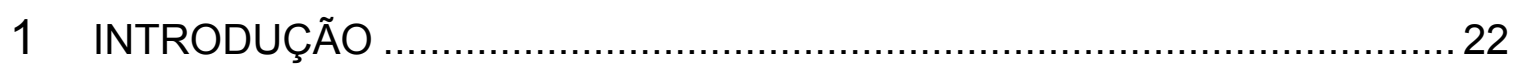

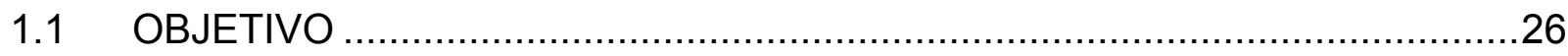

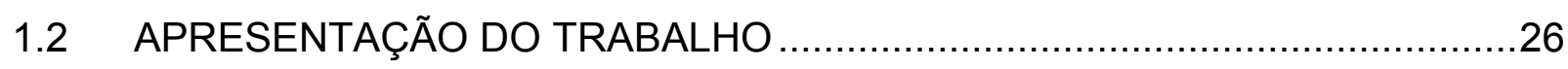

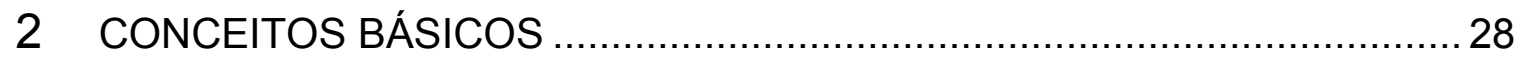

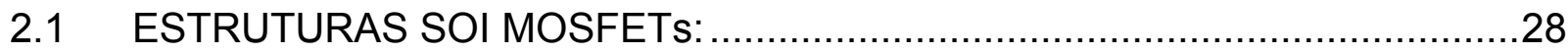

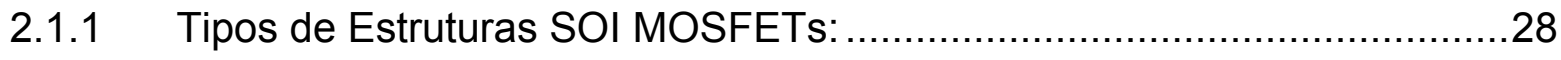

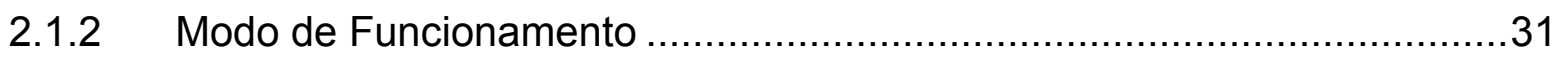

2.2 CARACTERÍSTICAS ELÉTRICAS DOS TRANSISTORES SOI MOSFETS ....32

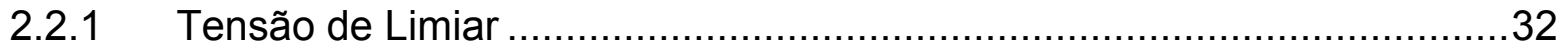

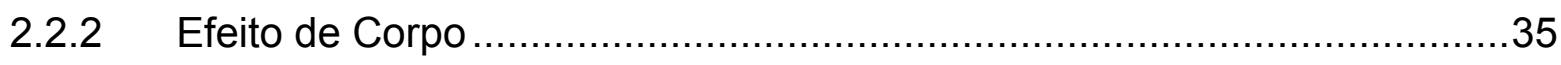

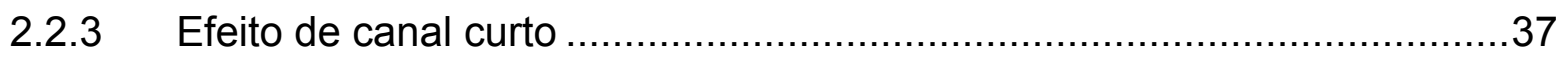

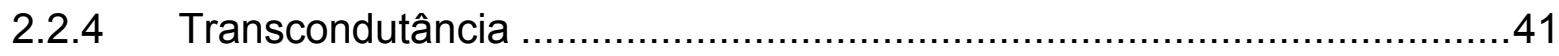

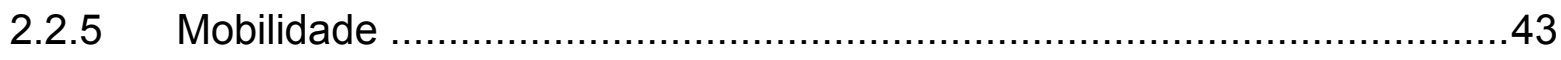

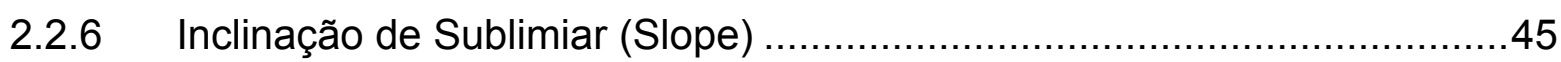

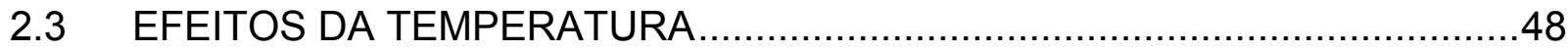

2.3.1 Corrente de Fuga através das Junções .................................................49

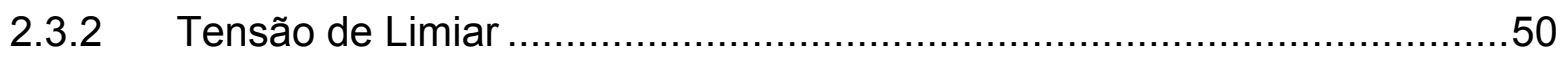

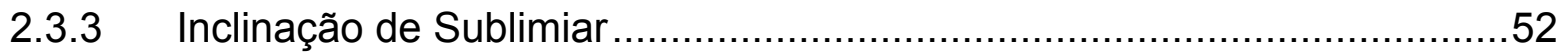

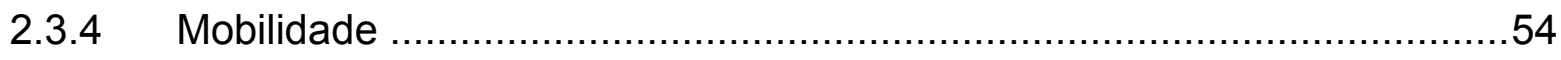

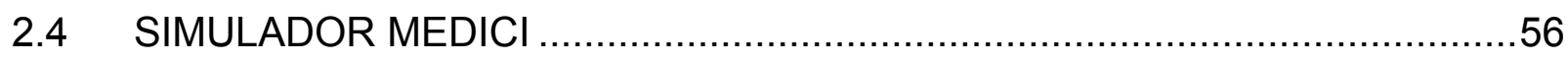

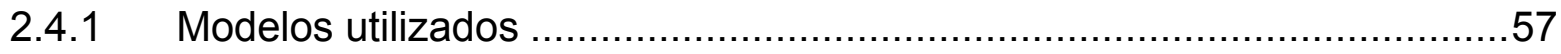

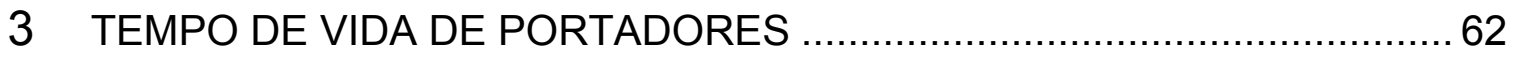

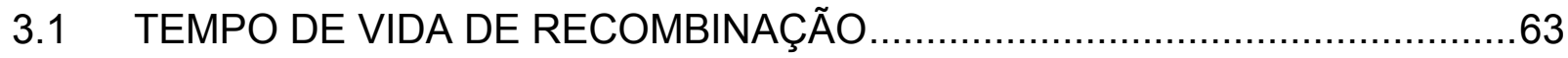

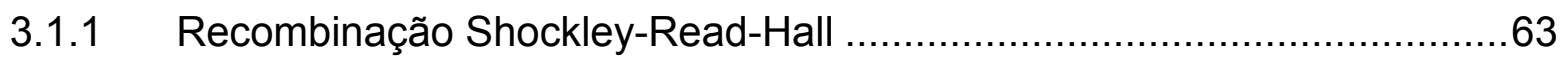

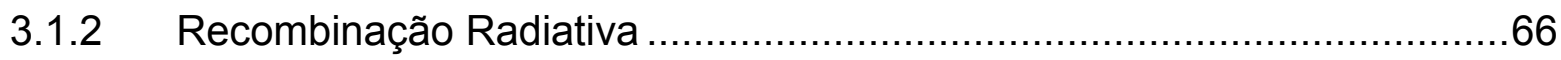

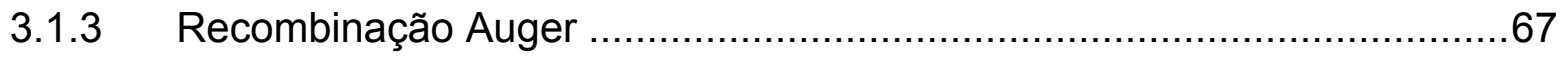

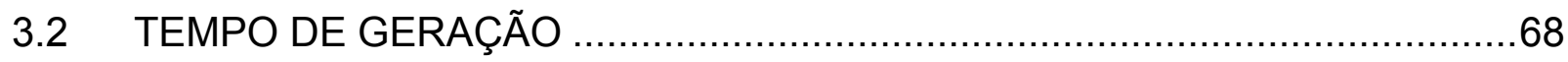


3.3 TÉCNICAS PARA EXTRAÇÃO DO TEMPO DE VIDA DE GERAÇÃO-

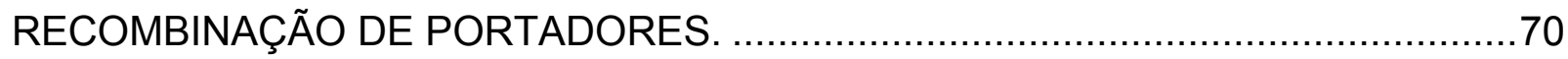

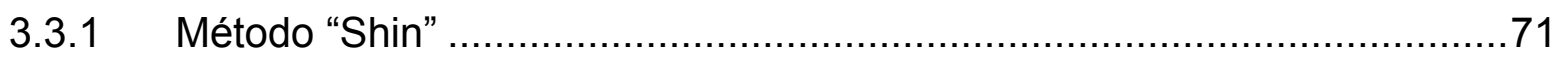

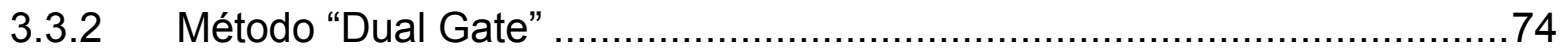

4 CONTRIBUIÇÕES AOS MÉTODOS DE EXTRAÇÃO DE TEMPO DE VIDA

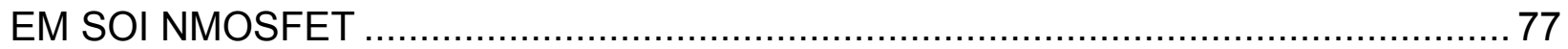

4.1 PROPOSTA DE UM MÉTODO PARA ESTIMAR O TEMPO DE VIDA DE GERAÇÃO EM FUNÇÃO DA TEMPERATURA ……......................................

4.2 O IMPACTO DA IMPLANTAÇÃO DE HALO NO TRANSITÓRIO DA

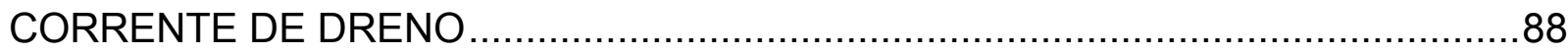

4.3 NOVO MODELO PARA DETERMINAÇÃO DO TEMPO DE VIDA DE GERAÇÃO EM DISPOSITIVOS SOI NMOSFET COM CANAL CURTO....................99 4.4 ADAPTAÇÃO DO NOVO MODELO PARA DETERMINAÇÃO DO TEMPO DE VIDA DE GERAÇÃO EM DISPOSITIVOS SOI NMOSFET DE PORTA DUPLA. .....109 4.5 ANÁLISE DO TRANSITÓRIO DA CORRENTE DE DRENO EM DISPOSITIVOS FinFETS DE PORTA TRIPLA .............................................118

5 CONCLUSÕES 130 REFERÊNCIAS 


\section{INTRODUÇÃO}

A contínua redução das dimensões na tecnologia CMOS convencional, necessária para o aumento no desempenho dos circuitos integrados (IC), tem sido dificultada pela presença dos efeitos de canal curto (SCEs - Short Channel Effects) $)^{1,2}$. A tecnologia SOI (Silicon On Insulator) MOSFET tem se destacado como uma alternativa viável na indústria de circuitos integrados com larga escala de integração $(\mathrm{ULSI})^{3,4}$. Nesta tecnologia a camada de silício, na qual os dispositivos são implementados, está sobre uma camada de isolante (Silicon On Insulator - SOI) o que reduz a espessura da região ativa destes dispositivos, tornando-os inerentemente menos susceptíveis aos $\mathrm{SCEs} \mathbf{s}^{1,2,5,6}$. Além disso, permite uma isolação dielétrica intrínseca entre os mesmos, proporcionando alta resistência à radiação ${ }^{7,8}$ e baixa sensibilidade à variação da temperatura ${ }^{9,10}$.

Desta forma, em tecnologias com dimensões inferiores a $50 \mathrm{~nm}^{11,12}$ a tecnologia SOI vem gradualmente substituindo a tecnologia MOS convencional em circuitos com larga escala de integração e aplicações em altas freqüências. Trabalhos recentes demonstraram que a superioridade dos dispositivos $\mathrm{SOI}$ associada com os constantes avanços da tecnologia CMOS tem proporcionado melhorias significativas tanto em termos de velocidade dos circuitos como em fornecimento de corrente ${ }^{13}$. Algumas aplicações evidenciam a superioridade da tecnologia SOI em relação à CMOS convencional, como por exemplo os microprocessadores que apresentaram um aumento de $20 \%{ }^{14}$ na sua velocidade, assim como nos amplificadores de RF onde também foi observada uma maior eficiência no fornecimento de corrente pelos dispositivos ${ }^{15}$.

Como resultado dos crescentes avanços obtidos nas técnicas usadas para a redução das geometrias tem-se um número muito maior de transistores por circuito integrado. Logo, um número maior de linhas de metal é necessário para possibilitar a interconexão do crescente número de transistores por pastilha ou circuitos integrados. Desta forma, ocorreu um aumento na complexidade de interconexão e o tempo de propagação do sinal passou a ser limitante na performance destes circuitos. Devido à 
possibilidade de integração tridimensional na tecnologia SOI, pesquisas realizadas pela Intel ${ }^{16}$ demonstraram a redução da complexidade de interconexão com o uso desta tecnologia. Seguindo esta nova tendência, empresas como IBM e AMD ${ }^{13,17}$ já usam a tecnologia SOI em microprocessadores comerciais.

Dentro do cenário de contínuo esforço para aumentar a capacidade de fornecimento de corrente dos transistores, sempre buscando um melhor controle dos SCEs, a tecnologia SOI tem evoluído dos dispositivos planares de porta única para dispositivos tridimensionais com múltiplas portas. Os SCEs surgem quando o controle da porta sobre a região do canal é afetado pelas linhas do campo elétrico proveniente das regiões de fonte e dreno. Na tecnologia convencional, estas linhas se propagam através das regiões de depleção associadas às junções. Esta influência pode ser reduzida com o aumento da concentração de dopantes na região do canal, mas para dimensões muito reduzidas este aumento pode comprometer a capacidade de fornecimento de corrente, além de ocorrer a redução na mobilidade de portadores destes dispositivos.

A arquitetura de múltiplas portas tem apresentado um desempenho superior quando comparados com a de porta simples ${ }^{18,19}$. Dentre as vantagens observadas podem ser citadas o aumento da transcondutância, uma inclinação de sublimiar próxima ao ideal e a redução dos efeitos de canal curto.

A complexidade de fabricação dos dispositivos de porta dupla, em particular a fabricação de portas inferiores perfeitamente alinhadas com as portas superiores limitou o desenvolvimento industrial da tecnologia de porta dupla planar. Esta barreira tecnológica foi transposta fabricando-se estruturas verticais com portas laterais, chamadas FinFETs ${ }^{20,21}$. A tecnologia FinFET é muito atrativa devido a fácil implementação do seu processo de fabricação com as técnicas já existentes. A tecnologia consiste em obter-se uma ilha de silício estreita através do processo de corrosão e após o crescimento do óxido de porta é feita a deposição do material que irá formar a porta. Sendo assim, o perfeito alinhamento entre as portas se faz de forma natural.

Nos dispositivos FinFETs, a porta recobre três lados do corpo, o lado superior e as laterais. O lado superior pode ou não ser utilizado como porta dependendo da 
espessura do óxido de porta. Caso o óxido na parte superior seja espesso, o controle do canal será feito predominantemente através das portas laterais. Contudo, com a inclusão da porta superior, estudos demonstraram um aumento de $20 \%$ na corrente de dreno $^{22}$. Dependendo da razão de aspecto entre a largura e a altura do canal, a camada de inversão pode ter maior dependência da porta superior ou das laterais, respectivamente. Foi demonstrado na literatura que, caso a largura do canal exceda a altura, a camada de inversão controlada pela porta superior pode prover um ganho extra na corrente de dreno ${ }^{23}$.

Diante do contexto atual de constante busca pela redução das dimensões e melhora do desempenho dos circuitos integrados se faz necessária a inclusão de novos materiais, novas etapas de processo, assim como novas técnicas para caracterizá-los.

O tempo de vida de portadores é um parâmetro importante para avaliar a qualidade final do filme de silício após as etapas do processo de fabricação dos circuitos integrados. Com as constantes melhorias no processo de fabricação e também na obtenção das lâminas, a quantidades de defeitos na rede cristalina vem diminuindo consideravelmente, com isto, além do conhecimento da teoria clássica ${ }^{24,25,26}$ sobre extração do tempo de vida de portadores, surge a grande necessidade no desenvolvimento de novas técnicas de medida para este parâmetro que possa levar em consideração o escalamento das dimensões.

Dentro da tecnologia SOI MOSFET planar, os dispositivos parcialmente depletados também tem sido foco de grande interesse devido ao melhor controle da tensão de limiar, a maior facilidade nos processos de fabricação e ao melhor escalamento em relação aos dispositivos MOSFETs convencionais ${ }^{27,28,29,30}$. Um dos principais fatores que limitam o desempenho destes dispositivos é a forte influência do efeito de corpo flutuante.

O efeito de corpo flutuante, em dispositivos SOI MOSFET, se manifesta principalmente no transitório da corrente de dreno que ocorre quando o dispositivo é ligado ou desligado, causando distorções e afetando significativamente a velocidade dos circuitos SOI MOSFET ${ }^{31}$. Contudo, existem situações em que pode ser vantajosa a presença do corpo flutuante, como no caso da caracterização elétrica para a extração do tempo de vida de portadores. 
A maioria dos métodos não destrutivos aplicados em dispositivos SOI que usam medidas elétricas para a extração do tempo de vida de geração e recombinação se baseiam na análise do transitório da corrente de dreno. Esta análise é realizada em dispositivos parcialmente depletados e pode ser obtida com a medida dinâmica da corrente de dreno após a variação da polarização na porta do transistor. Outra técnica, também aplicada em transistores SOI, requer uma polarização fixa na porta e a variação ocorre no substrato, desta forma também é possível observar um transitório de corrente no dreno. Além da análise do transitório da corrente de dreno é possível também obter o tempo de vida dos portadores através da medida da corrente de polarização direta em junções pn, porém nesta técnica são necessárias estruturas especiais de junções pn controladas por porta ${ }^{32}$.

Devido à complexidade dos métodos existentes e também pela importância e dificuldade de obtenção deste parâmetro, faz-se necessário o desenvolvimento de novos modelos que considere as mudanças de geometria nas novas tecnologias e que também sejam de fácil aplicação. 


\subsection{OBJETIVO}

Este trabalho tem como objetivo estudar teórica e experimentalmente o comportamento do transitório da corrente de dreno e o tempo de vida de portadores em transistores SOI MOSFET de porta simples, dupla e tripla, com maior foco nos transistores parcialmente depletados, que atualmente são as aplicações mais comuns da tecnologia SOI disponível comercialmente. Os transistores caracterizados neste trabalho foram fabricados no IMEC (Interuniversity Microelectronics Center), que fica na Universidade Católica de Leuven (KUL) na Bélgica.

Através deste estudo e de uma análise detalhada sobre o impacto da geometria dos dispositivos e da temperatura no tempo de vida de portadores, propor uma nova técnica para extração deste parâmetro que considere a redução do comprimento de canal nestes dispositivos. Esta nova técnica considera o impacto da lateralidade não uniforme da dopagem do canal no efeito de corpo flutuante, devido à presença das regiões de implantação de HALO, assim como a contribuição das cargas controladas pelas junções de fonte e dreno.

\subsection{APRESENTAÇÃO DO TRABALHO}

Neste primeiro capítulo, apresentamos a introdução e os objetivos deste trabalho. Os outros capítulos estão organizados como segue:

No capítulo 2 são apresentados alguns conceitos básicos sobre a estrutura SOI MOSFET com o objetivo de fundamentar as análises sobre o principal parâmetro estudado neste trabalho, que é o tempo de vida de geração. São abordados neste capítulo os tipos de estruturas SOI considerando a espessura da camada de silício, o modo de funcionamento destas estruturas, as características elétricas do transistor SOI, os principais efeitos da temperatura nas estruturas SOI e uma descrição dos modelos de simulação bidimensional utilizados neste trabalho.

O capítulo 3 apresenta os conceitos básicos sobre as propriedades de geraçãorecombinação dos portadores no silício. Estes conceitos são fundamentais para o 
entendimento das técnicas para extração deste parâmetro em dispositivos SOI MOSFET, sendo que algumas destas técnicas também estão descritas neste capítulo.

No capítulo 4 estão apresentadas as contribuições dadas por este trabalho ao estudo do transitório da corrente de dreno em transistores SOI nMOSFETs de porta simples, dupla e FinFETs de porta tripla, assim como, aos métodos de extração de tempo de vida de geração em transistores planares parcialmente depletados. Os dados apresentados neste capítulo são provenientes tanto de resultados experimentais como de simulações numéricas bidimensionais.

E, finalmente, no capítulo 5, estão descritas as principais conclusões extraídas do estudo realizado neste trabalho e as perspectivas futuras. 


\section{CONCEITOS BÁSICOS}

Neste capítulo estão apresentados os conceitos básicos sobre a estrutura SOI MOSFET considerando a espessura da camada de silício e o modo de funcionamento destas estruturas. Estão também abordados os principais parâmetros elétricos dos transistores SOI, assim como a influência da temperatura nestes parâmetros. Finalmente, é apresentada uma breve descrição dos modelos de simulação numérica bidimensional utilizados neste trabalho.

\subsection{ESTRUTURAS SOI MOSFETS:}

A tecnologia SOI (Silicon-On-Insulator) consiste na fabricação de circuitos integrados em uma camada de silício sobre uma camada de material isolante. Os dispositivos SOI MOSFET são uma alternativa viável para a total eliminação do efeito tiristor parasitário ("latch-up"), pois a isolação entre os transistores NMOS e PMOS nesta tecnologia é quase perfeita devido à presença da camada de óxido enterrado que isola a região ativa do transistor. A área lateral entre dreno/fonte e canal nos dispositivos SOI MOSFETs é menor que a dos MOSFETs convencionais ("bulk"), o que diminui muito a corrente de fuga através das junções, além da redução das capacitâncias de junção e o aumento da transcondutância ${ }^{29}$.

\subsubsection{Tipos de Estruturas SOI MOSFETs:}

Na tecnologia SOI a espessura da camada de silício, na qual são construídos os dispositivos, influencia fortemente as características físicas dos mesmos. Dependendo da espessura da camada de silício e de sua concentração, os dispositivos podem ser classificados como parcialmente depletado ou totalmente depletado, sendo que este último tem seu comportamento fortemente influenciado pelas condições de polarização do substrato ("back gate") ${ }^{29}$. 
A profundidade máxima da região de depleção nos dispositivos MOS convencionais, considerando-se a concentração uniforme do substrato, é dada pela equação (1):

$$
x_{\text {dmáx }}=\sqrt{\frac{4 \varepsilon_{\text {si }} \phi_{F}}{q N_{a}}}
$$

Onde

$\phi_{\mathrm{F}}=\frac{k T}{q} \ln \left(\frac{N_{a}}{n_{i}}\right)$ é o potencial de Fermi;

$\varepsilon_{S \mathrm{i}}$ é a permissividade do silício;

q é a carga elementar do elétron;

$\mathrm{N}_{\mathrm{a}}$ é a concentração de dopantes no semicondutor;

k é a constante de Boltzmann;

T é a temperatura absoluta;

$n_{i}$ é a concentração intrínseca de portadores do semicondutor.

Em estruturas SOI MOSFETs totalmente depletadas, a espessura da camada de silício é menor que a profundidade máxima de depleção $\left(\mathrm{x}_{\text {dmáx }}\right)$. Quando a tensão aplicada na porta ("front gate") atinge a tensão de limiar, a região de depleção já atingiu a segunda interface, deixando a camada de silício totalmente depletada independentemente da depleção gerada pela tensão aplicada no substrato. Neste caso, os dispositivos são comumente chamados de FD ("Fully Depleted") SOI MOSFET ${ }^{29}$.

Nos dispositivos SOI MOSFETs parcialmente depletados (PD) a espessura da camada de silício é maior que o dobro da profundidade máxima de depleção $\left(2 x_{d m a ́ x}\right)$. Sendo assim, as camadas de depleção induzidas pela primeira e segunda interface agem independente, não havendo interação substancial entre elas ${ }^{29}$.

A Figura 2-1 apresenta os diagramas de faixas de energia para transistores MOS convencional, SOI parcialmente depletado e SOI totalmente depletado. Nesta figura, $\mathrm{E}_{\mathrm{C}}$, $E_{V}, E_{i}, E_{F}, V_{G}, V_{G F}$ e $V_{G B}$ representam o nível de energia inferior da faixa de condução, o nível de energia superior da faixa de valência, o nível intrínseco, nível de Fermi do semicondutor, a tensão aplicada à porta do transistor MOS, a tensão aplicada à porta do transistor SOI e a tensão aplicada ao substrato do transistor SOI, respectivamente. 

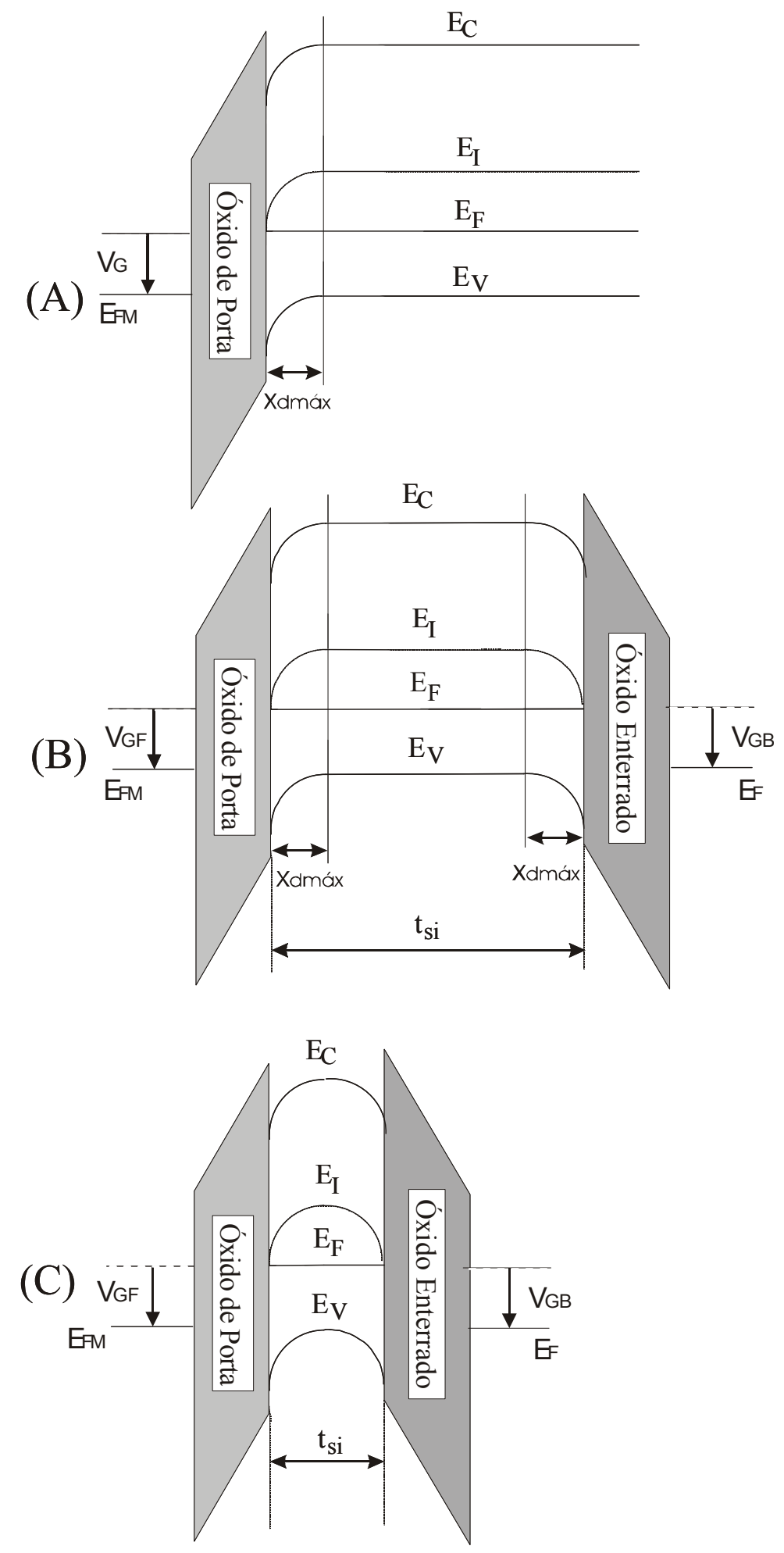

Figura 2-1-Diagramas de faixas de energia para transistores MOS convencional (A), SOI parcialmente depletado (B) e SOI totalmente depletado $(C)^{29}$. 


\subsubsection{Modo de Funcionamento}

Para dispositivos SOI MOSFETs, existem dois modos possíveis de funcionamento: o modo enriquecimento e o modo acumulação.

No modo enriquecimento a passagem de corrente entre fonte e dreno ocorre devido à inversão dos portadores da região do canal, ou seja, na interface entre o óxido de porta e a camada de silício. A Figura 2-2 apresenta o perfil de um transistor SOI MOSFET modo enriquecimento.

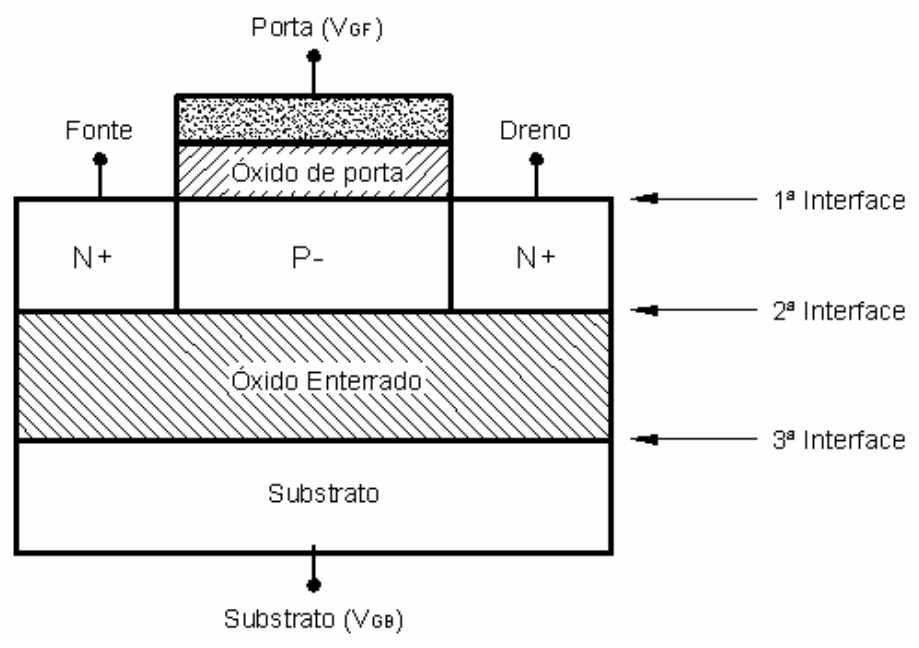

Figura 2-2 - Perfil do transistor SOI modo enriquecimento

No modo acumulação, os dispositivos são formados por semicondutor do mesmo tipo, tanto na região de fonte e dreno como na região do canal, sendo que na região do canal a dopagem do semicondutor é menor que a dopagem nas outras duas regiões, como pode ser visto na Figura 2-3. Assim, a condução de corrente entre fonte e dreno ocorre com a acumulação dos portadores na região do canal. 


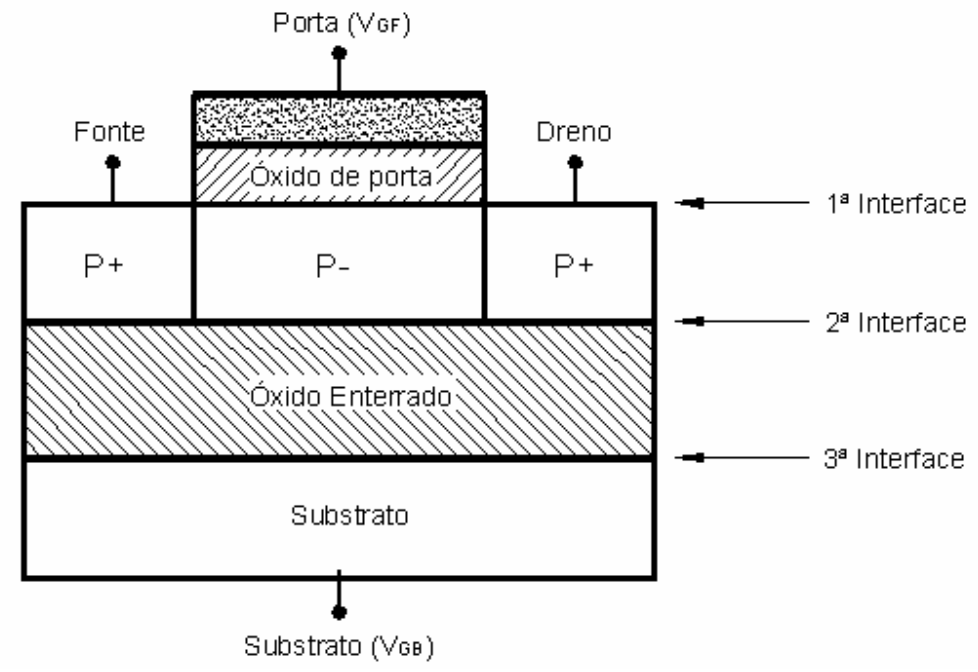

Figura 2-3 - Perfil do transistor SOI modo acumulação.

\subsection{CARACTERÍSTICAS ELÉTRICAS DOS TRANSISTORES SOI MOSFETS}

\subsubsection{Tensão de Limiar}

Tensão de limiar $\left(\mathrm{V}_{\text {th }}\right)$ é o valor de tensão aplicada na porta, para o qual um número suficiente de cargas móveis se acumule na região do canal, de forma a inverter a sua superfície formando um canal de condução entre fonte e dreno.

A tensão de limiar $\left(\mathrm{V}_{\text {th }}\right)$ nos dispositivos nMOS convencionais, com concentração uniforme na região do canal, é dada por:

$$
V_{t h}=V_{F B}+2 \phi_{F}+\frac{q N_{a} X_{d m a ́ x}}{C_{o x}}
$$

com,

$$
V_{F B}=\phi_{M S}-\frac{Q_{o x}}{C_{o x}}
$$

onde:

$V_{F B}$ é tensão de faixa plana da estrutura MOS;

$Q_{o x}$ é a densidade de carga fixa no óxido de porta;

$\mathrm{C}_{\mathrm{ox}}$ é a capacitância do óxido de porta por unidade de área $\left(\mathrm{C}_{\mathrm{ox}}=\varepsilon_{\mathrm{ox}} / \mathrm{t}_{\mathrm{oxf}}\right)$;

$t_{\text {oxf }}$ é a espessura do óxido de porta;

$\phi_{M S}$ é a diferença de função trabalho entre metal de porta e semicondutor. 
Em um dispositivo SOI parcialmente depletado, como não há interação entre as regiões de depleção geradas pelas duas interfaces, a tensão de limiar é dada pela mesma equação (Eq.(2)) do dispositivo MOS convencional.

Para o transistor SOI nMOS totalmente depletado, no modo enriquecimento com dopagem uniforme na região do canal, podem ser obtidas as equações que descrevem o acoplamento entre os potenciais de superfície da primeira e segunda interface ( $\phi_{\mathrm{SF}} \mathrm{e}$ $\phi_{S B}$, respectivamente) em função das tensões aplicadas à porta $\left(V_{G F}\right)$ e ao substrato $\left(V_{G B}\right)$. Estas são obtidas integrando-se a equação de Poisson, e aplicando o teorema de Gauss na primeira e segunda interfaces ${ }^{33}$.

$$
\begin{gathered}
V_{G F}=\phi_{M S 1}-\frac{Q_{o \times 1}}{C_{o x f}}+\left(1+\frac{C_{S i}}{C_{o x f}}\right) \phi_{S F}-\frac{C_{S i}}{C_{o \times f}} \phi_{S B}-\frac{\frac{1}{2} Q_{\text {dep } 1}+Q_{i n v 1}}{C_{o \times f}} \\
V_{G B}=\phi_{M S 2}-\frac{Q_{o \times 2}}{C_{o \times b}}-\frac{C_{S i}}{C_{o x b}} \phi_{S F}+\left(1+\frac{C_{S i}}{C_{o x b}}\right) \phi_{S B}-\frac{\frac{1}{2} Q_{d e p 1}+Q_{S 2}}{C_{o x b}}
\end{gathered}
$$

onde:

$Q_{o x 1}$ é a densidade de cargas efetivas na primeira interface;

$Q_{o x 2}$ é a densidade de cargas efetivas na segunda interface;

$Q_{\text {inv1 }}$ é a carga de inversão na primeira interface $\left(Q_{\text {inv1 }}<0\right)$;

$Q_{\mathrm{S} 2}$ é a carga de acumulação $\left(Q_{\mathrm{S} 2}>0\right)$ ou inversão $\left(Q_{\mathrm{S} 2}<0\right)$ na $2^{\mathrm{a}}$ interface;

$\mathrm{C}_{\mathrm{oxf}}$ é a capacitância do óxido de porta por unidade de área, definida por $\mathrm{C}_{\mathrm{oxf}}=\varepsilon_{\mathrm{ox}} / \mathrm{t}_{\mathrm{oxf}}$;

$\mathrm{C}_{\text {oxb }}$ é a capacitância do óxido enterrado por unidade de área, definida por $\mathrm{C}_{\mathrm{oxb}}=\varepsilon_{0 \times} / \mathrm{t}_{\mathrm{oxb}}$;

$t_{\text {oxf }}$ é espessura do óxido de porta;

$t_{\text {oxb }}$ é a espessura do óxido enterrado;

$\mathrm{C}_{\mathrm{Si}}$ é a capacitância da camada de silício por unidade de área, definida por $\mathrm{C}_{\mathrm{Si}_{\mathrm{i}}}=\varepsilon_{\mathrm{S}} / \mathrm{t}_{\mathrm{Si}}$;

$\mathrm{N}_{\mathrm{a}}$ é a concentração da camada de silício;

$Q_{d e p 1}$ é a carga de depleção na camada de silício, definida por $Q_{d e p 1}=-q N_{a} t_{S i}$. 
Combinando-se as equações (4) e (5), são obtidas as equações da tensão de limiar para o SOI nMOSFET totalmente depletado no modo enriquecimento, em função das condições de polarização do substrato:

a) Com a segunda interface acumulada

$$
V_{\text {thl } 1, a c c 2}=\phi_{M S 1}-\frac{Q_{o x 1}}{C_{o x f}}+\left(1+\frac{C_{S i}}{C_{o x f}}\right) 2 \phi_{F}-\frac{Q_{\text {dep } 1}}{2 C_{o x f}}
$$

b) Com a segunda interface invertida

$$
V_{\text {th1,inv2 }}=\phi_{M S 1}-\frac{Q_{o x 1}}{C_{o x f}}+2 \phi_{F}-\frac{Q_{\text {dep } 1}}{2 C_{o x f}}
$$

c) Com a segunda interface depletada

$$
V_{t h 1, d e p l 2}=V_{t h 1, a c c 2}-\frac{C_{S i} C_{o x b}}{C_{o x f}\left(C_{S i}+C_{o x b}\right)}\left(V_{G B}-V_{G B, a c c 2}\right)
$$

A Figura 2-4 mostra o comportamento da tensão de limiar em função da variação da tensão aplicada no substrato $\left(\mathrm{V}_{\mathrm{GB}}\right)$.

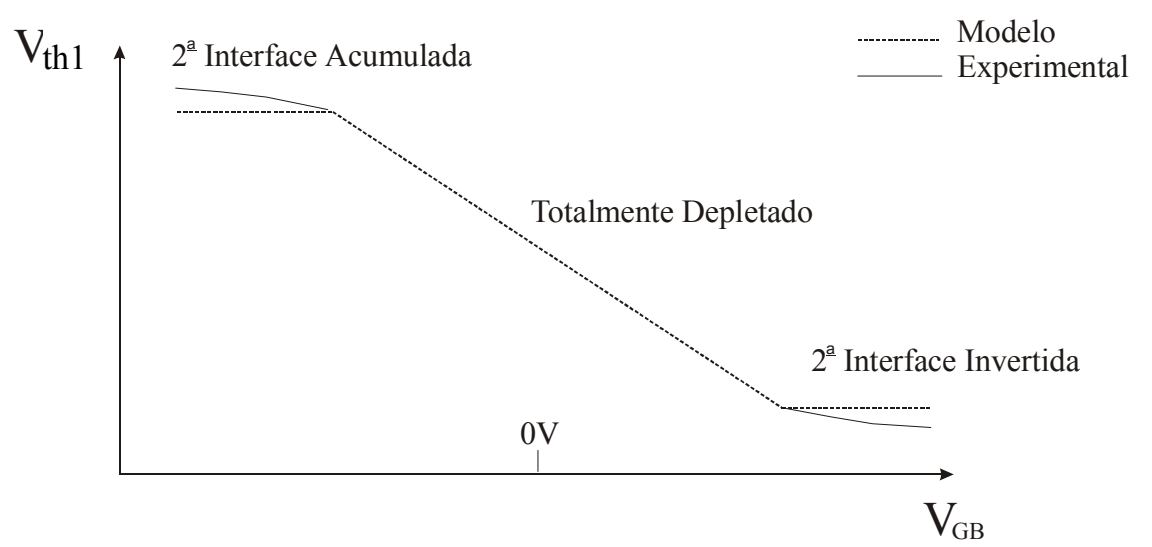

Figura 2-4 - Variação da tensão de limiar em função da tensão aplicada no substrato ${ }^{29}$. 


\subsubsection{Efeito de Corpo}

O efeito de corpo em um transistor MOS convencional é definido como a dependência da tensão de limiar com a polarização aplicada no substrato. Este mesmo conceito também pode ser usado para os dispositivos SOI.

Para dispositivos nMOS convencionais, a tensão de limiar pode ser reescrita considerando a polarização do substrato ${ }^{34}$ :

$$
V_{t h}=\phi_{M S}+2 \phi_{F}-\frac{Q_{o x}}{C_{o x}}+\frac{\sqrt{2 \varepsilon_{s i} q N_{a}\left(2 \phi_{F}-V_{B S}\right)}}{C_{o x}}
$$

Onde $\mathrm{V}_{\mathrm{BS}}$ é a polarização do substrato.

Definindo $\gamma$ como:

$$
\gamma=\frac{\sqrt{2 \varepsilon_{s i} q N_{a}}}{C_{o x}}
$$

A equação de $V_{\text {th }}$ pode ser reescrita como:

$$
V_{\text {th }}=\phi_{M S}+2 \phi_{F}-\frac{Q_{o x}}{C_{o x}}+\gamma \sqrt{2 \phi_{F}}+\gamma\left(\sqrt{2 \phi_{F}-V_{B S}}-\sqrt{2 \phi_{F}}\right)
$$

O último termo da equação (11) descreve a dependência da tensão de limiar com a polarização do substrato. Se considerarmos $V_{\text {tho }}$ como a tensão de limiar para $V_{B S}=0$, a equação (11) pode ser escrita como:

$$
V_{t h}\left(V_{B S}\right)=V_{t h 0}+\gamma\left(\sqrt{2 \phi_{F}-V_{B S}}-\sqrt{2 \phi_{F}}\right)
$$

Nos dispositivos SOI parcialmente depletados com contato de corpo, o efeito de corpo ocorre de forma similar aos dispositivos MOS convencionais, conforme descrito acima ${ }^{29}$. Contudo, o uso de contato de corpo nas estruturas SOI não é desejável, pois estes consomem uma área extra aumentando a complexidade do "layout"

O potencial de corpo nos dispositivos SOI parcialmente depletados, sem contato de corpo, é determinado pelas capacitâncias de acoplamento (corpo/portas e corpo/junções), pelas correntes nas junções $\mathrm{PN}$ e pela corrente de ionização por impacto $^{36}$. No caso das tecnologias mais recentes, que utilizam baixas potências e 
baixas tensões, a corrente de ionização por impacto não é significativa para tensões de alimentação abaixo de 1,1V.

A instabilidade do potencial do corpo pode ser analisada através das capacitâncias de acoplamento. O corpo dos dispositivos parcialmente depletados estão acoplados com os quatros terminais através das capacitâncias representadas na Figura 2-5. As capacitâncias da porta e do substrato tendem a estabilizar o potencial do corpo, sendo que o aumento da capacitância de porta provoca a melhora da inclinação de sublimiar e o aumento da corrente de dreno ${ }^{37}$.

Com a redução do comprimento de canal, o acoplamento entre as regiões de depleção associadas à porta e as regiões de fonte e dreno do dispositivo se torna mais significativo. Este acoplamento leva a um efeito de acomodamento de cargas dinâmico governado por portadores livres, que passam a polarizar a região do corpo. Este efeito associado com o funcionamento dinâmico do dispositivo provoca um transitório na corrente de dreno dependente do potencial do corpo que varia em função do tempo ${ }^{38}$.

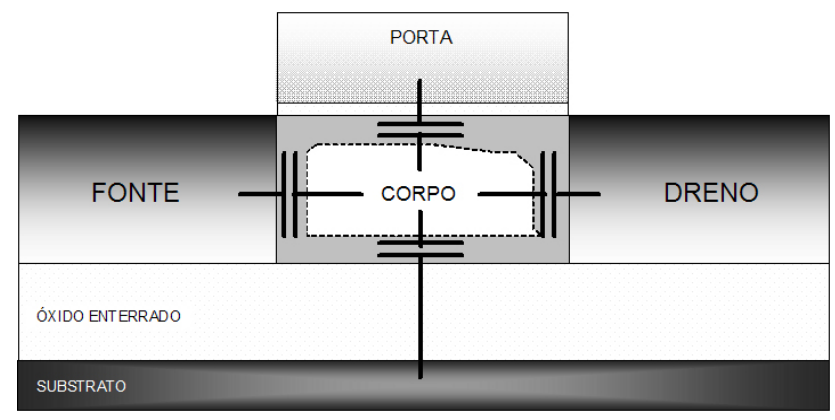

Figura 2-5 - Esquemático do acoplamento capacitivo em um PD SOI MOSFET.

Em dispositivos SOI totalmente depletado, o efeito de corpo é regido pela capacitância de acoplamento entre a porta e o substrato através da associação série das capacitâncias do óxido de porta, do óxido enterrado e do filme de silício, sendo dado por $^{29}$ :

$$
\alpha=\frac{C_{S i} C_{o x b}}{C_{o x f}\left(C_{S i}+C_{o x b}\right)}
$$

Sendo $\alpha$ um número adimensional. Em muitos casos, a seguinte aproximação é utilizada: 


$$
\alpha \cong \frac{t_{o x f}}{t_{o x b}}
$$

A dependência de $V_{\text {thF }}$ com $V_{G B}$ diminui com o aumento de $t_{o x b}$. Quando $t_{\text {oxb }}$ é muito espesso $\left(C_{o x b} \cong 0\right)$, a tensão de limiar é virtualmente independente de $V_{G B}{ }^{29}$.

\subsubsection{Efeito de canal curto}

Este efeito ocorre devido à diminuição das cargas de depleção controladas pela porta, ou seja, com a diminuição do comprimento do canal as regiões de depleção de fonte e dreno tornam-se significativas em relação à depleção controlada pela porta.

No caso de transistores MOSFETs convencionais, a carga de depleção controlada pela porta não será mais igual a $Q_{d e p l}=q N_{a} X_{d m a ́ x}$, mais sim uma fração desta que será chamada de $Q_{\text {depl,ef, }}$ sendo ${ }^{34}$ :

$$
Q_{\text {depl }, e f}=Q_{\text {depl }}\left[1-\frac{r_{j}}{L}\left(\sqrt{1+\frac{2 x_{\text {dmáx }}}{r_{j}}}-1\right)\right]
$$

Sendo $r_{j}$ a profundidade da junção de fonte e dreno e $L$ é o comprimento do canal.

Em dispositivos SOI totalmente depletado, a carga de depleção controlada pela porta é dada por ${ }^{29}$ :

$$
Q_{\text {depl,ef }}=Q_{\text {depl }}\left(1-\frac{d}{L}\right)
$$

Onde d está representado na Figura 2-6 e $Q_{\text {depl }}=q N_{a} t_{s i}$. 

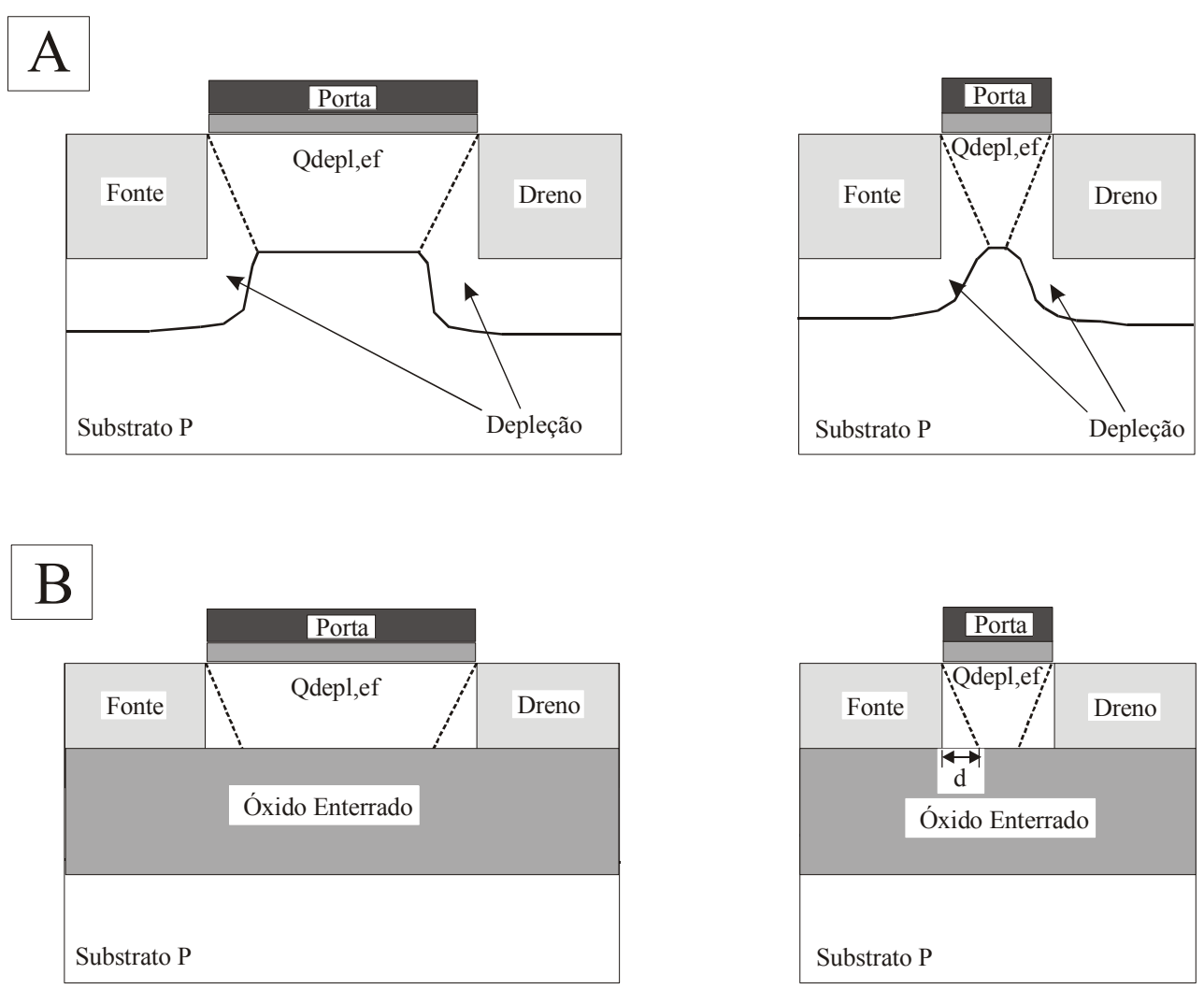

Figura 2-6 - Distribuição das cargas de depleção em um dispositivo MOS convencional (A) e em um dispositivo SOI nMOSFET (B), de canal longo (esquerda) e de canal curto (direita).

Uma descrição do método para o cálculo da distância d é apresentada na referência ${ }^{39}$.

De um modo geral, os dispositivos MOSFET convencionais assumem um perfil triangular para $Q_{\text {depl,ef }}$ e não trapezoidal como no caso dos dispositivos de camada fina. Desta forma, a seguinte aproximação pode ser feita ${ }^{29}$ :

$$
Q_{\text {depl }, e f} \cong \frac{Q_{\text {depl }}}{2}
$$

Através da Figura 2-7, pode-se perceber que a tensão de limiar começa a diminuir significativamente em um comprimento de canal maior para dispositivos MOSFET convencionais quando comparado com os transistores SOI totalmente depletados. 


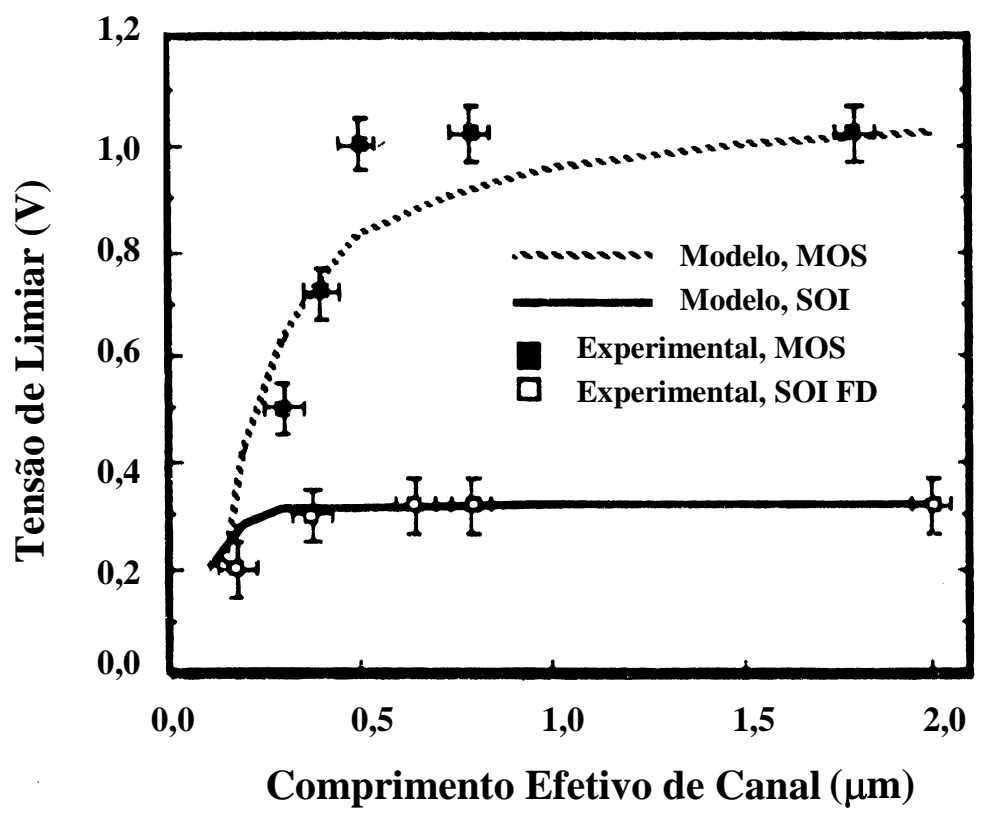

Figura 2-7 - Tensão de limiar em função do comprimento de canal em um dispositivo MOS convencional e um SOI MOSFET totalmente depletado ${ }^{29}$.

O efeito de canal curto é menor em dispositivos SOI MOSFETs totalmente depletados com a segunda interface acumulada quando comparados ao caso em que a segunda interface está depletada, mas ambos são menores que o efeito de canal curto em transistores MOS convencionais ${ }^{29}$.

Com o contínuo escalamento das dimensões dos dispositivos MOSFETs, muitos efeitos físicos ocorrem em dispositivos de canal curto, como a redução da tensão de limiar e da tensão de perfuração MOS, o aumento da corrente de fuga na região de sublimiar e da velocidade de saturação se tornaram cada vez mais significativas ${ }^{40,41}$. Para contornar o problema associado com a redução da tensão de limiar e da tensão de perfuração MOS, a tecnologia MOS implementou dentro do canal, junto às regiões de fonte e dreno, uma região com alta concentração de dopantes chamada região de implantação de HALO ${ }^{42,43}$.

Com a presença da região de implantação de HALO ocorre um efeito inverso na tensão de limiar, ou seja, um aumento desta com a redução do comprimento de canal. Este fato resulta do aumento da concentração efetiva de dopantes ocasionada pela 
presença das regiões de HALO, que se tornam cada vez mais significativas com a redução do canal.

A literatura tem reportado uma série de trabalhos que descrevem e modelam este fenômeno que é denominado como efeito de canal curto reverso (RSCE) (4, $45,46^{\text {. }}$ Um novo modelo para extração da tensão de limiar $\left(\mathrm{V}_{\mathrm{th}}\right)$ em dispositivos MOSFET convencionais, com a tecnologia de implantação de HALO ${ }^{47}$, considera como concentração efetiva, a média das concentrações de dopantes ao longo do canal, com um perfil triangular da concentração na região de HALO, como está representado na Figura 2-8.
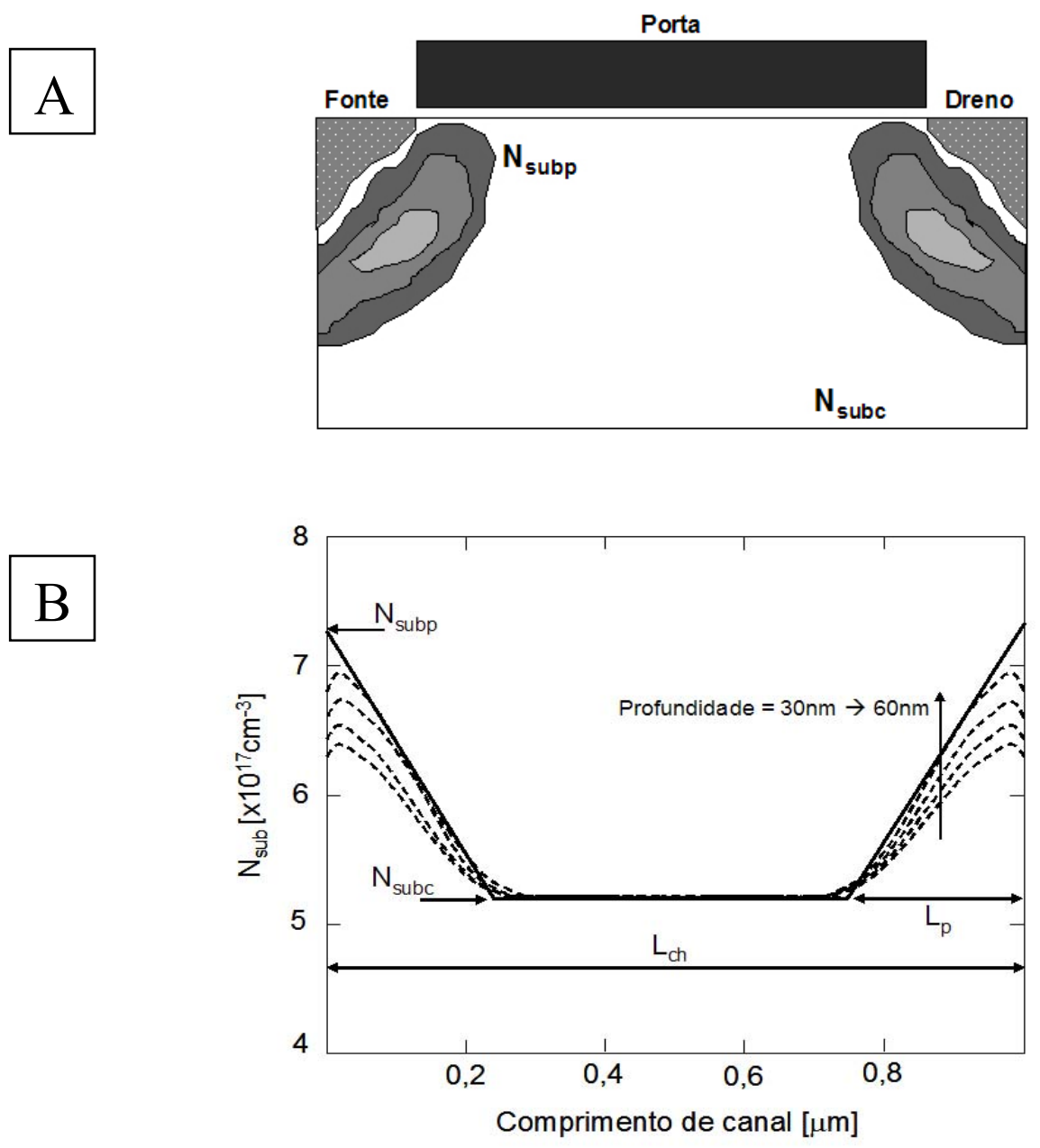

Figura 2-8 - Perfil da concentração de dopantes ao longo do canal de um dispositivo MOSFET convencional com Halo: (A) Corte transversal e (B) Perfil bidimensional ${ }^{47}$. 
A média das concentrações de dopantes ao longo do canal que considera um perfil triangular da concentração, para $L_{c h} \geq L_{P}$, é dada pela equação (18):

$$
N_{\text {subeff }}=\frac{\left(L_{c h}-L_{P}\right) N_{\text {subC }}+L_{P} N_{\text {subP }}}{L_{c h}}
$$

Onde o potencial de superfície pode ser aproximado, com um erro máximo de $10 \%$, conforme a equação (19).

$$
\phi_{s}=\frac{k T}{q} \ln \left(\frac{N_{\text {subeff }}}{n_{i}}\right)
$$

De posse do potencial de superfície, a tensão de limiar nos dispositivos MOSFETs convencionais, com a presença da região de implantação de HALO, pode ser calculada através da equação (20).

$$
V_{t h}=2 \phi_{s}+V_{F B}+\frac{\sqrt{2 q N_{s u b e f f} \varepsilon_{s i}\left(2 \phi_{s}-V_{B S}\right)}}{C_{o x}}
$$

\subsubsection{Transcondutância}

A capacidade de fornecer corrente de um SOI MOSFET depende basicamente de três fatores: da corrente de saturação, da transcondutância e da mobilidade dos portadores no canal invertido. Considerando os mesmos parâmetros de processo, a corrente de saturação ( $I_{\text {Dsat }}$ ) é maior em um dispositivo SOI MOSFET totalmente depletado, com a segunda interface depletada, do que em um dispositivo MOSFET convencional. Mas I Isat é menor em um dispositivo SOI MOSFET totalmente depletado, com a segunda interface acumulada, do que em um dispositivo MOS convencional ${ }^{29}$.

A transcondutância de um MOSFET, gm, é uma medida da eficácia do controle da corrente de dreno pela tensão aplicada na porta e é definida por:

$$
g m=\frac{d I_{D S}}{d V_{G F}}
$$


Em transistores nMOSFET convencionais, em saturação, gm é dado por ${ }^{48}$ :

$$
g m=\frac{W}{L} \mu_{n} C_{o x}\left(V_{G F}-V_{t h}\right)
$$

$\operatorname{com} C_{D}=\frac{\varepsilon_{s i}}{X_{\text {dmáx }}} 48$.

Por outro lado, a corrente de saturação pode ser escrita como indicado na equação (23):

$$
I_{D s a t} \cong \frac{W \mu_{n} C_{o x f}}{2 L(1+\alpha)}\left(V_{G F}-V_{t h}\right)^{2}
$$

Em dispositivos MOS tem-se que:

$$
\alpha=\frac{\varepsilon_{S i}}{x_{d \max } C_{o x}}
$$

No SOI MOSFET, totalmente depletado, a transcondutância é dada por:

$$
g m=\frac{d I_{\text {Dsat }}}{d V_{G F}}=\frac{W \mu_{n} C_{o x f}}{L(1+\alpha)}\left(V_{G F}-V_{\text {th1 }}\right), \text { para } V_{D S}>V_{\text {Dsat }}
$$

Nos dispositivos totalmente depletados, com a $2^{\mathrm{a}}$ interface acumulada ${ }^{49}$.

$$
\alpha=\frac{\varepsilon_{s i}}{t_{s i} C_{o x f}}=\frac{C_{S i}}{C_{o x f}}
$$

Nos dispositivos totalmente depletados, com a $2^{\mathrm{a}}$ interface depletada.

$$
\alpha=\frac{C_{S i} C_{o x b}}{C_{o x f}\left(C_{S i}+C_{o x b}\right)}
$$

Sendo assim,

$$
\alpha_{\text {SOI totalmente depletado }}<\alpha_{\text {convencional }}<\alpha_{\text {SOI }} 2^{\text {a interface acumulada }}
$$

Quando comparamos dispositivos com os mesmos parâmetros de processo, pode-se concluir que a transcondutância em um SOI MOSFET totalmente depletado, com a segunda interface depletada, é maior do que em um MOS convencional. Mas gm é menor em um SOI MOSFET totalmente depletado, com a segunda interface acumulada, do que em um dispositivo MOS convencional. 
Com o escalamento da tecnologia CMOS para dimensões nanométricas, fez-se necessário o uso de óxidos de porta extremamente finos para suprir o nível de corrente desejável com a redução das tensões de alimentação dos circuitos. Com o decréscimo da espessura do óxido de porta, a corrente de tunelamento através da porta aumenta exponencialmente. Este aumento tanto é prejudicial do ponto de vista de circuitos integrados CMOS, devido à alta dissipação de potência, como também do ponto de vista dos dispositivos isoladamente, pois o aumento da corrente de porta afeta o desempenho destes dispositivos ${ }^{50}$.

Com a redução da espessura do óxido de porta nos dispositivos SOI parcialmente depletados, um novo tipo de efeito de corpo flutuante se associa com a corrente de tunelamento direto entre o corpo e a porta destes transistores, quando operando na região linear ${ }^{51}$. O fenômeno pode ocorrer devido ao tunelamento de elétrons da banda de valência, quando é aplicada tensão suficientemente grande na porta, de modo que esta corrente de tunelamento supra a quantidade de portadores majoritários necessária para carregar o corpo e polarizar diretamente a junção entre o corpo e a fonte, induzindo a uma anomalia na curva da corrente de dreno em função da tensão aplicada à porta. Este efeito denominado "Linear Kink Effect" (LKE) gera como conseqüência um segundo pico na curva da transcondutância de dreno ${ }^{52}$.

\subsubsection{Mobilidade}

A mobilidade dos elétrons $\left(\mu_{n}\right)$ dentro da camada de inversão, em um dispositivo MOS, é uma função do campo elétrico vertical abaixo do óxido de porta, podendo ser aproximada pela equação $(28)^{29}$, onde os eixos assumidos nesta seção estão representados na Figura 2-9: 


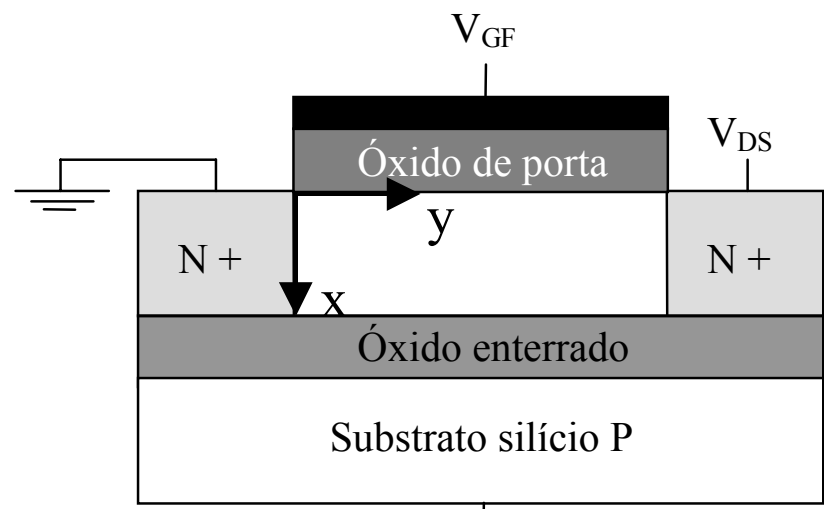

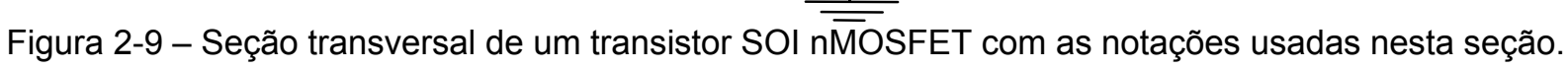

$$
\mu_{n}(y)=\mu_{\text {máx }}\left[\frac{E_{C}}{E_{\text {eff }}(y)}\right]^{C} \text {, para } E_{\text {eff }}(y)>\mathrm{E}_{\mathrm{C}}
$$

Sendo que $\mu_{\text {máx }}$, $E_{C}$ e c são parâmetros que dependem do processo de oxidação da porta e das propriedades do dispositivo. O campo elétrico efetivo ( $\left.E_{\text {eff }}\right)$ é dado por $^{53,54}$ :

$$
E_{\text {eff }}(y)=E_{S F}(y)-\frac{Q_{i n v 1}(y)}{2 \varepsilon_{s i}}
$$

O campo elétrico vertical abaixo do óxido de porta $\left(E_{S F}\right)$ é dado por ${ }^{53}$ :

$$
E_{S F}(y)=\left(\frac{\phi_{S F}(y)-\phi_{S B}(y)}{t_{s i}}+\frac{q N_{a} t_{s i}}{2 \varepsilon_{s i}}\right)
$$

Em um dispositivo SOI MOSFET totalmente depletado, operando com baixa tensão de dreno $\left(\mathrm{V}_{D S} \cong 0\right)$, a expressão do campo elétrico na superfície pode ser simplificada considerando os potenciais de superfície na primeira e segunda interface independentes de y.

Se a segunda interface estiver depletada e próxima da inversão $\left(\phi_{\mathrm{SF}}-\phi_{\mathrm{SB}} \cong 0\right)$, o campo elétrico na primeira interface será:

$$
E_{S F}=\frac{q N_{a} t_{s i}}{2 \varepsilon_{s i}}
$$

Neste caso, o campo elétrico é menor do que em um dispositivo MOSFET convencional (desde que $t_{s i}<x_{d m a ́ x}$ ) dado por: 


$$
E_{S F}=\frac{q N_{a} X_{d m a ́ x}}{\varepsilon_{s i}}
$$

Se o filme está totalmente depletado, mas ainda não está próximo da inversão, o campo elétrico na superfície é ainda menor do que no dispositivo MOSFET convencional, já que $\mathrm{x}_{1}<\mathrm{t}_{\mathrm{si}}<\mathrm{x}_{\mathrm{dmáx}}$, e é aproximado pela equação (33):

$$
E_{S F} \cong \frac{q N_{a} x_{1}}{\varepsilon_{\text {si }}}
$$

Onde $x_{1}$ é o ponto de mínimo potencial no filme de silício ( $x=0$ na primeira interface).

O campo elétrico na primeira interface $\left(E_{S F}\right)$ é menor em um dispositivo $\mathrm{SOI}$ do que em um dispositivo MOS convencional. Mas, é importante notar que se a segunda interface do dispositivo SOI totalmente depletado estiver acumulada ( $\phi_{S F}-\phi_{S B}=2 \phi_{F}$ ), o campo elétrico na superfície será maior do que no dispositivo MOS convencional ${ }^{29}$.

Através da equação (29), pode-se notar que a mobilidade máxima é obtida quando a tensão aplicada na porta ( $\left.\mathrm{V}_{\mathrm{GF}}\right)$ está logo acima da tensão de limiar $\left(\mathrm{Vth}_{\mathrm{F}}\right)$. Com o aumento de $V_{G F}$, a mobilidade decresce rapidamente devido ao aumento das cargas de inversão ( $\left.Q_{\text {inv }}\right)$.

\subsubsection{Inclinação de Sublimiar (Slope)}

Quando o valor da tensão aplicada à porta está abaixo da tensão de limiar e a primeira interface do transistor está em inversão fraca, a corrente de dreno é chamada de corrente de sublimiar. O inverso da inclinação de sublimiar, ou simplesmente inclinação de sublimiar (slope ou fator $S$ ), é definido como o inverso da inclinação da curva $I_{D S} \times V_{G F}$ em regime de sublimiar, com a corrente de dreno em escala logarítmica, sendo descrita na equação (34) e expressa em milivolts por década. A inclinação de sublimiar é particularmente importante nas aplicações digitais, porque quanto menor este valor, maior será a velocidade de chaveamento dos dispositivos. 


$$
S=\frac{d V_{G F}}{d\left(\log I_{D S}\right)}=\frac{\ln (10)}{\frac{d\left(\ln \left(I_{D S}\right)\right)}{d V_{G F}}}
$$

A corrente de sublimiar em um transistor MOS consiste em uma corrente predominantemente de difusão de portadores minoritários, sendo dada por ${ }^{55}$ :

$$
I_{D S}=-q A D_{n} \frac{d n}{d y} \cong q A D_{n} \frac{n(0)-n(L)}{L}
$$

Onde $A$ é área da seção transversal por onde flui a corrente, $D_{n}$ é o coeficiente de difusão dos elétrons, $n(0)$ e $n(L)$ são as densidades de elétrons do lado da fonte e do dreno, respectivamente. Estas densidades de elétrons são dadas por:

$$
\begin{aligned}
& n(0)=n_{p 0} e^{\frac{q \phi_{s}}{k T}} \\
& n(L)=n_{p 0} e^{\frac{q\left(\phi_{s}-V_{D S}\right)}{k T}}
\end{aligned}
$$

Considerando que a fonte aterrada e $n_{p 0}=\frac{n_{i}^{2}}{N_{a}}$.

Baseado no modelo clássico, é conhecido que a concentração de elétrons varia com $\exp (q \phi(x) / k T)$ na profundidade de canal. Com o objetivo de simplificar os cálculos é feita uma aproximação do perfil exponencial de elétrons por uma densidade de elétrons constante, estendendo para uma profundidade $d$ abaixo da superfície. A profundidade $d$ pode ser definida como a profundidade em que o potencial diminui de kT/q abaixo do valor do potencial de superfície ${ }^{29}$. De posse da relação de Einstein $D_{n}=\frac{k T}{q} \mu_{n}$ é possível obter a equação da corrente de dreno, a partir da equação (35), na região de sublimiar. Como segue:

$$
I_{D S}=\mu_{n} \frac{W}{L} q\left(\frac{k T}{q}\right)^{2} \frac{n_{i}^{2}}{N_{a}}\left[1-\exp \left(-q V_{D S} / k T\right)\right] \frac{\exp \left(q \phi_{S} / k T\right)}{\frac{-d \phi_{s}}{d x}}
$$

Usando a relação entre a tensão na porta $\left(\mathrm{V}_{\mathrm{GF}}\right)$ e as cargas no silício e nas interfaces $\left(V_{G F}=\phi_{M S}+\phi_{S}+\frac{-Q_{D}-Q_{o x}+C_{i t} \phi_{S}}{C_{o x}}\right)$, é possível obter a variação do potencial 
de superfície em função da variação do potencial na porta $\left(\frac{d \phi_{S}}{d V_{G F}}=\frac{C_{o x}}{C_{o x}+C_{D}+C_{i t}}\right)$. Desta forma, combinando-se as equações (34) e (38) e desprezando-se a capacitância associada às armadilhas de interface, obtém-se de uma forma geral a equação:

$$
S=\frac{k T}{q} \ln (10)(1+\alpha)
$$

onde, $\alpha$ representa a mesma relação de capacitâncias citadas anteriormente na análise de transcondutância, sabendo que:

$\alpha_{\text {SOI totalmente depletado }}<\alpha_{\text {convencional }}<\alpha_{\text {SOI } 2^{\text {a }} \text { interface acumulada }}$

Conclui-se assim que o fator S é menor no SOI totalmente depletado, maior no MOS convencional e ainda maior no SOI com a segunda interface acumulada.

A inclinação de sublimiar dá uma indicação da condição de operação do transistor SOI MOSFET. Para valores entre 60 e $70 \mathrm{mV} / \mathrm{dec}$ corresponde à situação em que o dispositivo de camada fina está totalmente depletado ${ }^{29}$.

Comparando-se os valores da inclinação de sublimiar entre o SOI e os dispositivos MOS convencionais, percebe-se que estes valores são menores para os dispositivos SOI totalmente depletados, o que habilita sua utilização com tensões de limiar menores, sem o aumento da corrente de fuga. Como conseqüência, pode-se obter melhor desempenho em alta velocidade, principalmente em baixas tensões de alimentação. Da mesma maneira que nos dispositivos MOS convencionais, um aumento da inclinação de sublimiar é observado em dispositivos de canal curto ${ }^{56}$.

Conforme elucidado anteriormente, na seção 2.2.3, com o escalamento das dimensões tornou-se cada vez mais freqüente o uso das regiões de implantação de HALO, junto a fonte e o dreno dos dispositivos. A presença destas regiões de HALO ocasiona o fenômeno denominado como efeito de canal curto reverso (RSCE) ${ }^{44,45,46}$, que é observado no aumento da tensão de limiar quando o comprimento de canal é reduzido. Este aumento na tensão de limiar é explicado pelo aumento da concentração efetiva de dopantes na região de canal, devido a maior concentração nas regiões de HALO. 
As características da região de sublimiar também apresentam uma anomalia devido à maior concentração de dopantes junto às regiões de fonte e dreno. Ao contrário do esperado, nestes dispositivos as características de sublimiar são praticamente independentes do comprimento de canal ${ }^{57}$. Nestes casos, as características de sublimiar são dominadas pelas regiões de maior concentração, porque o potencial de superfície destas regiões é menor do que o da região do canal com menor concentração de dopante. O baixo potencial de superfície nestas regiões de maior concentração de dopantes limita a corrente dos dispositivos MOSFET na região de sublimiar, como conseqüência a razão a corrente de ligamento e a corrente de desligamento ( $\left.\mathrm{I}_{\text {on }} / \mathrm{l}_{\text {off }}\right)$ aumenta com o decréscimo do comprimento de canal ${ }^{57}$.

\subsection{EFEITOS DA TEMPERATURA}

Uma das principais vantagens da tecnologia SOI MOSFET em relação à tecnologia MOS convencional é ter se demonstrado como uma melhor alternativa para aplicações em altas temperaturas, devido à baixa variação da tensão de limiar, ao menor aumento da corrente de fuga, à ausência do efeito tiristor parasitário e à condutância de saída que permanece constante ${ }^{58,59}$.

No setor automotivo, por exemplo: a monitoração do motor que exige uma grande tolerância ao nível de temperatura (acima de $600{ }^{\circ} \mathrm{C}$ ), pois os sensores usados na monitoração do sistema de injeção de combustível estão posicionados bem próximos ou até mesmo dentro do bloco do motor. O monitoramento do sistema de freios $A B S$ (acima de $300^{\circ} \mathrm{C}$ ), onde os sensores estão instalados próximos ao sistema, onde há uma grande dissipação de energia térmica quando os freios são acionados. $A$ eletrônica de bordo que deve ser capaz de suportar temperaturas até de $200^{\circ} \mathrm{C}^{60}$.

O setor aeroespacial também possui uma grande demanda para os dispositivos SOI MOSFETs operando em altas temperaturas: a eletrônica de bordo $\left(150-250{ }^{\circ} \mathrm{C}\right)$ e a monitoração dos motores $\left(300-600{ }^{\circ} \mathrm{C}\right)$ do avião. Como também na área espacial, circuitos utilizados nos satélites $\left(150-600^{\circ} \mathrm{C}\right)$. 
Um outro campo importante de aplicação é na área de energia nuclear (30$550^{\circ} \mathrm{C}$ ), onde há a necessidade não só de circuitos que operem em altas temperaturas, mas que também possam ser submetidos à radiação ${ }^{60,61,62}$.

\subsubsection{Corrente de Fuga através das Junções}

Uma das principais limitações dos circuitos MOS, operando em altas temperaturas, é o aumento da corrente de fuga através das junções. Esta corrente é proporcional à área da junção, com a redução significativa destas áreas, tratando-se dos dispositivos SOI, esta corrente também é diminuída habilitando estes dispositivos a operar em temperaturas maiores que $150^{\circ} \mathrm{C}$.

A corrente de fuga ( $\left(_{\text {leak }}\right)$ através de uma junção PN reversamente polarizada pode ser expressa por ${ }^{55}$ :

$$
I_{\text {leak }}=q A\left(\frac{D_{n}}{\tau_{n}}\right)^{\frac{1}{2}} \frac{n_{i}^{2}}{N_{a}}+q A \frac{n_{i} W}{\tau_{e}}
$$

onde q é a carga do elétron, $A$ é a área da junção, $D_{n}$ é o coeficiente de difusão de elétrons, $\tau_{n}$ é o tempo de vida de elétrons em um região quase neutra de silício tipo $p, n_{i}$ é concentração intrínseca de portadores, $\mathrm{N}_{\mathrm{a}}$ é a concentração de dopantes da região do corpo, $W$ é a largura de depleção e $\tau_{\mathrm{e}}=\left(\tau_{\mathrm{n}}+\tau_{\mathrm{p}}\right) / 2$ é o tempo de vida efetivo relacionado com o processo de geração térmica dentro da região de depleção. A concentração intrínseca de portadores no silício depende da temperatura e é dada por ${ }^{34}$ :

$$
n_{i}=3.9 \times 10^{16} T^{\frac{3}{2}} e^{-\left(\frac{E g}{2 k T}\right)}
$$

Conforme pode ser observado na equação (40), o primeiro termo referente a componente de difusão é proporcional à $n_{i}^{2} \mathrm{e}$ o segundo termo referente a componente de geração é proporcional à $n_{\mathrm{i}}$. A literatura reporta a observação experimental ${ }^{61}$ que a corrente de fuga em transistores $\mathrm{SOI}$, assim como em diodos polarizados reversamente, varia proporcionalmente com $n_{i}$ em temperaturas abaixo de $150^{\circ} \mathrm{C}$ e com $n_{i}^{2}$ em temperaturas superiores a esta. Sabe-se que a área das junções é menor em 
transistores SOI quando comparados com MOS convencionais e, conseqüentemente, o volume da região de carga espacial associada às mesmas é menor, fato este que ocasiona a redução significativa da corrente de fuga nestes dispositivos.

\subsubsection{Tensão de Limiar}

A tensão de limiar de um transistor MOSFET canal-n é dada por:

$$
V_{t h}=\phi_{M S}+2 \phi_{F}-\frac{Q_{o x}}{C_{o x}}-\frac{Q_{\text {depl }}}{C_{o x}}
$$

Onde $\phi_{\mathrm{MS}}$ é a diferença de função trabalho entre metal e semicondutor, $\phi_{\mathrm{F}}$ é o potencial de Fermi, $C_{o x}$ é a capacitância do óxido de porta, e $Q_{o x}$ e $Q_{\text {depl }}$ são as cargas no óxido e as cargas de depleção controladas pela porta, respectivamente.

Tanto nos dispositivos MOS convencionais como nos SOI parcialmente depletados $Q_{\text {depl }}=q N_{a} x_{\text {dmáx }}$, onde $x_{\text {dmáx }}$ é a largura de depleção máxima correspondente a concentração de dopantes na região do canal. Sendo, $x_{\text {dmáx }}=\sqrt{\frac{4 \varepsilon_{s i} \phi_{F}}{q N_{a}}}$.

A variação da concentração intrínseca de portadores no silício com a temperatura é dada pela equação (41). Pode-se assumir que $Q_{o x}$ e Eg não dependem da temperatura, gerando assim um erro menor que $0,3 \%$ para o intervalo de temperatura de $20^{\circ} \mathrm{C}$ à $250^{\circ} \mathrm{C}^{29}$. Quando há um aumento na temperatura a concentração de portadores intrínseca $\left(n_{i}\right)$ também aumenta, enquanto o potencial de Fermi $\left(\phi_{F}\right)$ diminui. Diminuindo o potencial de Fermi, segundo a equação (42), a tensão de limiar também decresce.

Os potenciais aplicados na primeira e na segunda porta, em um dispositivo SOI MOSFET totalmente depletado, são dados pelas equações (4) e (5), respectivamente, onde os termos dependentes da temperatura são $\phi_{M S 1}, \phi_{M S 2}, \phi_{S F}$ e $\phi_{S B}$. Desde que a porta seja de silício policristalino $\mathrm{N}^{+}$, tem-se ${ }^{29}$ :

$$
\phi_{M S 1}=-\frac{E g}{2 q}-\phi_{F f}=-\frac{E g}{2 q}-\frac{k T}{q} \ln \left(\frac{N_{a}}{n_{i}}\right)
$$




$$
\phi_{M S 2}=-\frac{k T}{q} \ln \left(\frac{N_{a b}}{N_{a}}\right)
$$

Com $\phi_{\mathrm{Ff}}, \mathrm{k}, \mathrm{q}, \mathrm{Eg}, \mathrm{T}, \mathrm{N}_{\mathrm{a}}, \mathrm{N}_{\mathrm{ab}}$ e $n_{i}$ sendo o potencial de Fermi do filme de silício, a constante de Boltzmann, a carga do elétron, a largura da faixa de energia proibida do silício, a temperatura, a concentração de dopantes da região de corpo, do substrato e a concentração intrínseca de portadores no silício, respectivamente.

Da mesma forma que no caso anterior, com o aumento da temperatura, em um dispositivo SOI MOSFET totalmente depletado, ocorre a diminuição do potencial de Fermi $\left(\phi_{\mathrm{Ff}}\right)$ e conseqüentemente da tensão de limiar.

Este decréscimo do potencial de Fermi também ocasiona um estreitamento nas regiões de máxima depleção provenientes da primeira e segunda interface. Nos dispositivos SOI MOSFETs totalmente depletado existe uma determinada temperatura, chamada de temperatura crítica $\left(T_{K}\right)$, em que a soma das regiões de depleção da primeira e segunda interface é igual à espessura do filme de silício. A partir da temperatura crítica ocorre o desacoplamento das regiões de depleção, fazendo com que o transistor opere parcialmente depletado a partir deste ponto.

$\mathrm{Na}$ figura 2.9, tem-se uma comparação do comportamento da tensão de limiar em função da temperatura entre um dispositivo SOI MOSFET totalmente depletado e um MOSFET convencional. Pode-se observar que, a partir da temperatura crítica (Tk), ambas as curvas possuem a mesma inclinação ${ }^{29}$. 


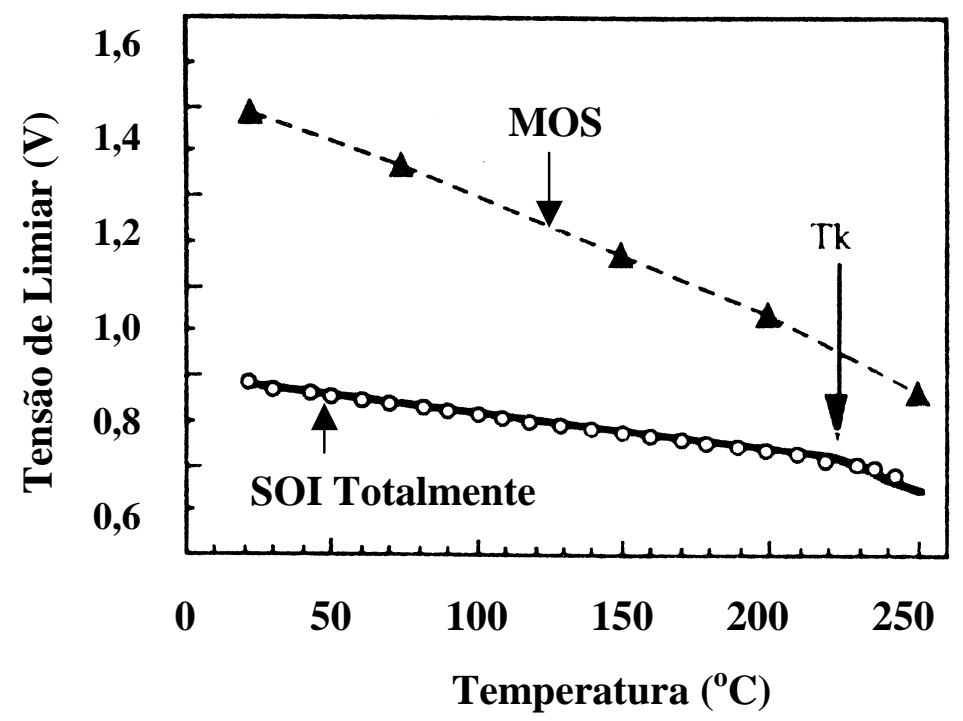

Figura 2-10 - Variação da tensão de limiar, do MOS convencional e do SOI totalmente depletado, com a temperatura ${ }^{29}$.

\subsubsection{Inclinação de Sublimiar}

A equação (39), apresentada na seção (2.2.6), é a expressão clássica usada para o cálculo da inclinação de sublimiar, que prevê como valor ideal $60 \mathrm{mV} / \mathrm{dec}$ na temperatura de 300k. Onde $\alpha$ representa a relação entre as capacitâncias efetivas do corpo e capacitância do óxido de porta. De acordo com a análise prévia (seção 2.2.4), assume-se que $\alpha$ é independente da temperatura nos dispositivos totalmente depletados e no caso dos parcialmente depletados esta dependência se deve ao decréscimo da profundidade máxima de depleção com o aumento da temperatura.

Quando analisa-se a expressão para o cálculo da inclinação de sublimiar (S), em dispositivos SOI MOSFETs totalmente depletados, é verificada uma dependência linear com a temperatura. Contudo, experimentalmente esta variação da inclinação de sublimiar com a temperatura nestes dispositivos não é linear ${ }^{59}$, conforme mostra a Figura 2-11. 


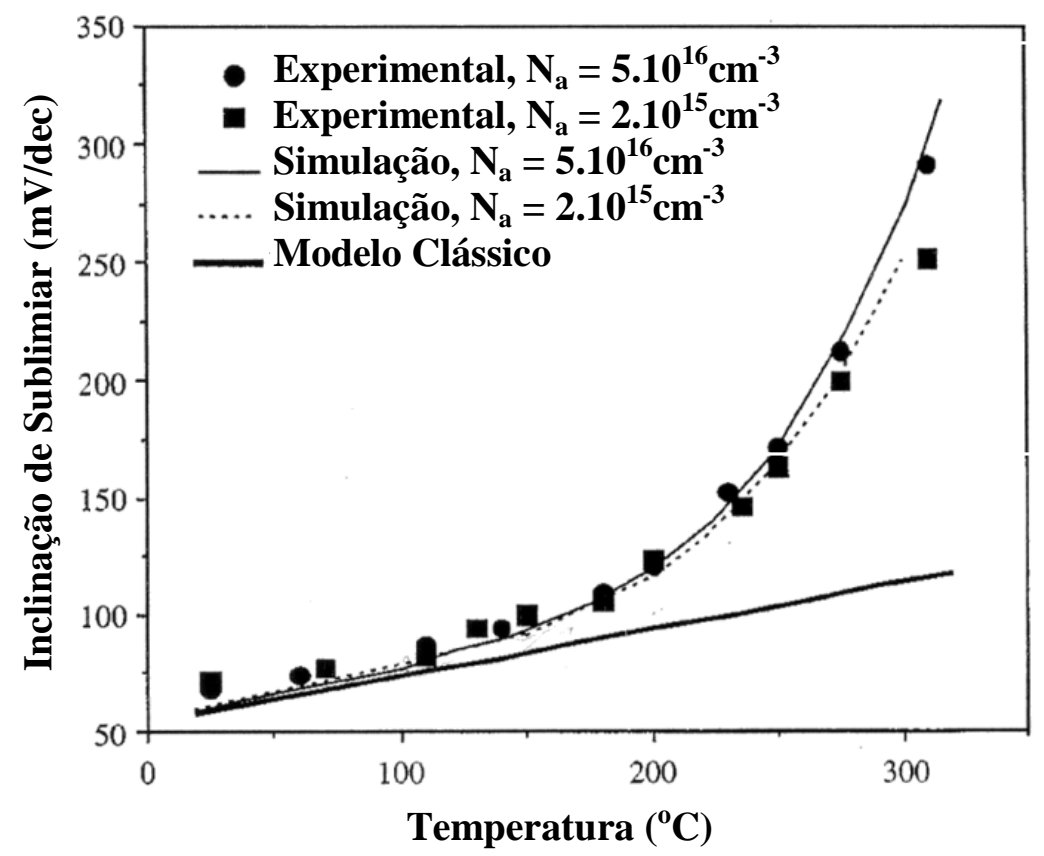

Figura 2-11 - Curvas experimentais, simuladas e calculada através do modelo clássico de um dispositivo SOI MOSFET com $\mathrm{L}=20 \mu \mathrm{m}$ e $\mathrm{W}=20 \mu \mathrm{m}^{59}$.

Este fenômeno ocorre devido ao aumento da capacitância efetiva do corpo causado pelo aumento da densidade de carga de portadores livres e pela diminuição do campo elétrico na superfície, que ocorre com o aumento da temperatura, quando o dispositivo se encontra na região de inversão fraca.

O modelo da inclinação de sublimiar que considera tanto a diminuição do campo elétrico superficial, no regime de inversão fraca (onde $\phi_{F} \leq \phi_{F f} \leq 2 \phi_{F}$ ), quanto a contribuição do aumento da densidade dos portadores livres com o aumento da temperatura é dado pela equação $(45)^{59}$.

$$
S=\frac{\eta k T}{q} \ln (10)\left(1+\frac{C_{D \text { tot }}}{C_{o x}}\right)
$$

sendo $C_{D \text { tot }}=\frac{d Q_{\text {tot }}}{d \phi_{s}}$ a capacitância total do corpo considerando os portadores livres e $\eta$ o fator de correção dado pela expressão:

$$
\eta=\left[\left(\frac{k T}{q}\right)\left(\frac{d \ln Q_{i n v}}{d \phi_{s}}\right)\right]^{-1}
$$




\subsubsection{Mobilidade}

O modelo clássico simplificado da mobilidade, que inclui o efeito das resistências de fonte e dreno juntamente com o efeito da temperatura segue abaixo ${ }^{62}$ :

$$
\mu=\mu_{0} \frac{1}{1+\left(\theta+\alpha_{R}\right)\left(V_{G S}-V t h_{F}\right)}
$$

onde, $\mu_{0}$ é a mobilidade para baixo campo elétrico e $\theta$ é o fator de atenuação da mobilidade.

$\alpha_{R}$ e $\mu_{0}$ podem ser calculados segundo as equações abaixo:

$$
\begin{gathered}
\alpha_{R}=\frac{2 \mu_{0} C_{o x} R_{S D} W}{L} \\
\mu_{0}=\mu_{273 K}\left(\frac{T}{273}\right)^{-m} \text {, com } \mathrm{m}=1,9
\end{gathered}
$$

A Figura 2-12 apresenta a variação da mobilidade com baixo campo elétrico, para os elétrons (dispositivo canal-n) e para as lacunas (dispositivo canal-p) em função da temperatura. 


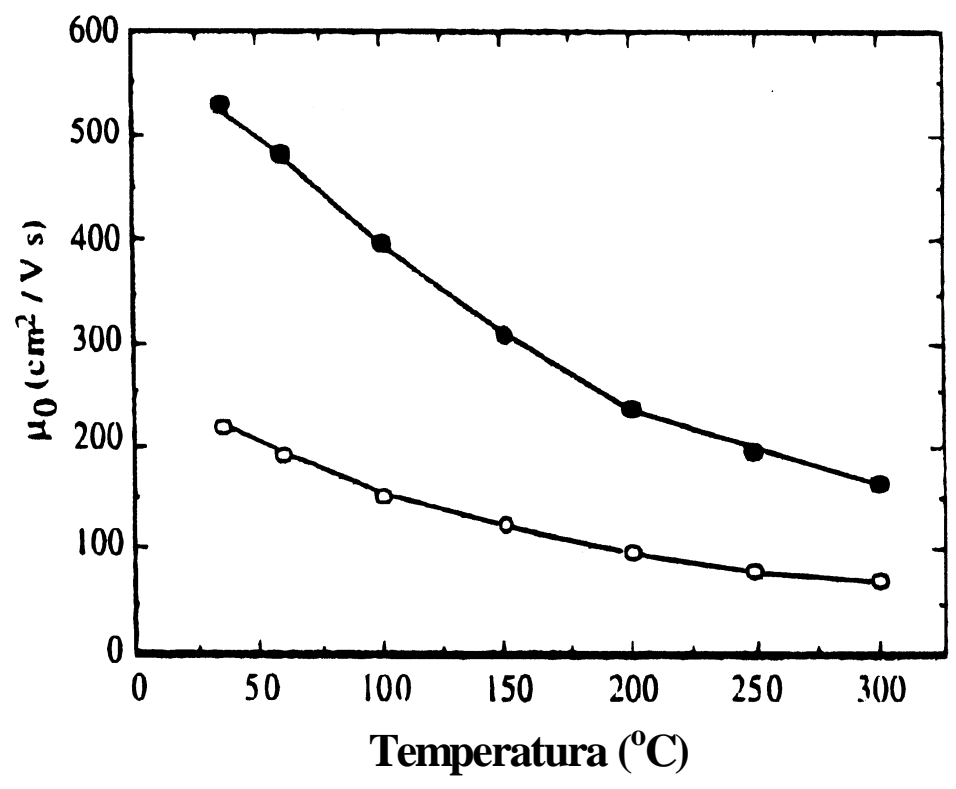

Figura 2-12 - Variação de $\mu_{0}$ em função da temperatura, em um SOI MOSFET canal-n $(\bullet)$ e em um SOI MOSFET canal-p (o) ${ }^{62}$.

Com o aumento da temperatura há um decréscimo na mobilidade para baixo campo elétrico $\left(\mu_{0}\right)$ e um aumento da resistência série de fonte e dreno. Embora a resistência série aumente, o decréscimo de $\mu_{0}$ é predominante, ocasionando assim uma leve diminuição do coeficiente $\alpha_{R}{ }^{62}$, conforme pode ser observado na Figura 2-13.

Pode-se também observar na Figura 2-13 que o fator de atenuação da mobilidade $(\theta)$ decresce com o aumento da temperatura. Sendo assim, o termo $\left(\theta+\alpha_{R}\right)$ diminui com o aumento da temperatura, atenuando a diminuição da mobilidade efetiva $(\mu)^{62}$. 


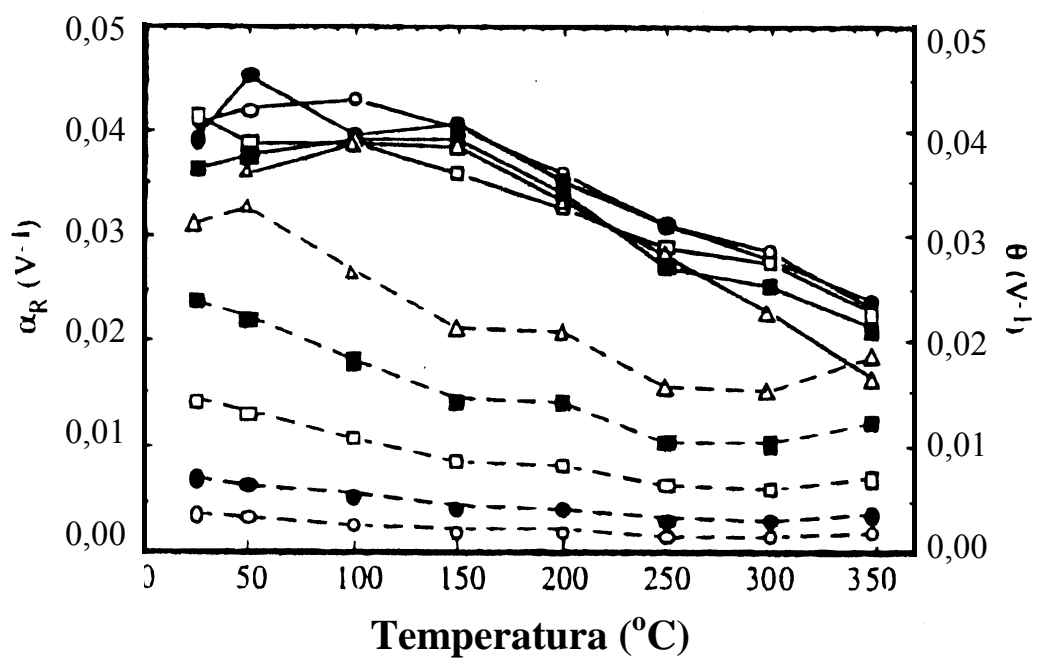

Figura 2-13 - Extração do $\theta$ (contínuo) e $\alpha_{R}$ (tracejado) em função da temperatura, para dispositivos SOI MOSFET canal-n com L $=20 \mu \mathrm{m}(O), 10 \mu \mathrm{m}(\bullet), 5 \mu \mathrm{m}(\square), 3 \mu \mathrm{m}(\boldsymbol{\square})$ e $2 \mu \mathrm{m}(\Delta)^{62}$.

\subsection{SIMULADOR MEDICI}

$\mathrm{O} \mathrm{MEDICl}{ }^{63}$ é um programa de simulação numérica usado para simular o comportamento de transistores MOS, bipolares, e outros dispositivos semicondutores. Este programa possui modelos bidimensionais para distribuição do potencial e concentração de portadores, podendo ser usado para prever o comportamento elétrico de um dispositivo para condições arbitrárias de polarização.

O programa $\mathrm{MEDICl}$, entre outras, resolve as equações de Poisson e as equações de continuidade de corrente, tanto para elétrons como para lacunas, para analisar o comportamento dos dispositivos. A simulação obedece uma grade triangular não uniforme que permite modelar arbitrariamente a geometria dos dispositivos para uma superfície topográfica planar ou não planar.

Esta grade de simulação pode ser refinada automaticamente durante o processo de solução. Nós adicionais e parâmetros como potencial ou concentração de impurezas podem ser inseridos ou variados conforme a especificação do usuário. Esta flexibilidade possibilita a modelagem de estruturas e dispositivos bastante complexos. 
Este simulador incorpora uma série de modelos físicos, incluindo modelos para recombinação, foto-geração, ionização por impacto, estreitamento das bandas de energia, tunelamento, mobilidade e tempo de vida dos portadores. Além de incorporar as estatísticas de Boltzmann e Fermi-Dirac, incluindo a ionização incompleta de impurezas com o objetivo de tornar os resultados mais precisos.

\subsubsection{Modelos utilizados}

Abaixo segue uma breve descrição dos modelos usados no presente trabalho:

ANALYTIC - Este modelo especifica a mobilidade de elétrons e lacunas para baixo campo elétrico dependendo da concentração e da temperatura, segundo as equações abaixo:

$$
\begin{gathered}
\mu_{0 n}=M U N \cdot M I N+\frac{M U N \cdot M A X\left(\frac{T}{300}\right)^{\text {NUN }}-\text { MUN.MIN }}{1+\left(\frac{T}{300}\right)^{X I N}\left(\frac{N_{\text {total }}(x, y)}{N R E F N}\right)^{A L P H A N}} \\
\mu_{0 p}=\text { MUP.MIN }+\frac{\text { MUP.MAX }\left(\frac{T}{300}\right)^{\text {NUP }}-\text { MUP.MIN }}{1+\left(\frac{T}{300}\right)^{X I P}\left(\frac{N_{\text {total }}(x, y)}{N R E F P}\right)^{A L P H A P}}
\end{gathered}
$$

Onde $N_{\text {total }}(x, y)$ é a concentração total de impurezas e $T$ a temperatura.

Os valores dos parâmetros usados nas equações (50) e (51), pré-definidos pelo simulador para o silício ${ }^{64,65}$, são mostrados na Tabela 1. 
Tabela 1 - Valores pré-definidos pelo simulador para o modelo ANALYTIC.

\begin{tabular}{cccccc}
\hline Parâmetro & Silício & Unidade & Parâmetro & Silício & Unidade \\
\hline MUN.MIN & 55,24 & $\mathrm{~cm}^{2} / \mathrm{V} . \mathrm{s}$ & MUP.MIN & 49,70 & $\mathrm{~cm}^{2} / \mathrm{V} . \mathrm{S}$ \\
\hline MUN.MAX & 1429,23 & $\mathrm{~cm}^{2} / \mathrm{V} . \mathrm{s}$ & MUP.MAX & 479,37 & $\mathrm{~cm}^{2} / \mathrm{V} . \mathrm{s}$ \\
\hline NREFN & $1,07210^{17}$ & $\mathrm{~cm}^{-3}$ & NREFP & $1,60610^{17}$ & $\mathrm{~cm}^{-3}$ \\
\hline NUN & $-2,3$ & -- & NUP & $-2,2$ & -- \\
\hline XIN & $-3,8$ & -- & XIP & $-3,7$ & -- \\
\hline ALPHAN & 0,73 & -- & ALPHAP & 0,70 & -- \\
\hline
\end{tabular}

FLDMOB - Quando é especificado FLDMOB=1, o simulador usa a expressão de Caughey-Thomas ${ }^{64}$, tanto para elétrons como para lacunas. Sendo esta expressão dependente da componente paralela do campo elétrico, conforme descrita abaixo.

$$
\begin{aligned}
& \mu_{n}=\frac{\mu_{S, n}}{\left[1+\left(\frac{\mu_{S, n} E_{\mathrm{II}, n}}{v_{n}^{\text {sat }}}\right)^{\text {BETAN }}\right]^{1 / \text { BETAN }}} \\
& \mu_{p}=\frac{\mu_{S, p}}{\left[1+\left(\frac{\mu_{S, p} E_{\mathrm{II}, p}}{v_{p}^{\text {sat }}}\right)^{\text {BETAP }}\right]^{1 / \text { BETAP }}}
\end{aligned}
$$

Onde $\mu_{\mathrm{s}, \mathrm{n}}$ e $\mu_{\mathrm{s}, \mathrm{p}}$ são as mobilidades para baixo campo elétrico incluindo o mecanismo de espalhamento, e $v_{n}{ }^{\text {sat }}$ e $v_{p}$ sat são as velocidades de saturação para elétrons e lacunas, respectivamente. Sendo que $B E T A N=2,0$ e $B E T A P=1,0$.

PRPMOB - Este modelo inclui a degradação da mobilidade com o campo elétrico transversal. $O$ modelo é aplicado em todas as posições do dispositivo e não somente nas interfaces ou na camada de inversão ${ }^{66,67}$. As mobilidades de elétrons e lacunas para baixo campo elétrico, na presença deste modelo, serão modificadas segundo as equações: 


$$
\begin{aligned}
& \mu_{S, n}=G S U R F N \frac{\mu_{0 n}}{\sqrt{1+\frac{E_{\perp, n}}{E C N \cdot M U}}} \\
& \mu_{S, p}=G S U R F P \frac{\mu_{0 p}}{\sqrt{1+\frac{E_{\perp, p}}{E C P . M U}}}
\end{aligned}
$$

Onde $E_{\perp, n}$ e $E_{\perp, p}$ são as componentes do campo elétrico que são perpendiculares a direção da corrente. Os valores das constantes assumidos pelo simulador para o silício estão relacionados na Tabela 2.

Tabela 2 - Valores pré-definidos pelo simulador para o silício no modelo PRPMOB.

\begin{tabular}{ccc}
\hline Parâmetros & Silício & Unidade \\
\hline GSURFN & 1,0 & -- \\
\hline GSURFP & 1,0 & -- \\
\hline ECN.MU & $6,4910^{4}$ & $\mathrm{~V} / \mathrm{cm}$ \\
\hline ECP.MU & $1,8710^{4}$ & $\mathrm{~V} / \mathrm{cm}$ \\
\hline
\end{tabular}

AUGER - Especifica a recombinação Auger, devendo ser habilitado na presença de regiões com alta concentração de dopantes.

BGN - Especifica o estreitamento da banda de energia devido à alta concentração de dopantes, incluindo a variação espacial na concentração intrínseca de portadores ${ }^{68}$ e na mudança das margens das bandas.

$$
\begin{gathered}
\Delta E_{g}=\frac{V 0 . B G N q}{2 k T}\left[\ln \frac{N_{\text {total }}(x, y)}{N 0 . B G N}+\sqrt{\left(\ln \frac{N_{\text {total }}(x, y)}{N 0 . B G N}\right)^{2}+C O N . B G N}\right] \\
n_{i e}(x, y)=n_{i} \exp \left(\Delta E_{g}\right)
\end{gathered}
$$


Os valores dos parâmetros usados na equação (56), pré-definidos pelo simulador para o silício, são mostrados na Tabela 3.

Tabela 3 - Valores pré-definidos pelo simulador para o modelo BGN.

\begin{tabular}{c|c|c}
\hline Parâmetro & Silício & Unidade \\
\hline V0.BGN & $910^{-3}$ & V \\
\hline N0.BGN & $110^{11}$ & $\mathrm{~cm}^{3}$ \\
\hline CON.BGN & 0.5 & $\mathrm{eV}$ \\
\hline
\end{tabular}

CONSRH - Especifica o modelo de recombinação de Shockley-Read-Hall com tempo de vida dos portadores dependentes da concentração.

$$
\begin{aligned}
& \frac{T A U N 0}{\tau_{n}(x, y)}=A N+B N\left(\frac{N_{\text {total }}(x, y)}{N S R H N}\right)+C N\left(\frac{N_{\text {total }}(x, y)}{N S R H N}\right)^{E N} \\
& \frac{T A U P 0}{\tau_{p}(x, y)}=A P+B P\left(\frac{N_{\text {total }}(x, y)}{N S R H P}\right)+C P\left(\frac{N_{\text {total }}(x, y)}{N S R H P}\right)^{E P}
\end{aligned}
$$

Os valores dos parâmetros usados nas equações (58) e (59), pré-definidos pelo simulador para o silício, são mostrados a seguir na Tabela 4.

Tabela 4 - Valores pré-definidos pelo simulador para o modelo CONSRH.

\begin{tabular}{ccc}
\hline Parâmetro & Silício & Unidade \\
\hline NSRHN & $510^{16}$ & $\mathrm{~cm}^{-3}$ \\
\hline NSRHP & $510^{16}$ & $\mathrm{~cm}^{-3}$ \\
\hline TAUN0 & $110^{-7}$ & $\mathrm{~s}$ \\
\hline TAUPO & $110^{-1}$ & $\mathrm{~s}$ \\
\hline AN & 1 & -- \\
\hline AP & 1 & -- \\
\hline BN & 1 & -- \\
\hline BP & 1 & -- \\
\hline CN & 0 & -- \\
\hline CP & 0 & -- \\
\hline EN & 2 & -- \\
\hline EP & 2 & -- \\
\hline
\end{tabular}


Usando os parâmetros pré-definidos pelo simulador, as equações (58) e (59) podem ser simplificadas, resultando nas equações abaixo:

$$
\begin{gathered}
\tau_{n}(x, y)=\frac{\text { TAUN } 0}{1+\frac{N_{\text {total }}(x, y)}{N S R H N}} \\
\tau_{p}(x, y)=\frac{\text { TAUP0 }}{1+\frac{N_{\text {total }}(x, y)}{N S R H P}}
\end{gathered}
$$

Desta forma o modelo calcula a taxa de recombinação de Shockley-Read-Hall, usando a equação (62), mostrada a seguir, considerando ETRAP $=0$.

$$
U_{S R H}=\frac{p n-n_{i e}^{2}}{\tau_{p}\left[n+n_{i e} \exp \left(\frac{E T R A P}{k T}\right)\right]+\tau_{n}\left[p+n_{i e} \exp \left(\frac{-E T R A P}{k T}\right)\right]}
$$

PRINT - Especifica que a situação atual de todos os modelos, algumas constantes, e alguns parâmetros dependentes da temperatura serão reportados no arquivo de saída.

TEMPERAT - Define a temperatura da rede na estrutura especificada.

DT.CUR - Quando este modelo é especificado, o simulador habilita a análise da corrente de tunelamento direto em todas as interfaces semicondutor/eletrodo separadas por um isolante.

DT.VBHT - Especifica que o tunelamento de lacunas da banda de valência será incluído na simulação.

FERMIDIR - Especifica que a estatística de Fermi-Dirac será usada. 


\section{TEMPO DE VIDA DE PORTADORES}

O conhecimento das propriedades de geração-recombinação dos portadores (tempo de vida, velocidade de recombinação/geração superficial) é fundamental para analisar o desempenho de alguns dispositivos SOI MOSFETs, pois parâmetros como correntes de fuga em junções pn, tempo de "refresh" de memórias dinâmicas (DRAMs), efeitos de corpo flutuante e o ganho dos transistores bipolares parasitários são dependentes destas propriedades ${ }^{69}$.

O tempo de vida dos portadores é definido como o tempo médio que se passa antes que os portadores minoritários, em excesso ou escassez, restabeleçam a concentração térmica de equilíbrio. Este parâmetro depende tanto dos defeitos cristalinos da lâmina como dos defeitos introduzidos pela fabricação dos circuitos integrados. Portanto, caso sejam utilizadas lâminas diferentes, sendo mantido o mesmo processo de fabricação dos dispositivos, será avaliada principalmente a qualidade inicial da lâmina (que no caso das lâminas $\mathrm{SOI}$, pode ser obtida de diferentes técnicas tais como: SIMOX ${ }^{70}$, UNIBOND $^{71}, \mathrm{BESOI}^{72}$, etc). No entanto, o uso do mesmo tipo de lâminas utilizadas em processos diferentes de fabricação pode permitir a avaliação do impacto de determinadas etapas de processo de fabricação nas características elétricas dos dispositivos.

Segundo reporta a literatura, as lâminas obtidas pela técnica UNIBOND apresentam um tempo de vida de portadores dez vezes maior quando comparadas com lâminas SIMOX de mesma concentração de dopantes (30-100 $\mu$ s comparado com 2-10 $\mu \mathrm{s}$, respectivamente $)^{73}$. A comparação entre dispositivos fabricados sobre o mesmo tipo de lâmina SOI (BESOI ou SIMOX), que passaram por diferentes etapas de processo para a implantação de ajuste da tensão de limiar (com e sem óxido sacrificial), mostrou que os dispositivos em que a implantação foi realizada através do óxido sacrificial apresentaram um tempo de vida por volta de $60 \%$ maior que os dispositivos onde a implantação foi realizada através da porta finalizada. No caso dos dispositivos fabricados sobre as lâminas BESOI este tempo variou de 0,6 à $0,9 \mu$ s e nos dispositivos fabricados em lâminas SIMOX esta variação foi de 0,13 à $0,2 \mu \mathrm{s}^{77}$. 
O conceito de tempo de vida se divide em duas categorias: tempo de vida de recombinação e tempo de vida de geração. O tempo de vida de recombinação é esperado quando há um excesso de portadores (elétrons ou lacunas) no semicondutor, que pode ser obtido através da incidência de luz na amostra ou pela polarização direta de uma junção pn, sendo que a diminuição deste excesso de portadores com passar do tempo é decorrente do fenômeno de recombinação. O tempo de vida de geração aplicase em regiões em que há escassez de portadores e o material tenta alcançar o equilíbrio, como por exemplo, na região de depleção de um diodo reversamente polarizado. Quando esses eventos de geração e recombinação ocorrem na superfície são caracterizados como velocidade de geração/recombinação superficial ${ }^{74}$.

\subsection{TEMPO DE VIDA DE RECOMBINAÇÃO}

Basicamente o evento de recombinação está associado com três mecanismos físicos distintos. A recombinação Shockley-Read-Hall (SRH) ou por multifonon, a recombinação radiativa e a recombinação Auger $^{74}$.

\subsubsection{Recombinação Shockley-Read-Hall}

A recombinação Shockley-Read-Hall (SRH) ou por multifonon, onde os pares elétron-lacuna se recombinam em um nível energético intermediário de armadilhas, introduzido pela presença de impurezas, defeitos ou contaminações, localizado entre o nível superior de valência e o inferior de condução, e a energia liberada durante o evento de recombinação é dissipada através de vibrações na rede cristalina ${ }^{74}$, conforme mostra a Figura 3-1. 


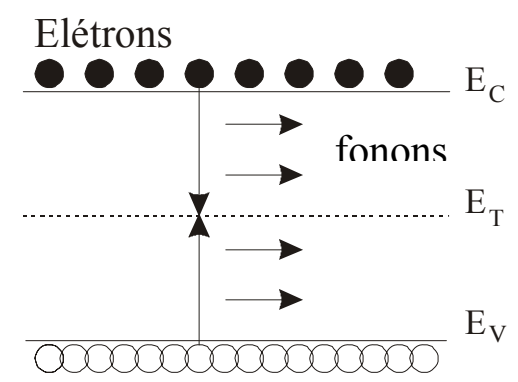

\section{Lacunas}

Figura 3-1 - Recombinação Shockley-Read-Hall (SRH) ou por multifonon ${ }^{74}$.

O tempo de vida SRH $\left(\tau_{S R H}\right)$ é dado por ${ }^{74}$ :

$$
\tau_{S H R}=\frac{\tau_{p}\left(n_{0}+n_{1}+\Delta_{n}\right)+\tau_{n}\left(p_{0}+p_{1}+\Delta_{n}\right)}{p_{0}+n_{0}+\Delta_{n}}
$$

Com $n_{1}, p_{1}, \tau_{n}$ e $\tau_{p}$ definidos por:

$$
\begin{gathered}
n_{1}=n_{i} \exp \left(\frac{E_{T}-E_{i}}{k T}\right) \\
p_{1}=n_{i} \exp \left(-\frac{E_{T}-E_{i}}{k T}\right) \\
\tau_{n}=\frac{1}{\sigma_{n} v_{t h} N_{T}} \\
\tau_{p}=\frac{1}{\sigma_{p} v_{t h} N_{T}}
\end{gathered}
$$

Onde $\mathrm{N}_{\mathrm{T}}$ é a concentração de impurezas, $\mathrm{E}_{\mathrm{T}}$ o nível de energia das armadilhas, $\sigma_{n}$ e $\sigma_{p}$ as secções transversais de captura de elétrons e lacunas, respectivamente.

A taxa de recombinação SRH (U) que ocorre no substrato é dada por ${ }^{74}$ :

$$
U=\frac{\sigma_{n} \sigma_{p} v_{t h} N_{T}\left(p n-n_{i}^{2}\right)}{\sigma_{n}\left(n+n_{1}\right)+\sigma_{p}\left(p+p_{1}\right)}=\frac{p n-n_{i}^{2}}{\tau_{p}\left(n+n_{1}\right)+\tau_{n}\left(p+p_{1}\right)}
$$

Adicionalmente à taxa de recombinação SRH do substrato, há também a taxa de recombinação SRH superficial, que é dada pela equação ${ }^{74}$ (69): 


$$
U_{s}=\frac{\sigma_{n s} \sigma_{p s} v_{t h} N_{i t}\left(p_{s} n_{s}-n_{i}^{2}\right)}{\sigma_{n s}\left(n_{s}+n_{1 s}\right)+\sigma_{p s}\left(p_{s}+p_{1 s}\right)}=\frac{S_{n} S_{p}\left(p_{s} n_{s}-n_{i}^{2}\right)}{S_{n}\left(n_{s}+n_{1 s}\right)+S_{p}\left(p_{s}+p_{1 s}\right)}
$$

Onde,

$$
S_{n}=\sigma_{n s} v_{t h} N_{i t}, \quad S_{p}=\sigma_{p s} v_{t h} N_{i t}
$$

$\mathrm{O}$ índice "s" se refere à parcela superficial, $p_{s}$ e $n_{s}$ são as concentrações de elétron e lacunas por $\mathrm{cm}^{3}$ na superfície e $\mathrm{N}_{\mathrm{it}}$ é a densidade de armadilhas de interface, sendo nesse caso considerada constante.

A velocidade de recombinação na superfície é definida como $S_{r}=\frac{U_{s}}{\Delta n_{s}}$, resultando na equação ${ }^{74}(70)$ :

$$
S_{r}=\frac{S_{n} S_{p}\left(p_{s 0}+n_{s 0}+\Delta n_{s}\right)}{S_{n}\left(n_{s 0}+n_{1 s}+\Delta n_{s}\right)+S_{p}\left(p_{s 0}+p_{1 s}+\Delta p_{s}\right)}
$$

Caso os eventos de geração e recombinação ocorram tanto no corpo como na superfície do dispositivo simultaneamente, a separação desses eventos não é simples. Sendo que alguns métodos não chegam a prever esta separação.

O mecanismo de recombinação SRH aplica-se sempre que há impurezas ou defeitos na rede cristalina do semicondutor. Este mecanismo é particularmente importante em semicondutores com "gap" ou faixa proibida indireta como $\mathrm{Si}$, Ge e GaP.

O tempo de vida SRH é inversamente proporcional à concentração de centros de recombinação e a secção transversal de captura, mas não depende diretamente do nível de energia das impurezas. Isso ocorre porque a secção transversal de captura tende a ser maior para impurezas com nível de energia próximo ao meio da banda proibida e menor para níveis de energia que se aproximem das bandas de valência ou de condução ${ }^{74}$. 


\subsubsection{Recombinação Radiativa}

O segundo mecanismo físico é chamado de recombinação radiativa ${ }^{74}$, onde os pares elétron-lacuna se recombinam do nível de condução para o de valência e a energia resultante é dissipada através de fótons, como pode ser visto na Figura 3-2.

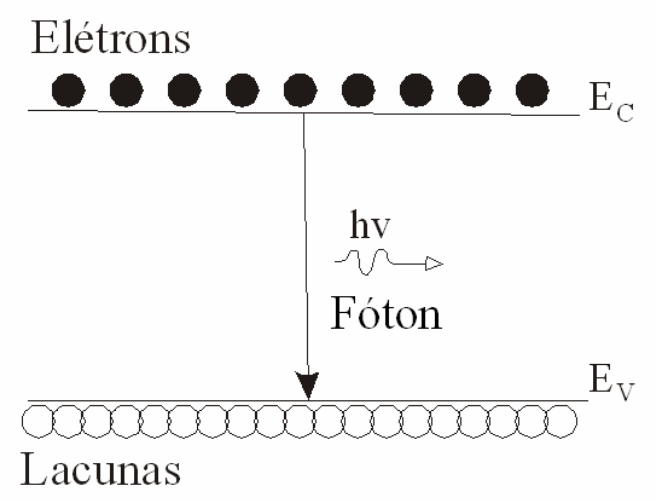

Figura 3-2 - Recombinação radiativa ${ }^{74}$.

O tempo de vida radiativo $\left(\tau_{\text {rad }}\right)$ é dado por:

$$
\tau_{\text {rad }}=\left[B\left(p_{0}+n_{0}+\Delta_{n}\right)\right]^{-1}
$$

onde B é o coeficiente de recombinação radiativa.

O tempo de vida radiativo é inversamente proporcional à concentração de portadores, devido ao fato de que neste mecanismo físico ambos, elétron e lacunas, devem estar presentes simultaneamente para ocorrer à recombinação.

A recombinação radiativa é aplicada em semicondutores com "gap" ou faixa proibida direta como GaAs e InP, onde o nível inferior de energia da faixa de condução esta alinhado com o nível superior da faixa de valência. 


\subsubsection{Recombinação Auger}

O terceiro mecanismo é chamado de recombinação Auger ${ }^{74}$, da mesma forma que no caso anterior, os pares elétron-lacuna se recombinam do nível energético de condução para o de valência, mas a energia resultante é fornecida a um terceiro portador conforme ilustrado na Figura 3-3. Devido haver três portadores envolvidos no mecanismo de recombinação, o tempo de vida Auger $\left(\tau_{\text {Auger }}\right)$ é inversamente proporcional ao quadrado da concentração de portadores.

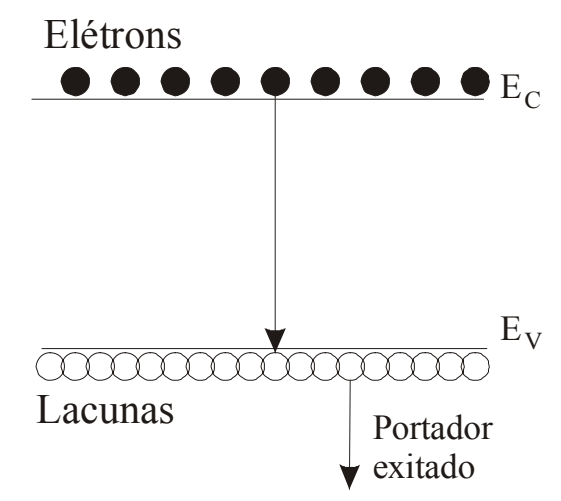

Figura 3-3 - Recombinação Auger ${ }^{74}$.

Sendo dado pela equação (72):

$$
\tau_{\text {Auger }}=\left[C_{p}\left(p_{0}^{2}+2 p_{0} \Delta n+\Delta n^{2}\right)+C_{n}\left(n_{0}^{2}+2 n_{0} \Delta n+\Delta n^{2}\right)\right]^{-1}
$$

Onde $C_{p}$ e $C_{n}$ são os coeficientes de recombinação Auger.

A recombinação Auger é observada em semicondutores com faixa proibida direta ou indireta em que a concentração do excesso de portadores majoritários ou minoritários é muito alta, este mecanismo de recombinação é dominante em semicondutores com pequena largura de faixa proibida. Da mesma forma que o tempo de vida radiativo, o tempo de vida Auger é independente da concentração de impurezas. É aplicado para dispositivos operando em altos níveis de injeção ou com nível de dopagem muito alto ${ }^{74}$. 
Em condições de baixo nível (II) de injeção, quando a concentração do excesso de portadores minoritários é pequena comparada com a concentração de portadores majoritários em equilíbrio $\left(\Delta_{n}<<p_{0}\right)$, ou em condições de alto nível $(h l)$ de injeção $\left(\Delta_{n}>>\right.$ $\left.p_{0}\right)$, as equações acima podem ser simplificadas resultando nas equações abaixo:

$$
\begin{gathered}
\tau_{\text {SHR }}(l l)=\tau_{n}, \quad \tau_{\text {SHR }}(h l)=\tau_{n}+\tau_{p} \\
\tau_{\text {rad }}(l l)=\frac{1}{B p_{0}}, \quad \tau_{\text {rad }}(h l)=\frac{1}{B \Delta n} \\
\tau_{\text {Auger }}(l l)=\frac{1}{C_{p} p_{0}^{2}}, \quad \tau_{\text {Auger }}(h l)=\frac{1}{\left(C_{p}+C_{n}\right) \Delta n^{2}} \\
S_{r}(l l)=S_{n}, \quad S_{r}(h l)=\frac{S_{n} S_{p}}{S_{n}+S_{p}}
\end{gathered}
$$

\subsection{TEMPO DE GERAÇÃO}

Em contra partida a cada processo de recombinação, mencionado anteriormente, existe um processo de geração. O processo de geração que acontece através de níveis energéticos intermediários, devido à energia proveniente de vibrações na rede cristalina, é a geração térmica de pares elétron-lacuna ou geração de Shockley-ReadHall, conforme mostra a Figura 3-4.

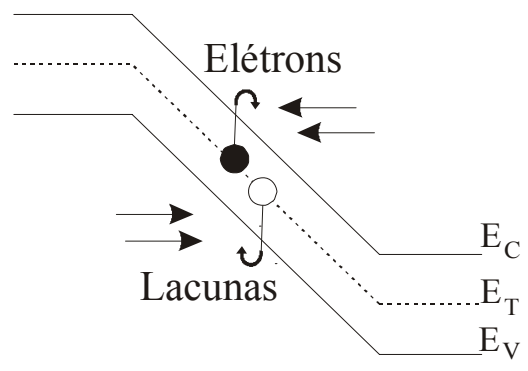

Figura 3-4 - Geração Shockley-Read-Hall ${ }^{74}$

Através da equação (68), que expressa a taxa de recombinação (U)/geração SRH (G), nota-se que para $p n>n_{i}^{2}$ o processo de recombinação é dominante e para 
pn $<<n_{i}^{2}$ o processo de geração é o que domina. Sabe-se que quanto menor o produto $p n$ maior será a taxa de geração, no limite $(p n \rightarrow 0)$ a taxa de recombinação torna-se negativa e a taxa de geração será dada por:

$$
G=-U=\frac{n_{i}^{2}}{\tau_{p} n_{1}+\tau_{n} p_{1}}=\frac{n_{i}}{\tau_{g}}
$$

Onde $\tau_{g}$ é o tempo de vida de geração,

$$
\tau_{g}=\tau_{p} \exp \left(\frac{E_{T}-E_{i}}{k T}\right)+\tau_{n} \exp \left(-\frac{E_{T}-E_{i}}{k T}\right)
$$

O tempo de vida de geração é inversamente proporcional à concentração de impurezas e a secção transversal de captura de elétrons e lacunas ${ }^{74}$, da mesma forma que o tempo de vida de recombinação. Contudo, o tempo de vida de geração também depende exponencialmente dos níveis de energia $E_{T}$ e $E_{i}$, sendo que $\tau_{g}$ pode ser bastante maior caso $E_{T}$ não coincida com $E_{i}$. Normalmente $\tau_{g}$ é muito maior do que $\tau_{\mathrm{r}}$, no silício $\tau_{g} \approx(50-100) \tau_{r}^{75}$.

A taxa de geração superficial $\left(\mathrm{G}_{\mathrm{s}}\right)$, quando $p_{s} n_{s}<<n_{i}^{2}$ é dada pela equação (79),

$$
G_{s}=-U_{s}=\frac{S_{n} S_{p} n_{i}^{2}}{S_{n} n_{1 s}+S_{p} p_{1 s}}=S_{g} n_{i}
$$

Onde $S_{g}$ é a velocidade de geração superficial

$$
S_{g}=\frac{S_{n} S_{p}}{S_{n} \exp \left[\left(E_{i t}-E_{i}\right) / k T\right]+S_{p} \exp \left[-\left(E_{i t}-E_{i}\right) / k T\right]}
$$




\subsection{TÉCNICAS PARA EXTRAÇÃO DO TEMPO DE VIDA DE GERAÇÃO- RECOMBINAÇÃO DE PORTADORES.}

Diversos autores têm reportado inúmeras técnicas para extração do tempo de vida de geração-recombinação de portadores no semicondutor. Algumas dessas técnicas de medidas usam a injeção óptica como um meio para a criação de pares elétrons-lacuna. Outra forma é a injeção elétrica, que é de mais fácil controle, mas necessita de uma junção pn, diretamente polarizada, como fonte de portadores minoritários. A principal diferença entre a injeção óptica e a elétrica é que durante a injeção óptica o excesso de portadores é gerado no volume da amostra, com a profundidade de geração controlada pelo coeficiente de absorção óptico do semicondutor. Enquanto que a injeção elétrica é planar, ou seja, o excesso de portadores existentes além do plano de injeção foi difundido para lá e não gerado lá.

Muitas das técnicas de injeção elétrica, usadas para extração do tempo de vida de geração-recombinação de portadores na camada de silício dos transistores SOI, são baseadas nas medidas de capacitâncias em regime transitório, que são muito complexas quando aplicadas em dispositivos SOI MOSFETs totalmente depletados. Essa complexidade se deve à elevada resistência série e pelo fato de que as capacitâncias parasitárias limitam a precisão das medidas de capacitâncias. Essas técnicas de extração trabalham com a variação da profundidade máxima de depleção, contudo em dispositivos SOI MOSFETs totalmente depletados, pela sua própria natureza, esta avaliação é bastante dificultada.

Como alternativa para extração do tempo de vida em dispositivos SOI MOSFET totalmente depletados, modo enriquecimento, foi proposto um método que analisa a distribuição temporal dos portadores através da camada de silício $^{76}$, porém esta técnica requer uma analise complicada de dados tornando-se muitas vezes inviável. 


\subsubsection{Método "Shin"}

Nesse método de extração do tempo de vida de geração dos portadores não se faz necessária o uso de análise numérica ${ }^{77}$. 0 método proposto consiste em aplicar um degrau negativo de tensão na porta de um transistor SOI nMOSFET parcialmente depletado, fazendo com que o dispositivo passe da inversão forte $\left(V_{G F}>V_{t h}\right)$ para inversão fraca $\left(\mathrm{V}_{\mathrm{GF}}<\mathrm{V}_{\mathrm{th}}\right)$. Desta forma, é observada uma corrente de dreno transitória devido à natureza do corpo flutuante nesses dispositivos.

Sabe-se que a geração de portadores em um dispositivo SOI MOSFET se dá devido aos quatro mecanismos diferentes, a geração no substrato que ocorre na região de depleção do corpo do dispositivo, a geração junto ao dreno/fonte, a geração superficial na primeira interface e a geração superficial na segunda interface, conforme mostrado na Figura 3-5. Esse método considera que o mecanismo de geração no corpo é dominante para os dispositivos e análises que serão apresentadas a seguir.

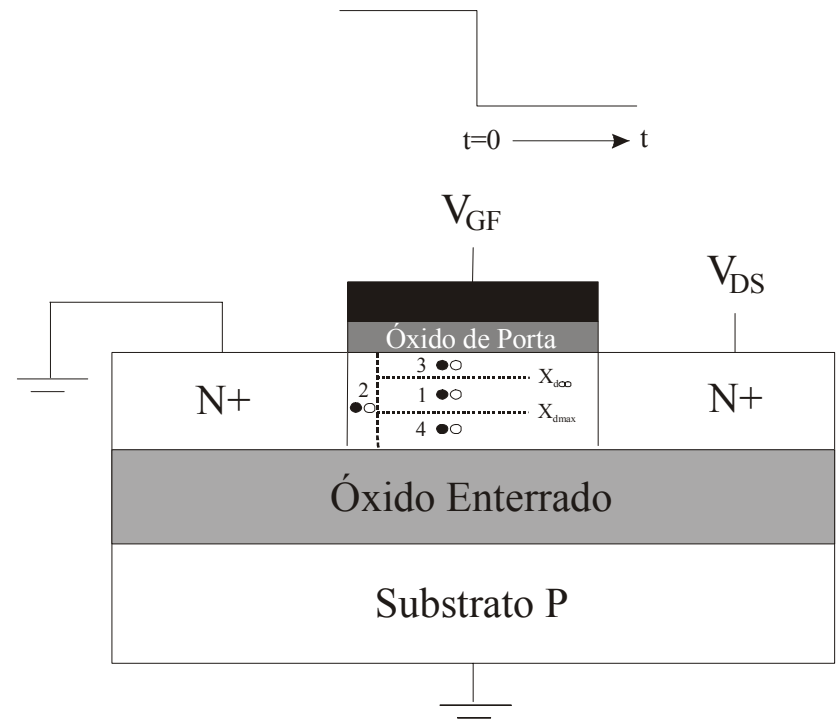

Figura 3-5 -SOI MOSFET submetido a um degrau na porta, os pares elétron-lacuna estão representados pelos círculos cheios e vazios. Mecanismo de geração 1 - no corpo, 2 - junto ao dreno/fonte, 3 - na primeira interface e 4 - na segunda interface.

Após a aplicação do degrau negativo de tensão na porta de um transistor SOI parcialmente depletado (da inversão forte para inversão fraca), o potencial na região de corpo destes dispositivos acompanha esta redução no potencial da porta devido a natureza do seu corpo flutuante. Com a redução do potencial no corpo há um aumento 
da tensão de limiar e a corrente $I_{D S}$ é suprimida, como pode ser observado esquematicamente através da Figura 3-6. Então, corrente de dreno gradualmente alcança o estado de equilíbrio, devido à geração de portadores, que retorna o potencial do corpo a zero e a tensão de limiar ao seu valor de equilíbrio.

$$
\begin{aligned}
& \mathrm{V}_{\text {Ghigh }}=0.7 \mathrm{~V} \\
& \mathrm{~V}_{\text {Glow }}=0.1 \mathrm{~V}
\end{aligned}
$$

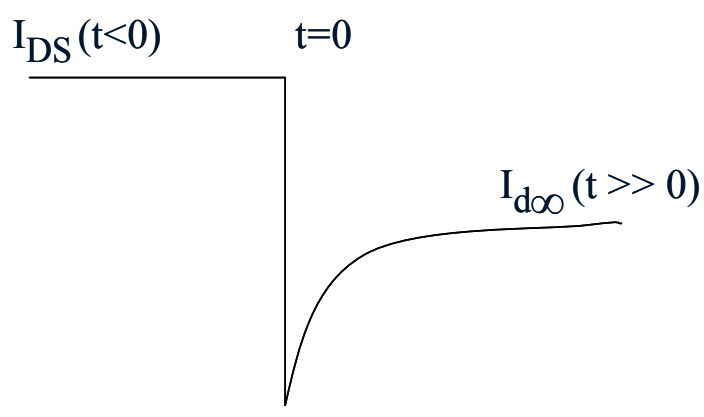

Figura 3-6 - Desenho esquematizado do degrau negativo de tensão aplicado na porta do transistor, juntamente com a corrente de dreno após variação de tensão na porta.

O tempo transitório $\left(T_{0}\right)$ é definido como o tempo necessário para corrente de dreno atingir $90 \%$ do seu valor de equilíbrio. Durante o período de transitório os portadores são gerados para preencher a região de carga espacial (região de depleção), localizada entre o estado de equilíbrio (com largura $x_{d \infty}$ ) e região de máxima depleção (com largura $x_{d \max }$ ). A magnitude do transitório diminui com o aumento da temperatura devido à maior quantidade de portadores livres $\left(n_{i}\right)$.

No caso de um transistor SOI nMOSFET, lacunas precisam ser geradas para preencher a região cuja depleção diminuirá do seu máximo valor (na inversão forte) para o seu valor de equilíbrio (na inversão fraca). A variação da região de depleção $\left(x_{d}\right)$ em função do tempo pode ser descrita através da equação (81).

$$
x_{d}(t)=\left(x_{d \max }-x_{d \infty}\right) \cdot e^{\left(\frac{-n_{i} t}{N_{a} \tau_{g}}\right)}+x_{d \infty}
$$

Onde $\tau_{g}$ é tempo de geração de portadores, $n_{i}$ e $N_{a}$ são a concentração intrínseca e de dopantes da camada de silício, respectivamente. 
$O$ fato de $x_{d}$, durante algum tempo, ser maior para a condição de $V_{G F}=0,1 \mathrm{~V}$, é responsável pelo efeito de corpo, e conseqüentemente pelo efeito transitório em IDs. A corrente $I_{D S}$ pode então ser calculada pela equação (82).

$$
\frac{I_{D S}(t)}{I_{D S \infty}}=e^{\left(\frac{q \gamma\left(\sqrt{2 \phi_{f}}-\sqrt{2 \phi_{f}-V_{B S}(t)}\right)}{\xi k T}\right)}
$$

onde $\gamma$ é a constante de efeito de corpo, $\phi_{f}$ é o potencial de substrato e $\xi=1+\left[C_{D}(t) / C_{o x}\right]$, com $C_{D}(t)$ e $C_{o x}$ sendo a capacitância de depleção do silício e do óxido de porta, respectivamente. $O$ potencial de corpo aumenta devido ao excesso de portadores na região de depleção, sendo esse dado pela equação (83).

$$
\mathrm{V}_{\mathrm{BS}}(\mathrm{t})=-\frac{\mathrm{qN}_{\mathrm{a}}}{2 \varepsilon_{\mathrm{Si}}}\left(\left(\mathrm{x}_{\mathrm{d}}(\mathrm{t})\right)^{2}-\mathrm{x}_{\mathrm{d} \infty}^{2}\right)
$$

O tempo de geração de portadores $\left(\tau_{g}\right)$ pode ser obtido relacionando-se as equações (81), (82) e (83) e através do tempo de transitório $\left(T_{0}\right)$, já definido anteriormente como o tempo necessário para a corrente de dreno atingir $90 \%$ do seu valor de equilíbrio. A seguir é dada a equação usada neste método para cálculo de $\tau_{g}$.

$$
\tau_{g}=\frac{\frac{n_{i}}{N_{a}} T_{o}}{\ln \left[\frac{x_{d \max }-x_{d \infty}}{\left.\sqrt{x_{d \infty}^{2}+\frac{2 \varepsilon_{S i}}{q N_{a}}\left\{\left[\sqrt{2 \phi_{f}}+0.1 \frac{\xi K T}{\gamma q}\right]^{2}-2 \phi_{f}\right\}}-x_{d \infty}\right]}\right.}
$$

O método usado acima só pode ser aplicado em dispositivos parcialmente depletados de canal longo e largo, pois não considera a influência das junções e nem a presença das regiões de implantação de HALO no efeito de corpo flutuante. 


\subsubsection{Método "Dual Gate"}

Nas estruturas $\mathrm{N}^{+} \mathrm{P} \mathrm{N} \mathrm{N}^{+}$, o dreno e a fonte provêm os portadores minoritários para formar quase instantaneamente o canal de inversão. Até então não há nenhuma fonte de portadores minoritários, exceto o processo de geração, o experimento ilustrado pela Figura 3-7 é projetado para induzir um déficit na concentração de lacunas.

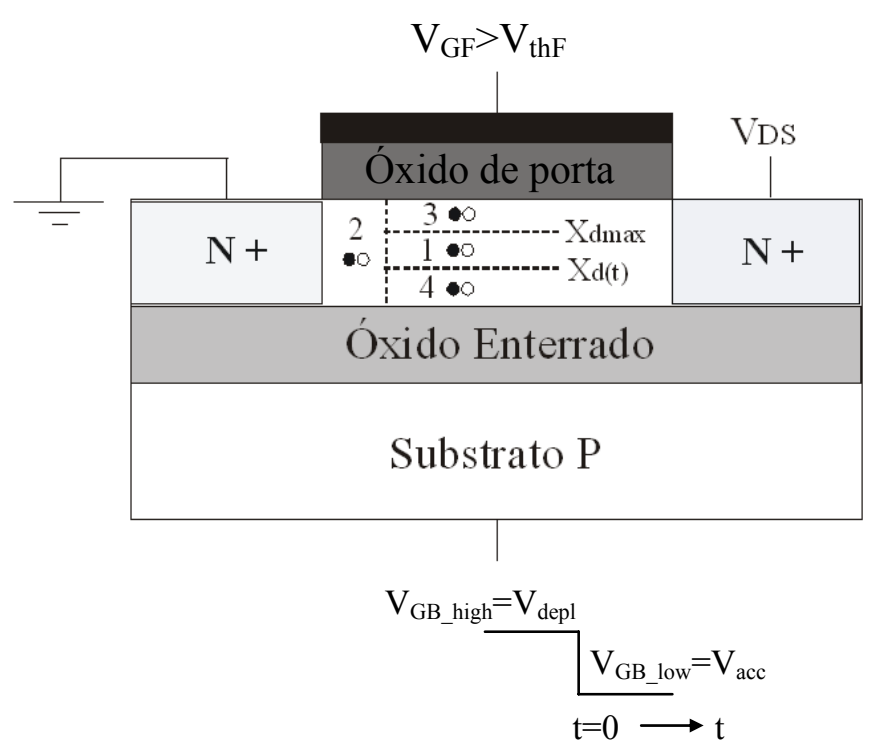

Figura 3-7 - Transistor SOI submetido a um degrau no substrato, os pares elétron-lacuna estão representados pelos círculos cheios e vazios. Mecanismo de geração 1 - no corpo, 2 - junto ao dreno/fonte, 3 - na primeira interface e 4 - na segunda interface.

A porta do transistor é polarizada na inversão forte, considerando que o substrato (back gate) é pulsado da depleção (ou acumulação fraca) para acumulação forte ${ }^{78}$. As lacunas requisitadas na camada de acumulação forte são desprendidas da região neutra do filme, uma região de depleção profunda é formada em baixo da porta do transistor e o potencial do filme de silício decai. A conservação de cargas na porta é descrita pela equação (85).

$$
Q_{i n v}+Q_{i t}=-C_{o x}\left(V_{G F}-V_{F B 1}-\phi_{S 1}\right)-Q_{\text {depl }}
$$

Onde $Q_{\text {inv }}$ é a carga de inversão, $Q_{i t}$ a carga de armadilha de interface, $Q_{\text {depl }}$ a carga de depleção e $\phi_{\mathrm{S} 1}$ é o potencial na primeira interface. 
O excesso de carga de depleção é compensado por uma queda temporária na carga de inversão e conseqüentemente na corrente de dreno. Enquanto a corrente de dreno retorna ao equilíbrio através da geração de portadores.

O potencial da primeira interface permanece quase constante na inversão forte, sendo assim é o potencial do filme de silício $\mathrm{V}_{B S}(\mathrm{t})$ que governa a densidade de carga de inversão, depleção e acumulação. Logo, a variação das cargas de depleção e acumulação em função do tempo será dada por:

$$
\begin{gathered}
Q_{\text {depl }}(t)=-q X_{d} N_{a}=-\sqrt{2 q \varepsilon_{s i} N_{a}\left(\phi_{S f}-V_{B S}(t)\right)} \\
Q_{a c c}(t)=-C_{o \times b}\left(V_{G B}-V_{F B 2}-V_{B S}(t)\right)
\end{gathered}
$$

Eliminando o $\mathrm{V}_{\mathrm{BS}}(\mathrm{t})$ entre estas equações e considerando o transistor operando na região linear, pode-se reescrever conforme a equação abaixo:

$$
-\frac{N_{a} C_{o x b}}{2 n i \varepsilon_{s i}} \frac{d}{d t}\left\{K\left(I_{D S \infty}-I_{D S}\right)+\frac{\varepsilon_{s i}}{C_{o x b}}+\sqrt{\frac{4 \varepsilon_{s i} \phi_{F}}{q N_{a}}}\right\}^{2}=\frac{K\left(I_{D S \infty}-I_{D S}\right)}{\tau_{g}}+s
$$

Onde $I_{D S_{\infty}}$ é a corrente de dreno em equilíbrio e $\mathrm{K}$ é determinado pela equação (89) que depende da dopagem do filme de silício $N_{a}$, da mobilidade $\mu$ da tensão aplicada ao dreno $V_{D S}$, da largura $W$, do comprimento do canal $L$ e da velocidade de geração superficial $s$.

$$
K=\frac{1}{q N_{a} \mu(W / L) V_{D S}}
$$

A extração dos parâmetros de geração não requer a resolução explicita da equação (88), de acordo com a método de Zerbst ${ }^{79}$, plotando o lado esquerdo da equação (LHS) em função de $K\left(I_{D S \infty}-I_{D S}\right)$ resultará em uma reta cuja o inverso da inclinação será $\tau_{g}$, e o ponto de intersecção com o eixo vertical representa a velocidade de geração superficial $s$. 
Em algumas situações particulares a variação da carga de acumulação pode ser seguramente negligenciada, e a corrente durante o transitório tem um comportamento exponencial simples que pode ser expresso pela equação abaixo.

$$
I_{D S \infty}-I_{D S}=I_{D S \infty} e^{-t / \tau_{R}}
$$

onde o tempo de restabelecimento é dado por: $\tau_{R}=\tau_{g} \frac{N_{a}}{n_{i}}$

Para $\Delta \mathrm{V}_{\mathrm{GB}}$ grande, a depleção pode se tornar profunda o suficiente para suprimir temporariamente a corrente que flui entre a fonte e o dreno. Durante um tempo $t_{\text {off, }}$, lacunas recém geradas contribuem para o relaxamento do potencial de superfície $\left(\phi_{s 1}\right)$ que varia em função do tempo. Desprezando esta variação e fixando $\phi_{S 1}=2 \phi_{f}$ e $Q_{\text {inv }}=0$ é possível calcular o período $t_{\text {off }}$ substituindo estes valores nas equações (85) e (86). Um método mais simples é comparar a carga positiva gerada durante o $t_{\text {off }}$ com o excesso de carga na porta necessário para cancelar a corrente de dreno. Certamente que a análise através do método de Zerbst, descrita anteriormente, é segura para $t>t_{\text {off. }}$.

Em filmes que são totalmente depletados, o conceito de profundidade de depleção não tem sentido. Contudo, a técnica "dual gate" pode ser bem sucedida pois simulações numéricas da taxa de geração mostram que a largura efetiva de geração corresponde à região do filme onde as concentrações de elétrons e lacunas são menores que a concentração intrínseca de portadores. Contanto que as duas interfaces estejam depletadas, estas representam papéis equivalentes no processo de geração e a equação de balanço de cargas pode ser reescrita em termos de lDs.

$$
\frac{d Q_{a}}{d t}=-\left(1+\frac{C_{o x b}}{C_{o x f}}\right) \frac{d Q_{i n v}}{d t}=q n_{i}\left(\frac{W_{d}}{\tau_{g}}+s\right)
$$

Esta técnica tem como inconveniente a dificuldade experimental. Para indução da segunda interface à acumulação, levando em consideração a grande espessura do óxido enterrado, faz necessário o uso de tensões elevadas para a obtenção do transitório da corrente de dreno $\mathrm{I}_{\mathrm{DS}}$, visto que são obtidos valores muito baixos de corrente, prejudicando as medidas. 


\section{CONTRIBUIÇÕES AOS MÉTODOS DE EXTRAÇÃO DE TEMPO DE VIDA EM SOI NMOSFET}

Este capítulo apresenta uma análise detalhada do transitório da corrente de dreno em transistores SOI nMOSFET parcialmente depletados de porta simples e dupla, assim como em FinFETs de porta tripla.

Primeiramente foi estudada a influência dos parâmetros tecnológicos, como espessura do óxido de porta e concentração de dopantes, juntamente com a variação da temperatura, no método de extração do tempo de vida de geração. Através deste estudo foi possível propor um método para a estimativa do tempo de vida de geração em função da temperatura.

A análise do transitório da corrente de dreno em função dos parâmetros geométricos possibilitou a implementação um novo modelo, a partir do modelo apresentado na seção 3.3.1, para extração do tempo de vida de geração considerando a redução do comprimento de canal e a presença da região de implantação de HALO. Após a implementação deste novo modelo em transistores de porta simples com comprimento de canal reduzido foi desenvolvida uma adaptação para o uso em dispositivos de porta dupla.

Por fim, um estudo do transitório da corrente é feito em transistores FinFETs de porta tripla, analisando a influência da largura do canal e a presença ou não da região de implantação de HALO. 


\subsection{PROPOSTA DE UM MÉTODO PARA ESTIMAR O TEMPO DE VIDA DE GERAÇÃO EM FUNÇÃO DA TEMPERATURA}

Os dispositivos caracterizados neste trabalho são SOI nMOSFET parcialmente depletados, fabricados com tecnologia SOI CMOS de $0,13 \mu \mathrm{m}$ usando um esquema de isolação PELOX ("polysilicon encapsulated local oxidation"), $2,5 \mathrm{~nm}$ de oxinitreto como material de porta $\left(\mathrm{SiO}_{\mathrm{x}} \mathrm{N}_{\mathrm{y}}\right)$, porta com $150 \mathrm{~nm}$ de Silício Poli $\mathrm{N}+$ e espaçadores de Nitreto de $80 \mathrm{~nm}$. O processo foi realizado em lâminas UNIBOND com espessura de óxido enterrado de 400nm, filme de Silício tipo $P$ com espessura final de 100nm e concentração de dopantes de $5,510^{17} \mathrm{~cm}^{-3}$.

As estruturas medidas foram cascatas com a variação do comprimento de canal, porta e fonte comuns e contatos separados para os drenos, sem contato com o corpo do dispositivo (corpo flutuante). O transitório da corrente de dreno foi medido usando o analisador de parâmetros HP4156C.

O uso do método descrito na seção (3.3.1) para obtenção do tempo de vida de geração $\tau_{g}$ em diferentes temperaturas pode consumir muito tempo, sendo que para muitas aplicações apenas uma estimativa de $\tau_{g}$ se faz necessária para uma avaliação da lâmina ou do processo de fabricação em temperatura de operação do dispositivo.

Para tempos de vida muito altos $(>10 \mu \mathrm{s})$, a duração do transitório da corrente de dreno pode se tornar muito longa em temperatura ambiente, assim as medidas podem ser realizadas em temperaturas maiores e uma estimativa de $\tau_{g}$ em uma escala de tempo mais razoável pode ser feita.

O propósito desta seção é estudar a influência da temperatura no método de determinação do tempo de vida de geração usando o transitório da corrente de dreno em SOI nMOSFETs parcialmente depletados. A sensibilidade do método decorrente da variação de parâmetros de processo também foi analisada. Este estudo resultou na proposta de um modelo simples para estimar $\tau_{g}$ em função da temperatura.

Os resultados simulados foram obtidos através do simulador numérico bidimensional $\mathrm{MEDICl}$, usando o modelo que descreve o mecanismo de recombinação 
de Shockley-Read-Hall dependente da concentração (CONSRH). As simulações foram extraídas de dispositivos SOI nMOSFETs parcialmente depletados, com espessura do filme de silício de $100 \mathrm{~nm}\left(\mathrm{t}_{\mathrm{si}}\right.$ ), largura do canal de $10 \mu \mathrm{m}(\mathrm{L})$, a dopagem do canal variando de 4,5 a $6,5 \times 10^{17} \mathrm{~cm}^{-3}$, espessura do óxido de porta variando de 2,0 a $3.0 \mathrm{~nm}$ e o tempo de vida de geração de $0.16 \mu$ s.

O método descrito na seção 3.3.1, consiste na aplicação de um degrau negativo de tensão na porta de um transistor SOI parcialmente depletado, levando o canal deste dispositivo da inversão forte para inversão fraca. Após a aplicação do degrau negativo de tensão, a corrente de dreno é suprimida e gradualmente alcança o estado de equilíbrio. Este fenômeno acontece devido à diminuição do potencial do corpo flutuante causando um aumento da tensão de limiar. A corrente de dreno gradualmente alcança o estado de equilíbrio devido à geração de portadores que retorna o potencial do corpo a zero e a tensão de limiar ao seu valor de equilíbrio.

A Figura 4-1 mostra o transitório da corrente de dreno $I_{D S}(t)$ normalizado pelo nível de corrente no estado de equilíbrio ( $\left.\mathrm{IDS}_{\infty}\right)$ em função do tempo, para um PD SOI nMOSFET com $\mathrm{L}=\mathrm{W}=10 \mu \mathrm{m}$ operando em temperaturas de 20 à $80^{\circ} \mathrm{C}$. Logo após a aplicação do degrau negativo na porta do dispositivo $\left(\mathrm{V}_{\mathrm{G} \_ \text {high }}=0,7 \mathrm{~V}\right.$ para $\left.\mathrm{V}_{\mathrm{G} \_ \text {low }}=0,1 \mathrm{~V}\right)$.

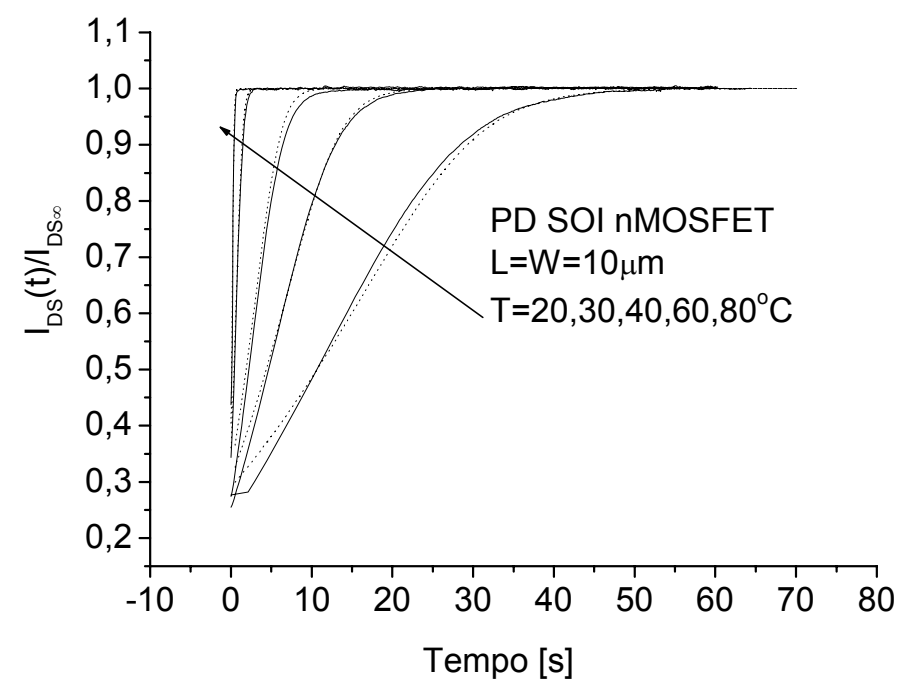

Figura 4-1 - O transitório da corrente de dreno obtida experimentalmente (sólida) e por simulação bidimensional (tracejada) depois de aplicar um degrau negativo na porta com $V_{D S}=25 \mathrm{mV}$ para um PD nMOSFET com $L=W=10 \mu \mathrm{m}^{80}$. 
O tempo de transitório $\left(T_{0}\right)$ é definido como o tempo necessário para corrente de dreno atingir $90 \%$ do seu valor de equilíbrio. Quando a tensão aplicada à porta de um nMOSFET varia, levando a primeira interface da inversão forte para inversão fraca, lacunas são geradas para preencher a região de carga espacial (região de depleção), localizada entre o estado de equilíbrio (com largura $x_{d \infty}$ ) e a região de máxima depleção (com largura $\mathrm{x}_{\mathrm{dmax}}$ ). $\mathrm{O}$ tempo de transitório diminui com o aumento da temperatura devido ao aumento na densidade de portadores livres $\left(n_{\mathrm{i}}\right)$.

A distribuição do potencial através do filme de silício para diferentes tempos pode ser observada na Figura 4-2. Imediatamente após a aplicação do degrau negativo de tensão na porta o potencial do corpo decresce devido ao acoplamento capacitivo da porta, considerando a natureza do corpo flutuante. Com o passar do tempo o potencial do corpo retorna a zero através do fenômeno de geração térmica de portadores.

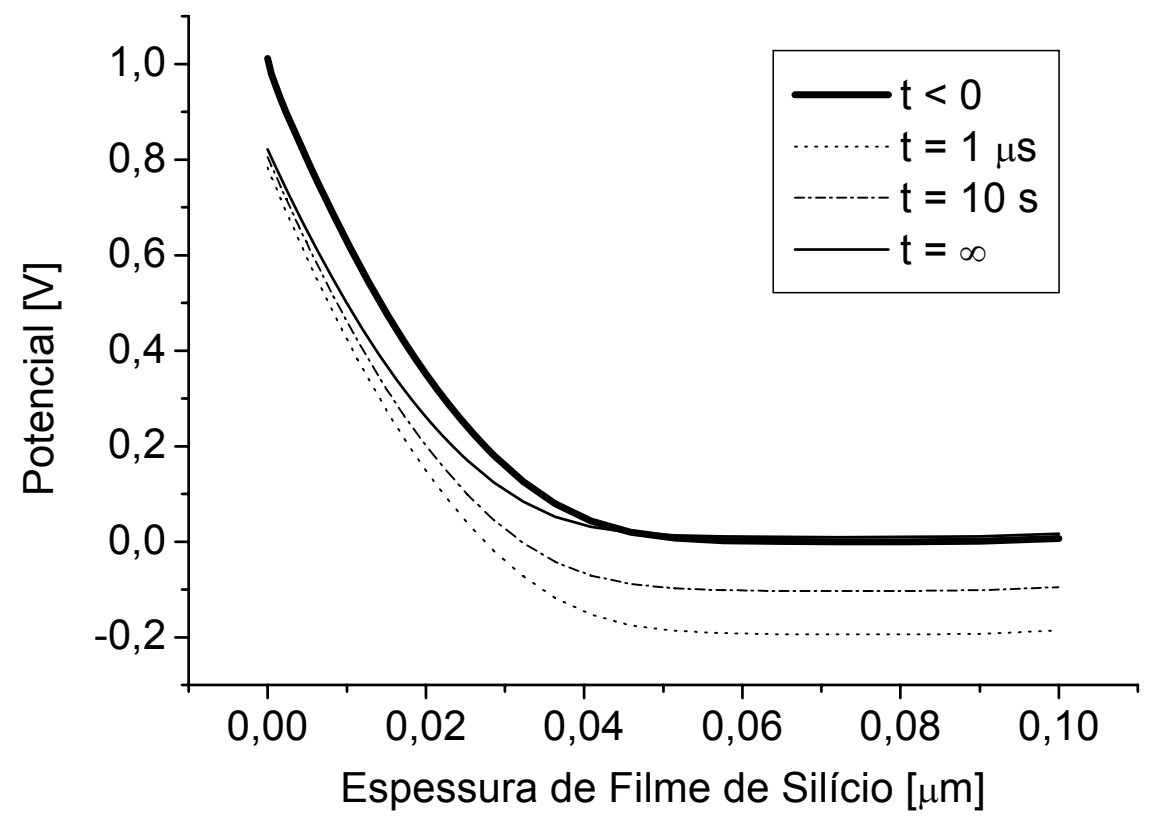

Figura 4-2 - Simulações MEDICI da distribuição de potencial através do filme de silício para diferentes tempos, em um PD SOI com $\mathrm{t}_{\mathrm{oxf}}=2,5 \mathrm{~nm}, \mathrm{~N}_{\mathrm{a}}=5,510^{17} \mathrm{~cm}^{-3}$ e temperatura de $30^{\circ} \mathrm{C}$. 
O tempo de vida de geração dos portadores $\left(\tau_{g}\right)$ pode ser calculado através da equação (84). Caso seja definido o fator $F$ pela expressão abaixo,

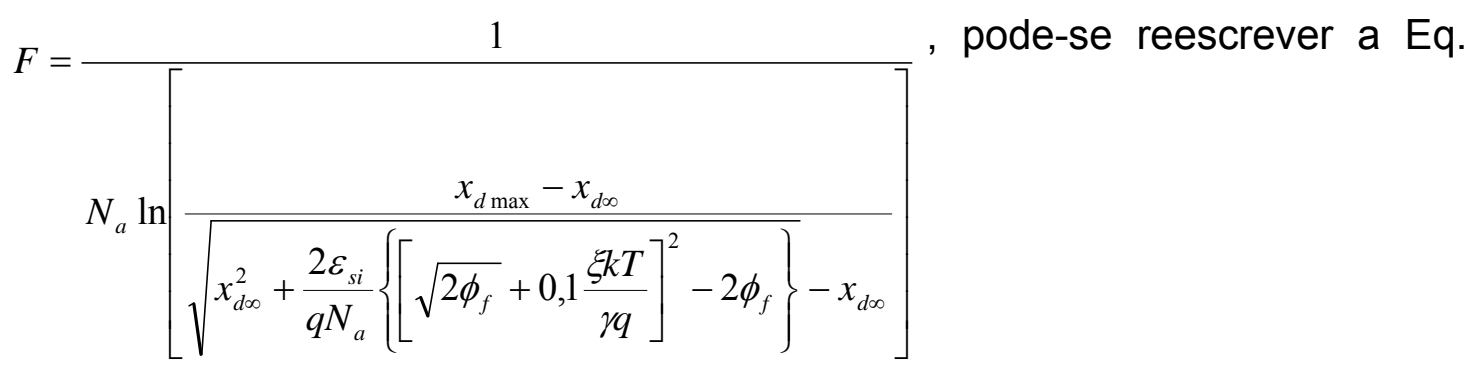

como um produto de três fatores, conforme a equação (92).

$$
\tau_{g}=F * n_{i} * T_{0}
$$

Para chegar a uma solução que possa prever a variação do tempo de vida de geração em função da temperatura, foi considerada a equação (92), que relaciona o fator $F$, a concentração intrínseca de portadores e o tempo de transitório em uma dada temperatura com o tempo de vida de geração. Caso o tempo de vida de geração $\left(\tau_{g 1}\right)$ em temperatura ambiente $\left(T_{1}\right)$ seja conhecido, pode-se determinar o tempo de vida $\left(\tau_{\mathrm{g} 2}\right)$ em outra temperatura ( $\left.T_{2}\right)$ através da equação (93), de acordo com a análise a seguir.

$$
\frac{\tau_{g 2}}{\tau_{g 1}}=\frac{F_{2}}{F_{1}} \cdot \frac{n_{i 2}}{n_{i 1}} \cdot \frac{T_{0,2}}{T_{0,1}}
$$

Onde $T_{0,1}$ e $T_{0,2}$ são os tempos de transitório para as temperaturas $T_{1}$ e $T_{2}$, respectivamente.

A Figura 4-3 mostra o fator $F, n_{i}$ e $T_{0}$ em função da temperatura para um PD SOI nMOSFET com $L=W=10 \mu \mathrm{m}, \mathrm{t}_{\mathrm{oxf}}=2,5 \mathrm{~nm}$ e $\mathrm{N}_{\mathrm{a}}=5,510^{17} \mathrm{~cm}^{-3}$. Em oposição ao fato que $n_{i}$ aumenta fortemente com a temperatura, $T_{0}$ decresce praticamente com a mesma taxa e o fator $F$ sofre um pequeno aumento de $6,75\left(\mathrm{em} 20^{\circ} \mathrm{C}\right)$ para $7,5910^{-19} \mathrm{~cm}^{3}\left(\mathrm{em} 80^{\circ} \mathrm{C}\right)$. Tomando com referência o fator $\mathrm{F}$ em $20^{\circ} \mathrm{C}\left(\mathrm{F}_{1}\right)$, a mudança para $80^{\circ} \mathrm{C}\left(\mathrm{F}_{2}\right)$ é de apenas $11 \%{ }^{80}$. 


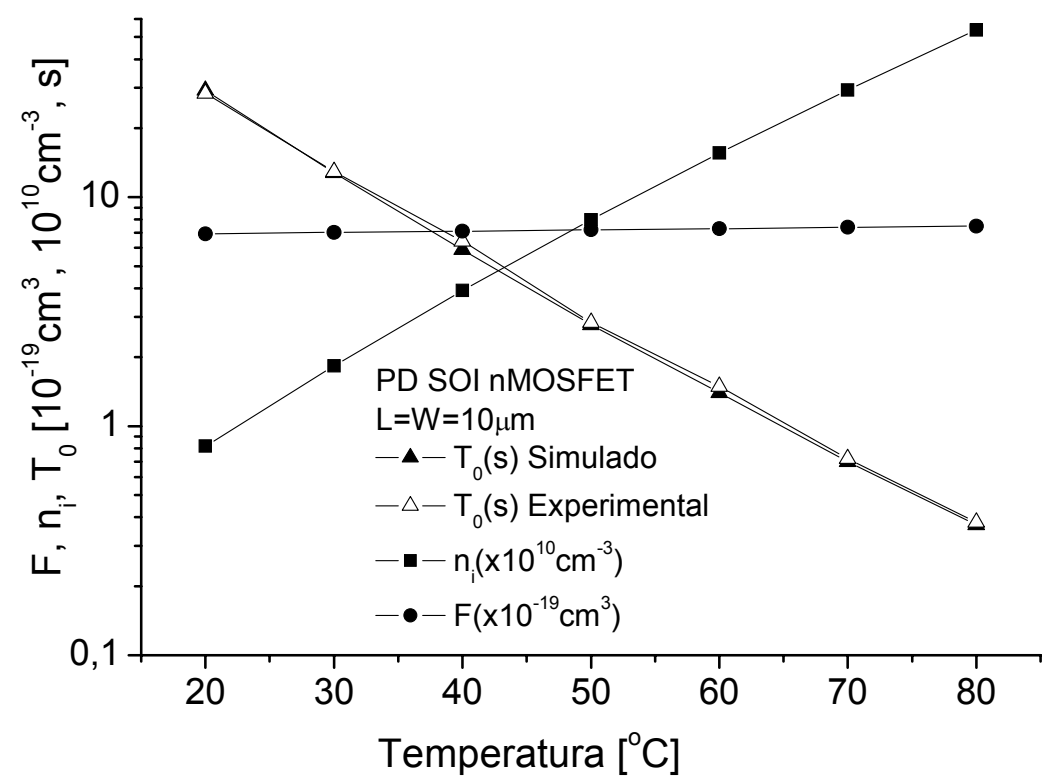

Figura 4-3 - Fator $F$ e $n_{i}$ calculados teoricamente e $T_{0}$ obtidos experimentalmente e por simulações em função da temperatura.

A sensibilidade do fator $F$ com as possíveis variações em alguns parâmetros de processo, como a espessura do óxido de porta ( $\left.t_{\text {oxf }}\right)$ e a concentração de dopantes na região do canal $\left(\mathrm{N}_{\mathrm{a}}\right)$, também foi investigada para a mesma faixa de temperatura com o objetivo de dimensionar o erro introduzido por estas variações na estimativa do tempo de vida de geração. A Figura 4-4 mostra o fator F em função da temperatura, com a variação de $t_{\text {oxf }}$ de 2 a $3 \mathrm{~nm}$. Considerando que o objetivo da tecnologia usada neste trabalho é de 2,5nm (adotada como referência), a máxima variação no fator $F$ introduzida por este parâmetro foi em torno de $7,3 \%$, que foi observada em $80^{\circ} \mathrm{C} \mathrm{com}$ um erro de $\pm 10 \%$ no parâmetro de entrada $t_{\text {oxf }}$.

Na Figura 4-5 pode-se observar a sensibilidade do fator $\mathrm{F}$ com a variação de $\mathrm{N}_{a}$ de 4,5 a $6,510^{17} \mathrm{~cm}^{-3}$. Assumindo que neste caso o objetivo é $5,510^{17} \mathrm{~cm}^{-3}$, a máxima variação observada no fator $F$ foi em torno de $13 \%$, que foi observada em $80^{\circ} \mathrm{C}$ com um erro de $\pm 10 \%$ na concentração de dopantes do filme de silício ${ }^{80}$. 


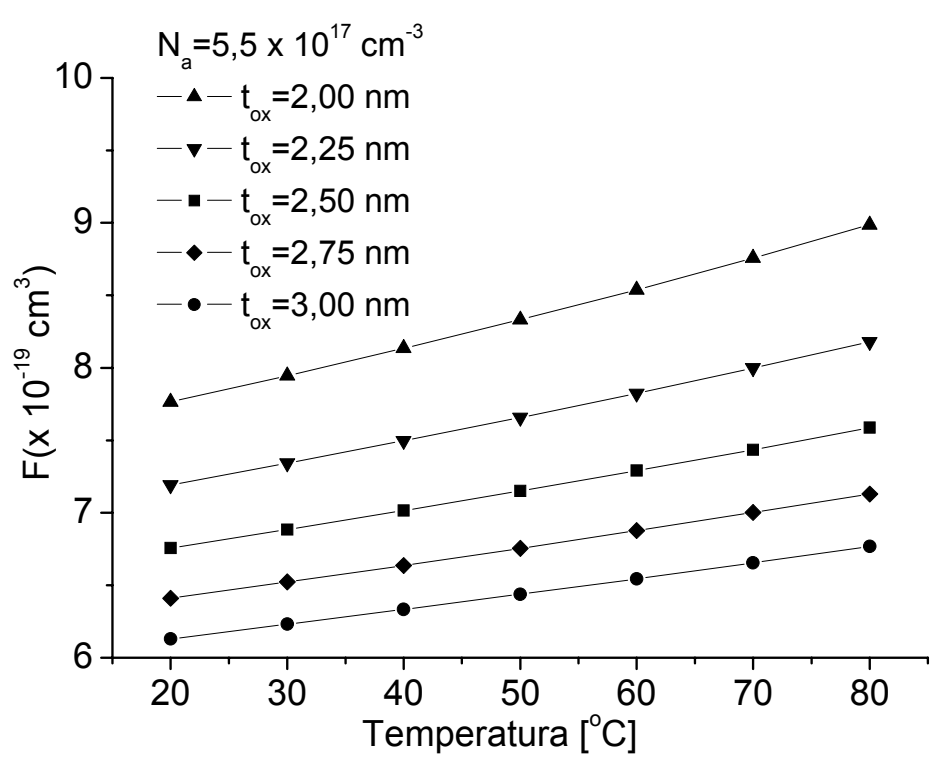

Figura 4-4 - Fator F calculado em função da temperatura para varias espessuras de óxidos de porta ( $\left.\mathrm{t}_{\mathrm{oxf}}\right)$.

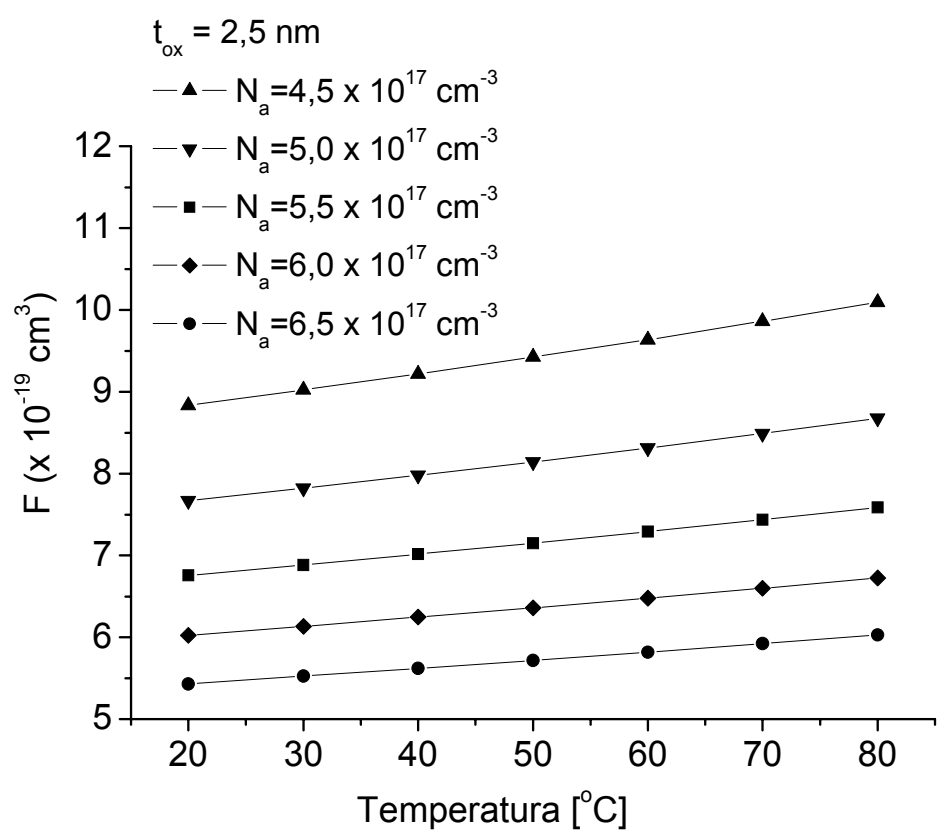

Figura 4-5- Fator $\mathrm{F}$ calculado em função da temperatura para várias concentrações de dopantes na região do canal $\left(\mathrm{N}_{\mathrm{a}}\right)$.

Considerando conhecida a variação de $\mathrm{n}_{\mathrm{i}}$, de acordo com o modelo apresentado na Ref. ${ }^{34}$, e desprezando-se a pequena variação do fator $\mathrm{F}$ com a temperatura, conforme observado em análise prévia, o tempo de vida de geração para a temperatura 
$\mathrm{T}_{2}\left(\tau_{\mathrm{g} 2}\right)$ pode ser isolado a partir da equação (93), e tem como resultado a equação (94). Desta forma, pode-se obter uma estimativa $\tau_{g 2}$, se for conhecido $\tau_{g 1}$ e os tempos de transitório $\left(T_{0,1}\right.$ e $\left.T_{0,2}\right)$ nas temperaturas $T_{1}$ e $T_{2}$, respectivamente.

$$
\left.\tau_{g 2} \cong \tau_{g 1} \cdot\left\{\frac{n_{i 2}}{n_{i 1}} \cdot \frac{T_{0,2}}{T_{0.1}}\right\}=\tau_{g 1} \cdot\left\{\left(\frac{T_{2}}{T_{1}}\right)^{3 / 2} \cdot e^{-\frac{1}{2 \cdot k}\left(\frac{E_{g 2}}{T_{2}}-\frac{E_{g 1}}{T_{1}}\right)}\right] \cdot \frac{T_{0,2}}{T_{0,1}}\right\}
$$

É possível observar o comportamento do tempo de transitório $\left(T_{0}\right)$ em função da temperatura (curva de Arrhenius), com a variação da espessura do óxido de porta (Figura 4-6) e concentração de dopantes no filme de silício (Figura 4-7). Os valores da energia de ativação permaneceram com valores em torno da metade da largura da faixa proibida do silício indicando que o mecanismo de geração que ocorre na região de carga espacial é dominante ${ }^{77}$. Para os valores de $t_{o x f}$ e $N_{a}$ estudados, a variação máxima da energia de ativação foi de $2,5 \%{ }^{80,81}$.

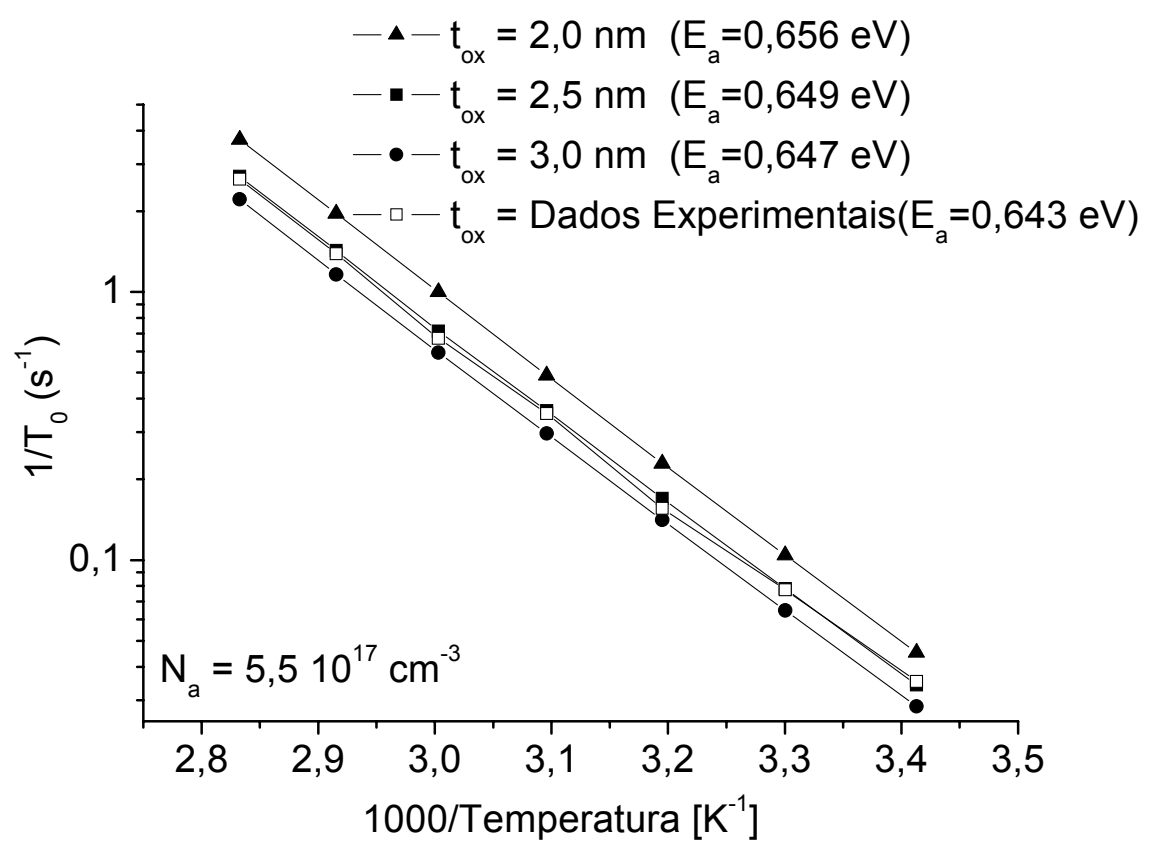

Figura 4-6 - Curva de Arrhenius para 1/T 0 variando a espessura do óxido de porta. 


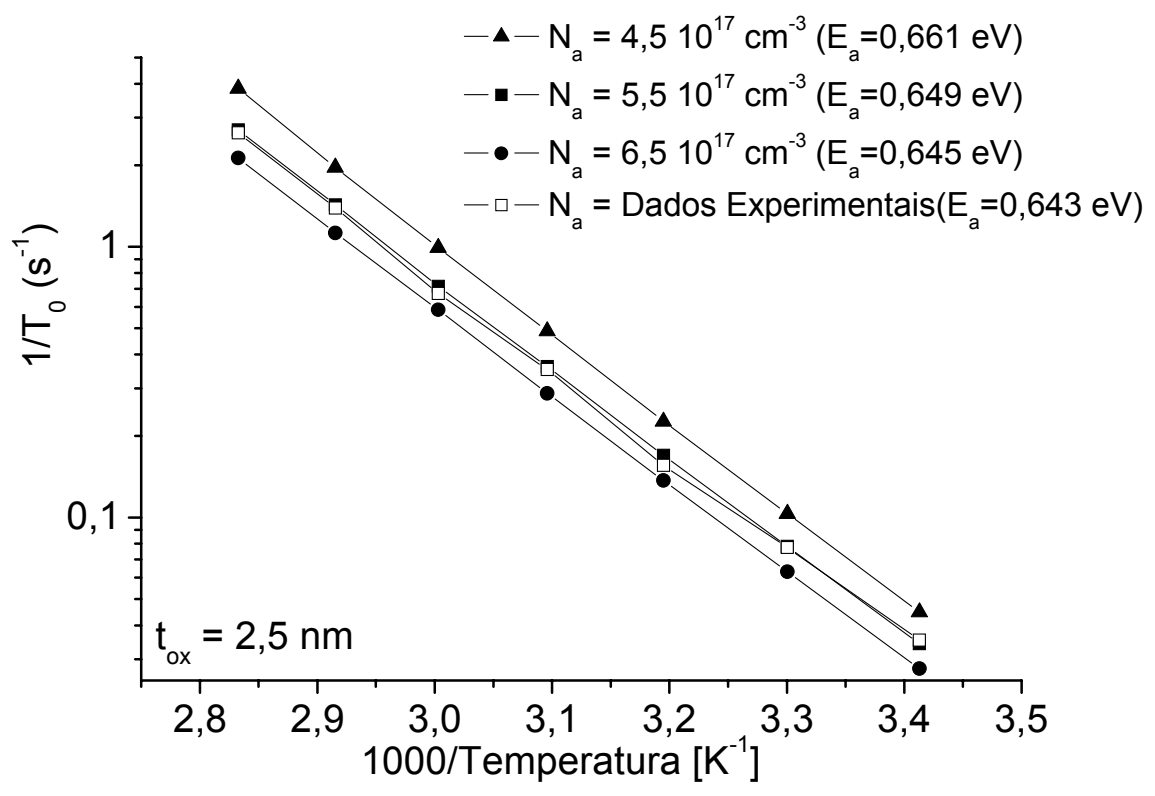

Figura 4-7 -Curva de Arrhenius para 1/T variando a concentração de dopantes no filme de silício.

Neste exemplo, os resultados mostram um ajuste de curva com um fator de correlação maior que 0,999 . Sendo assim, não há a necessidade de efetivar as medidas do tempo de transitório $\left(T_{0}\right)$ para todas as temperaturas. Ou seja, é suficiente extrair apenas duas medidas $\left(T_{0,1}\right.$ e $\left.T_{0,2}\right)$ para duas temperaturas diferentes $\left(T_{1}\right.$ e $\left.T_{2}\right)$. Considerando que $\tau_{g 1}$ é conhecido, é possível obter qualquer outro tempo de vida de geração $\tau_{93}$ para a temperatura $T_{3}$ usando a aproximação linear, resultando na equação (95).

$$
\tau_{g 3}=\left[\tau_{g 1} \cdot\left(\frac{T_{3}}{T_{1}}\right)^{3 / 2} \cdot e^{-\frac{1}{2 . k}\left(\frac{E_{g 3}}{T_{3}}-\frac{E_{g 1}}{T_{1}}\right)}\right]\left(\frac{T_{0,2}}{T_{0,1}}\right)\left(\frac{T_{3}-T_{1}}{T_{3} \cdot T_{1}}\right) \cdot\left(\frac{T_{2} \cdot T_{1}}{T_{2}-T_{1}}\right)
$$

Na Figura 4-8 pode-se observar tempo de vida de geração $\left(\tau_{g}\right)$ experimental e simulado em função da temperatura. $\tau_{\mathrm{g}}$ foi calculado através do método proposto na referência ${ }^{82}$ e estimado a partir do modelo descrito pela equação (95). Uma excelente aproximação pôde ser observada e o máximo erro obtido foi de $5 \%{ }^{80}$, incluindo o erro do fator $\mathrm{F}$ e da aproximação linear. 


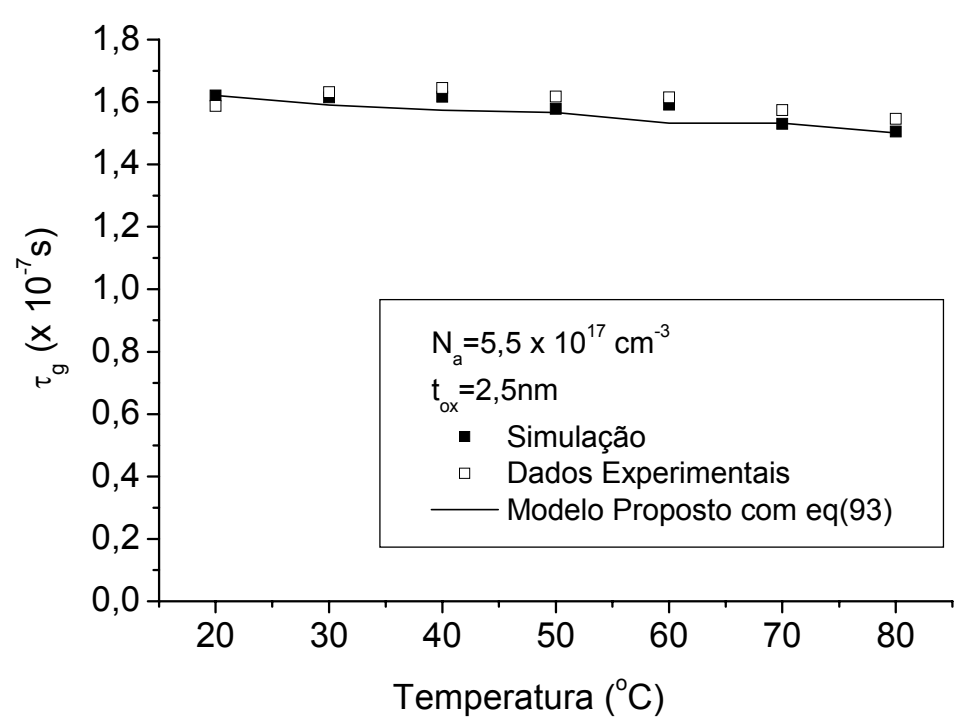

Figura 4-8 - Tempo de vida de geração experimental e simulado em função da temperatura, obtidos a partir do método proposto na ref. ${ }^{82}$ e estimado pelo modelo descrito pela eq. (95).

Esta técnica pode ser extrapolada para a faixa de temperatura estudada neste trabalho $\left(20-80^{\circ} \mathrm{C}\right)$, mas ainda é necessário a obtenção da janela de validade do método usado na determinação de $\tau_{\mathrm{g}}$. Caso o fator de correlação de $T_{0}$ em função da temperatura for menor que 0,999 , o erro obtido com o uso da equação (95) pode aumentar um pouco, e certamente deverá ser analisado de acordo com a aplicação. Caso contrário, a equação (94) é geral e pode sempre ser usada para um PD SOI nMOSFET, considerando a aproximação do fator F. Em ambos os casos é muito mais fácil estimar o tempo de vida de geração usando as equações (94) ou (93) do que calcular todos os parâmetros necessários para alimentar a equação (84) para cada temperatura.

Nesta seção foi estudada a influência da temperatura na determinação do tempo de vida de geração baseado no transitório da corrente de dreno em dispositivos SOI nMOSFET parcialmente depletados com corpo flutuante.

A expressão usada para o cálculo de $\tau_{g}$ foi divida em três fatores: $F, n_{i}$ e $T_{0}$. No pior caso, a variação do fator $F$ para faixa de temperatura estudada $\left(20\right.$ à $\left.80^{\circ} \mathrm{C}\right)$ foi em torno de $11 \%$. A sensibilidade do fator $\mathrm{F}$ com a espessura do óxido de porta e a concentração de dopantes no filme de silício foi menor do que $13 \%$, no pior caso. Desta 
forma as variações do fator $F$ puderam ser negligenciadas e um modelo simples para estimar $\tau_{\mathrm{g}}$ foi proposto. $\mathrm{O}$ modelo proposto foi experimentalmente aplicado para a tecnologia de $0,13 \mu \mathrm{m}$ em dispositivos PD SOI nMOSFETs e comparados com resultados obtidos através de simulações numéricas bidimensionais e o máximo erro encontrado na determinação de $\tau_{g}$ foi por volta de $5 \%$.

MARTINO, J. A.; GALETI, M.; RAFÍ, J. M.; et al.; Simple Model to Estimate the Temperature Dependence of the Generation Lifetime Extracted from Drain Current Transients in Partially Depleted SOI nMOSFETs. Journal of The Electrochemical Society. v.153, n.5, p.502, 2006. 


\subsection{O IMPACTO DA IMPLANTAÇÃO DE HALO NO TRANSITÓRIO DA CORRENTE DE DRENO}

Nesta seção será estudado o impacto da presença da região de implantação de HALO na análise do transitório da corrente de dreno. Este trabalho foi realizado baseando-se no transitório da corrente de dreno obtido através de simulações numéricas bidimensionais e dados experimentais extraídos em dispositivos $\mathrm{SOI}$ nMOSFETs parcialmente depletados que possuem os mesmos parâmetros de processo listados no início da seção 4.1.

A Figura 4-9 apresenta as curvas experimentais e simuladas do transitório da corrente de dreno com a variação do comprimento de canal, em dispositivos com a região de implantação de HALO e logo após a aplicação do degrau negativo de tensão (de $\mathrm{V}_{\mathrm{G}_{\text {_high }}}=0,7 \mathrm{~V}$ para $\mathrm{V}_{\mathrm{G}_{-} \text {low }}=0,1 \mathrm{~V}$ ). Conforme pode ser observado, apenas com a redução do comprimento de canal do dispositivo, ou seja, sem a variação de nenhum outro parâmetro de processo, ocorre também uma redução no tempo de transitório $\left(T_{0}\right)$, tanto nos resultados experimentais como nos simulados. Esta redução do tempo de transitório implica também em uma redução no tempo de vida de geração extraído a partir do modelo Shin (apresentado na seção 3.3.1), desta forma este modelo se restringe apenas a dispositivos de canal longo não possibilitando a extração deste parâmetro nesta seção. 


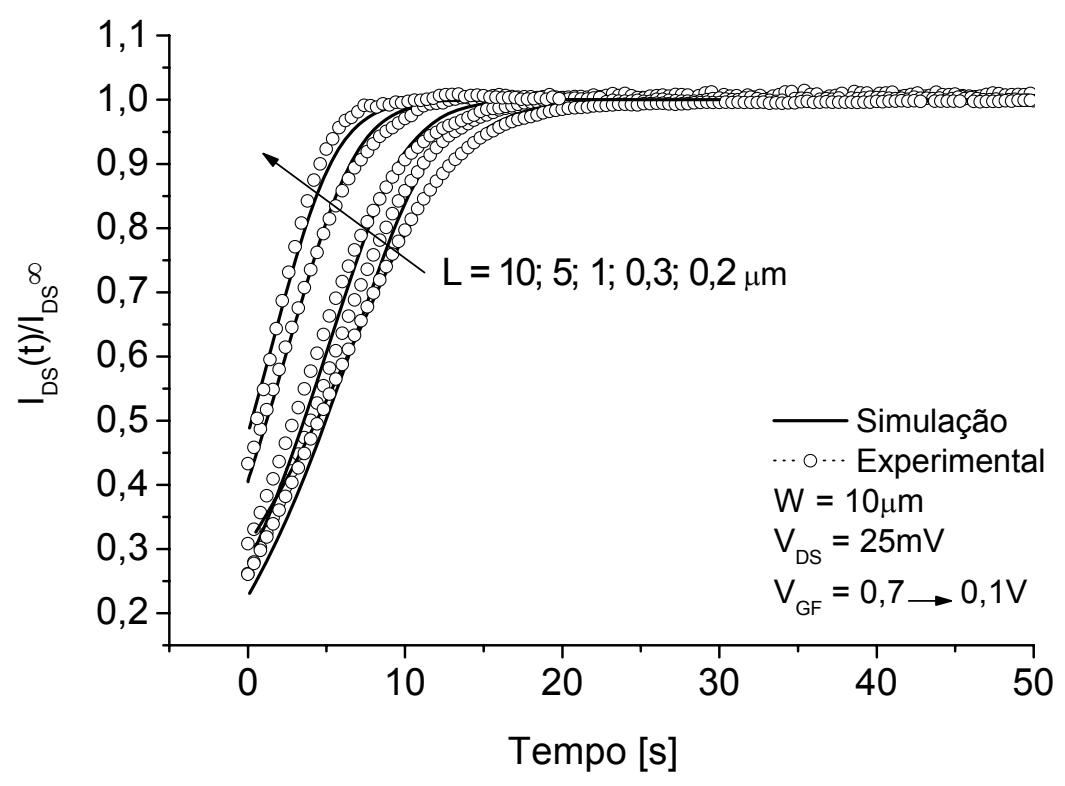

Figura 4-9 - Transitório da corrente de dreno para transistores SOI nMOSFETs parcialmente depletados com diferentes comprimentos de canal (L).

A Figura 4-10 apresenta a variação transversal do potencial dentro do filme de silício, extraida na metade do canal, com a variação do tempo. A profundidade do filme de silício igual a zero representa o potencial de superfície, onde é possível observar que antes da aplicação do degrau negativo de tensão o dispositivo se encontra em inversão forte passando para inversão fraca logo após a aplicação do degrau. Na inversão fraca a variação do potencial de superfície com o passar do tempo não é significativa, porém na região neutra (a partir de $50 \mathrm{~nm}$ ) é esta variação no potencial que ocasiona o transitório na corrente de dreno conforme elucidado na seção 3.3.1. 


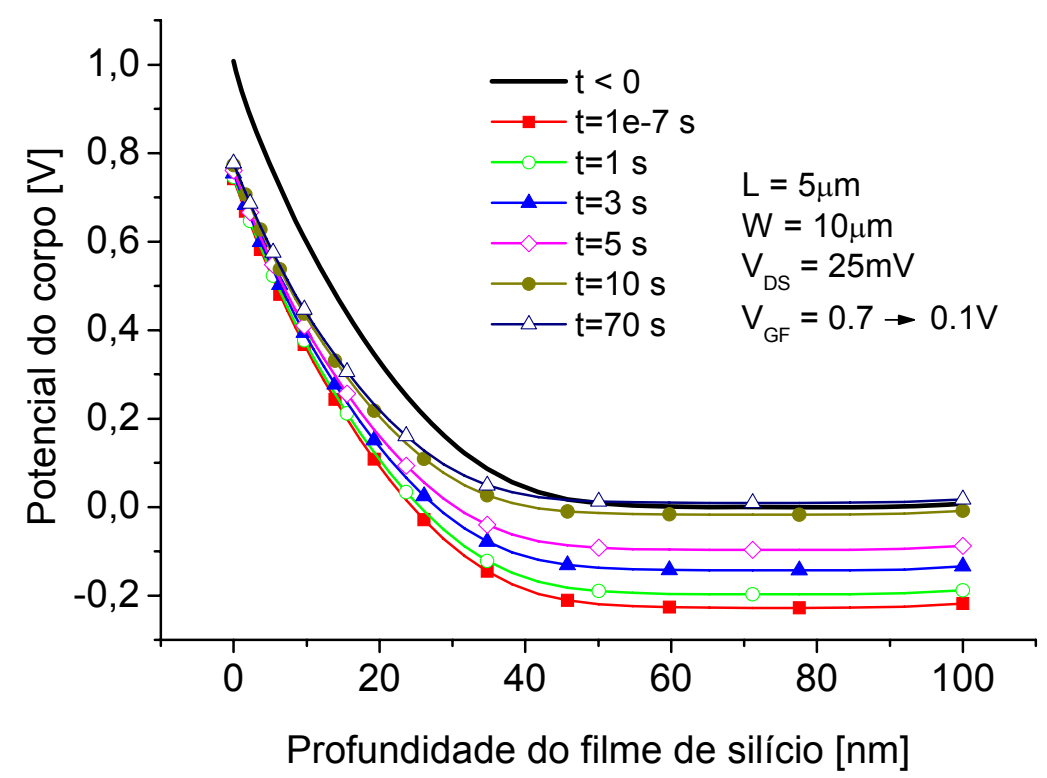

Figura 4-10 - Distribuição de potencial através do filme de silício em um PD SOI MOSFET com $\mathrm{t}_{\mathrm{oxf}}=2,5 \mathrm{~nm}, \mathrm{~N}_{\mathrm{a}}=5,510^{17} \mathrm{~cm}^{-3}$ com a variação do tempo.

Com a finalidade de estudar a redução do tempo de transitório em função da diminuição do comprimento de canal foram extraídos, a partir de simulações, os potenciais ao longo dos dispositivos (Dreno-Canal-Fonte) a uma profundidade de $80 \mathrm{~nm}$ em relação a $1^{\text {a }}$ interface (região neutra), conforme mostrado na Figura 4-11. O potencial foi extraído primeiramente com $\mathrm{V}_{\mathrm{G}_{-} \text {high }}=0,7 \mathrm{~V}$, em $\mathrm{t}=0 \mathrm{~s}$, e logo após a aplicação do degrau negativo de tensão com $V_{G_{-} \_ \text {low }}=0,1 \mathrm{~V}$, em $t=0^{+} s$, desta forma foi possível observar que quando é diminuído o comprimento de canal a influência das capacitâncias de acoplamento entre fonte/canal e dreno/canal se tornam mais significativas, fazendo com que o potencial do corpo em dispositivos com menores comprimentos de canal não consiga atingir o mesmo patamar atingido pelos dispositivos com comprimento de canal maiores ${ }^{83}$, após a aplicação do degrau negativo de tensão. 


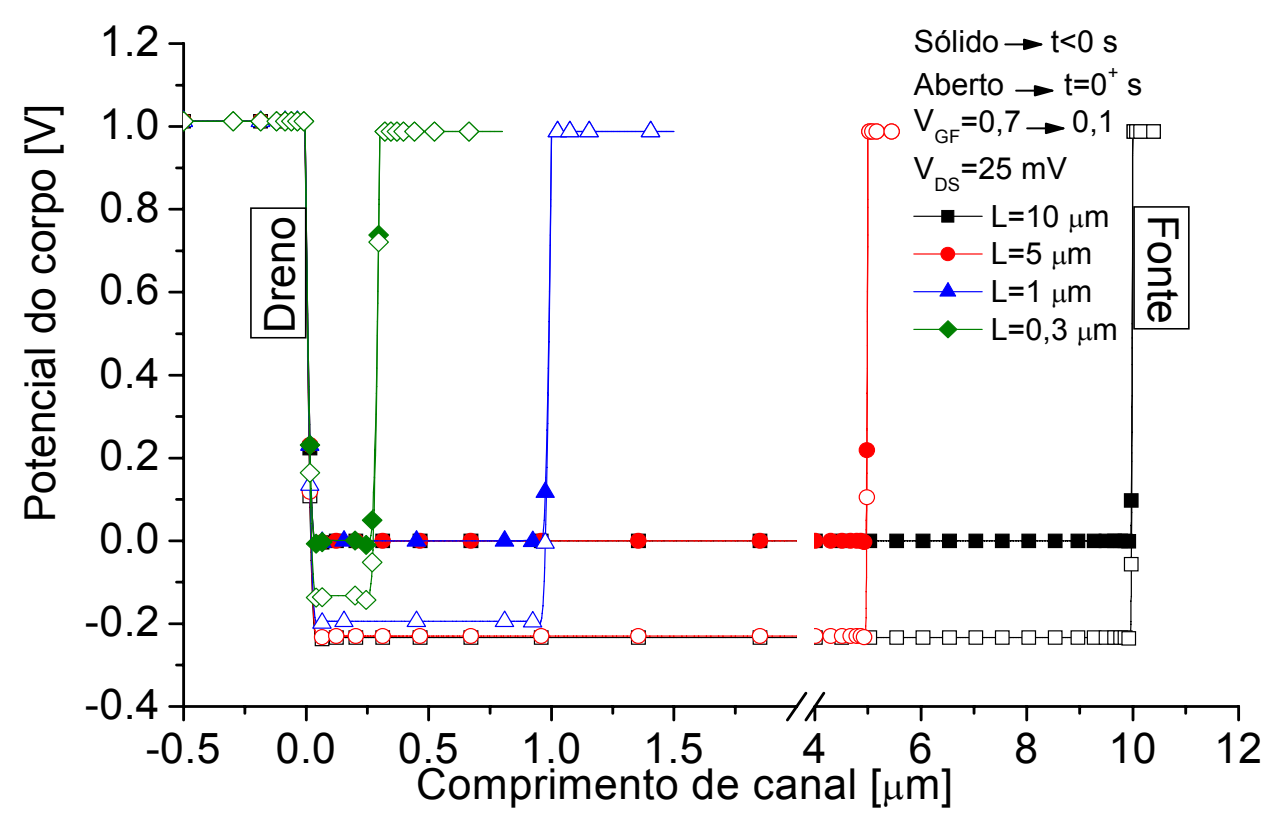

Figura 4-11 - Potencial ao longo do dispositivo, a uma profundidade de $80 \mathrm{~nm}$ em relação a $1^{\text {a }}$ interface, variando o comprimento de canal.

A Figura 4-12 descreve o comportamento do potencial do corpo juntamente com a tensão de limiar em função do tempo, para dispositivos com e sem a presença da região de implantação de HALO e com a variação do comprimento de canal.

Como pode ser observado na Figura 4-12 o potencial do corpo do dispositivo na situação de equilíbrio $\left(\mathrm{t}_{\infty}\right)$ independe do comprimento de canal. Contudo, logo após a mudança da polarização da porta de $\mathrm{V}_{\mathrm{G}_{-} \text {high }}=0,7 \mathrm{~V}$ para $\mathrm{V}_{\mathrm{G} \_l o w}=0,1 \mathrm{~V}\left(\mathrm{t}=0^{+} \mathrm{s}\right)$ o potencial no corpo é maior para dispositivos com comprimento de canal menores, conforme já visto na Figura 4-11, este fato ocasiona em uma redução no transitório do potencial. Sendo maior o potencial do corpo dos dispositivos com L menor, no instante inicial, acarreta em um valor menor da tensão de limiar neste mesmo instante. $O$ transitório do potencial do corpo, para os comprimentos de canal estudados, se mostrou pouco dependente da presença da região de implantação de HALO. Já o transitório da tensão de limiar é fortemente influenciado pela presença do HALO.

Nos dispositivos sem a presença da região de HALO a tensão de limiar assume valores inferiores, tanto no início do transitório $\left(\mathrm{t}=0^{+} \mathrm{s}\right)$ como no estado de equilíbrio $\left(\mathrm{t}_{\infty}\right)$, devido ao efeito de canal curto. Nos dispositivos com HALO, a diminuição do 
comprimento de canal ocasiona em um aumento da concentração efetiva de dopantes na região do canal, isto faz com que haja uma elevação na tensão de limiar na situação de equilíbrio ${ }^{83}$.

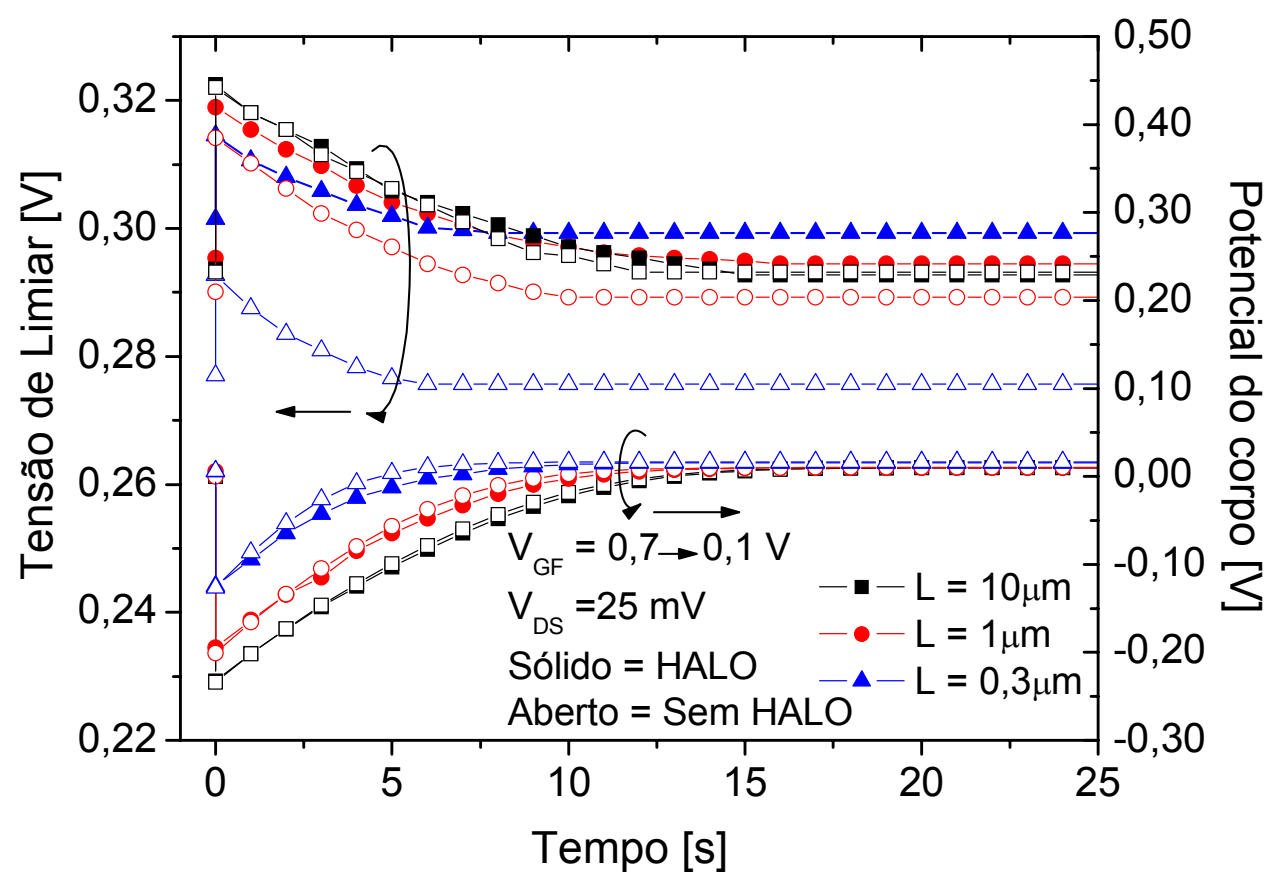

Figura 4-12 - Tensão de limiar e o potencial no corpo em função do tempo para diferentes comprimentos de canal $(L)$.

Os efeitos descritos acima, referentes ao transitório do potencial do corpo flutuante e da tensão de limiar, podem ser observados no transitório da corrente de dreno ilustrados na Figura 4-13, que mostra as curvas da corrente de dreno normalizada pelo comprimento de canal em função do tempo, para dispositivos com e sem a presença da região de implantação de HALO.

A maior influência das capacitâncias de acoplamento entre fonte/canal e dreno/canal, que ocorre com a diminuição do comprimento de canal, leva a uma menor variação do potencial do corpo flutuante e com isto uma redução dos valores da tensão de limiar no início do transitório. Estes fatores fazem com que o valor inicial do transitório da corrente de dreno aumente com a diminuição do comprimento de canal em ambos os dispositivos, com e sem HALO. Nos dispositivos sem a presença do 
HALO este aumento é acentuado devido a maior densidade de corrente de elétrons nas junções, como pode ser observado na Figura 4-15 ${ }^{83}$.

Nos dispositivos com a presença do HALO, o aumento da tensão de limiar ocasionado pelo aumento da concentração efetiva de dopantes, que ocorre com a diminuição do comprimento de canal, leva a uma diminuição do nível de corrente no estado de equilíbrio resultando em um transitório de menor duração. Já nos dispositivos sem a presença do HALO, o nível de corrente no estado de equilíbrio aumenta significativamente com a diminuição do canal, devido ao efeito de canal curto.

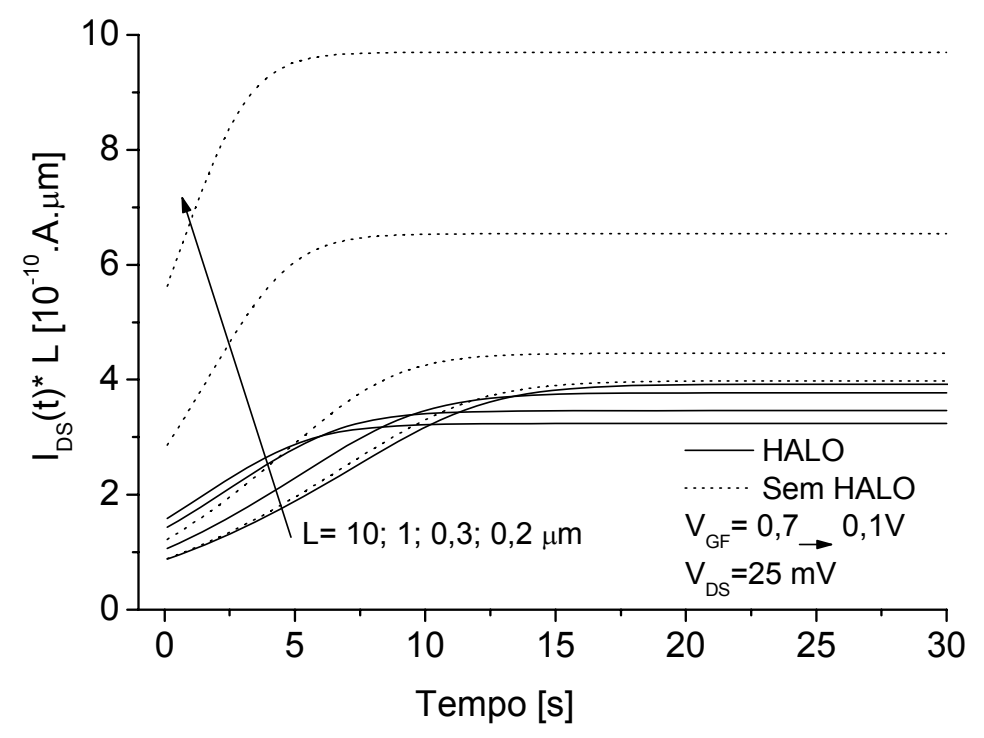

Figura 4-13 - Transitório da corrente de dreno normalizado pelo comprimento de canal (L) em função do tempo, variando $L$ dos dispositivos.

A Figura 4-14 apresenta a taxa de geração em função da profundidade da camada de silício para diversos comprimentos de canal (L). A taxa de geração foi extraída exatamente na metade do canal com o objetivo de conhecermos a profundidade em que a taxa de geração é máxima. Sendo que a profundidade de geração máxima é dependente do comprimento do canal. 


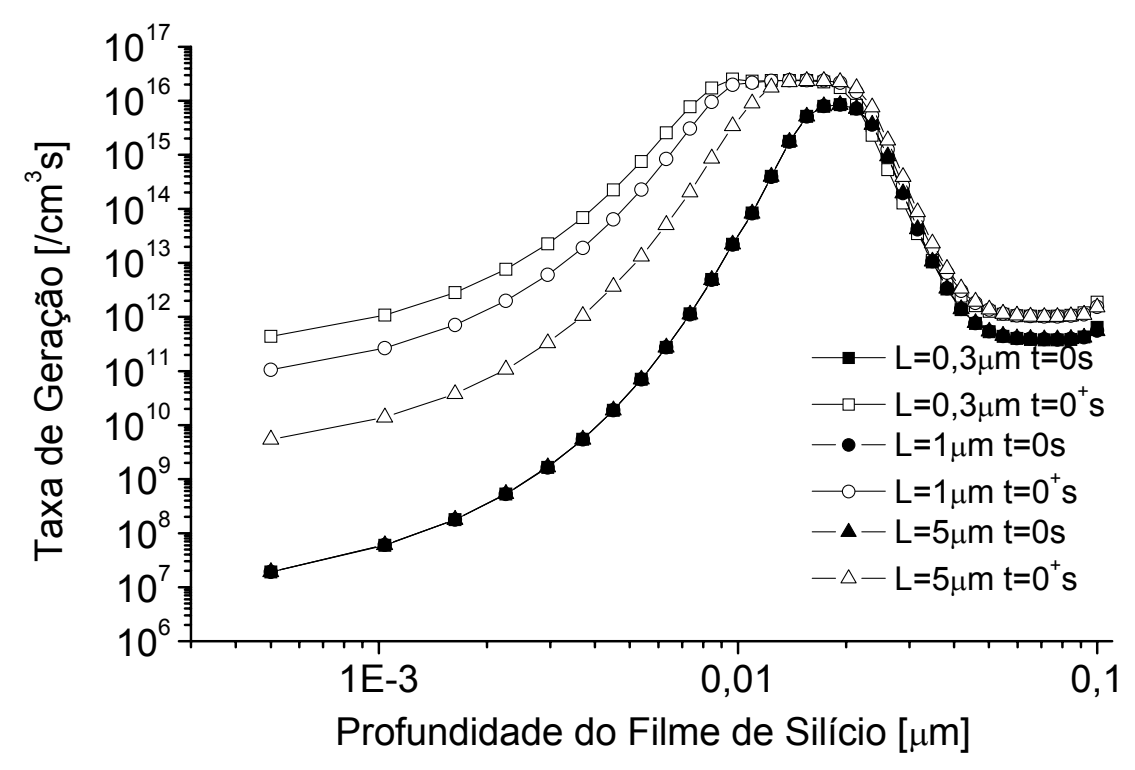

Figura 4-14 - Taxa de geração em função da profundidade do filme de silício, antes e depois da aplicação do degrau negativo de tensão, variando o comprimento de canal.

$\mathrm{Na}$ profundidade onde foi verificada a máxima taxa de geração, logo após a aplicação do degrau negativo de tensão, foram extraídas tanto as densidades de correntes de elétrons (Figura 4-15) como de lacunas (Figura 4-16) em função do comprimento total do dispositivo (incluindo as regiões de fonte e dreno), variando o comprimento de canal para dispositivos com e sem a presença da região de implantação de HALO ${ }^{83}$.

Conforme pode ser observado na Figura 4-15 a densidade de corrente de elétrons nas junções dreno/canal e canal/fonte é fortemente dependente do comprimento de canal. Com o decréscimo do comprimento de canal a densidade de corrente de elétrons aumenta, este aumento é ainda mais significativo nos dispositivos sem a presença do HALO. Confirmando assim os dados apresentados na Figura 4-13, que mostram um aumento significativo dos níveis do transitório da corrente de dreno nos dispositivos sem HALO. 


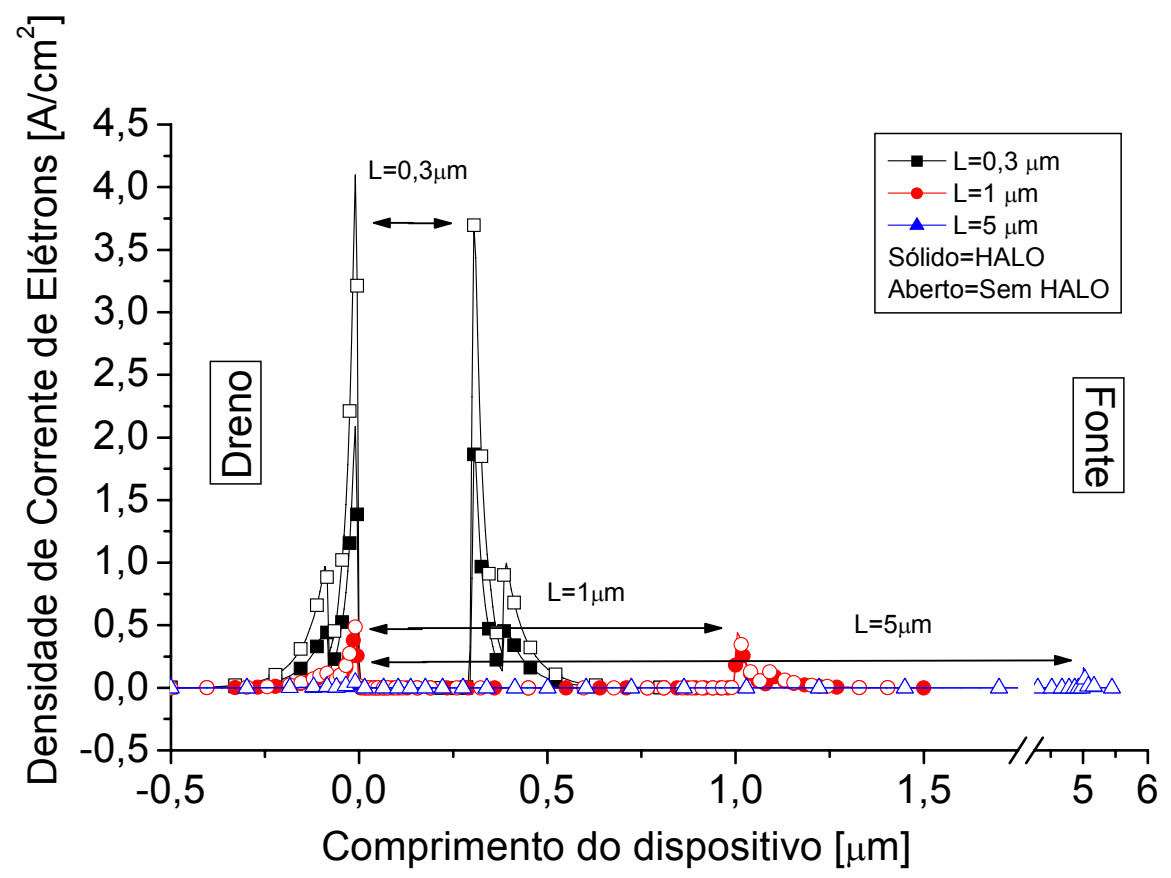

Figura 4-15 - Densidade de corrente de elétrons em função do comprimento do dispositivo, logo após a aplicação do degrau negativo de tensão $\left(t=0^{+} \mathrm{s}\right)$.

A Figura 4-16 mostra a densidade de corrente de lacunas em função do comprimento total do dispositivo, para dispositivos com e sem a presença de HALO. Da mesma forma que o caso anterior (para elétrons), a densidade de corrente de lacunas foi extraída na profundidade em que a taxa de geração é máxima e logo após a aplicação do degrau negativo de tensão. Como pode ser verificado a presença do halo ocasionou a redução da densidade de corrente de lacunas em todos os comprimentos de canal estudados. 


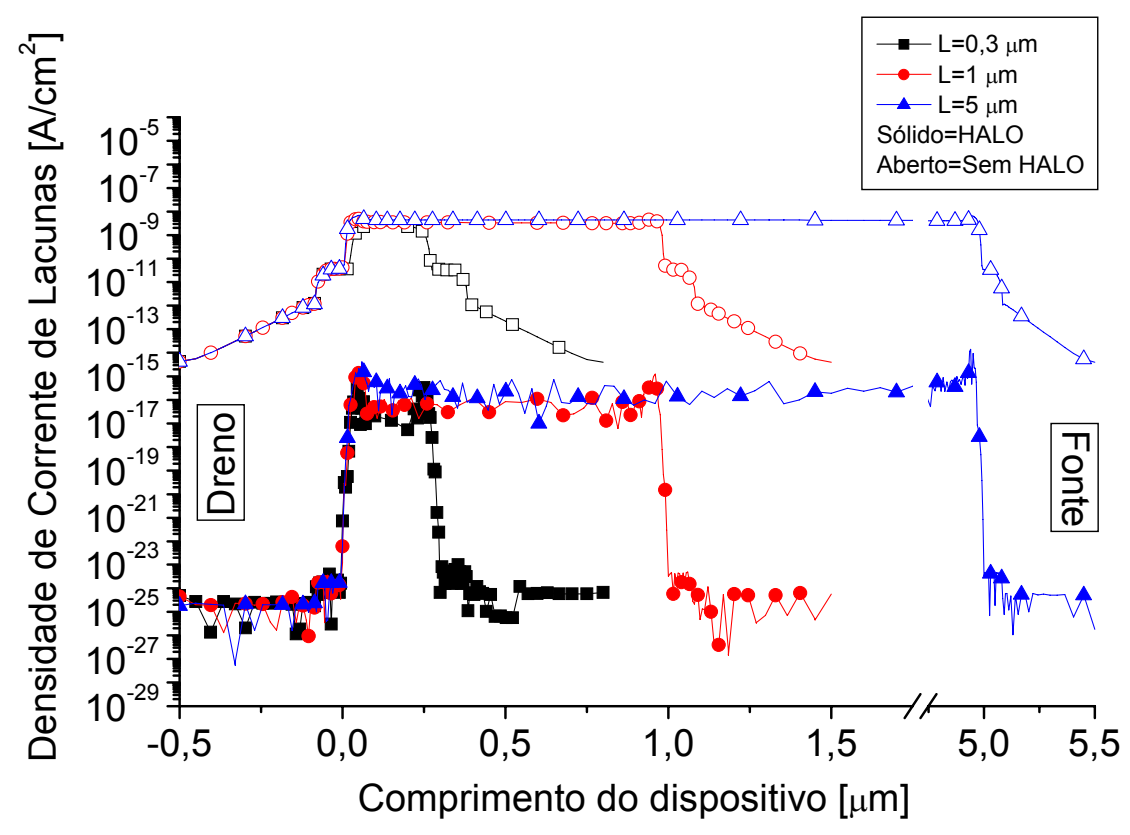

Figura 4-16 - Densidade de corrente de lacunas em função do comprimento do dispositivo, para dispositivos com e sem HALO, logo após a aplicação do degrau negativo de tensão $\left(t=0^{+} s\right)$.

Conforme elucidado na seção 3.3.1, o tempo transitório $\left(T_{0}\right)$ é definido como o tempo necessário para corrente de dreno atingir $90 \%$ do valor da corrente de equilíbrio. A Figura 4-17 apresenta o tempo de transitório $\left(T_{0}\right)$ em função do comprimento de canal (L) para dispositivos com e sem a presença do HALO.

Quando a tensão na porta de um nMOSFET é variada de um valor acima da tensão de limiar para um valor abaixo da mesma, lacunas são geradas para preencher a região de carga espacial localizada entre $X_{d m a ́ x}$ e $X_{d \infty}$. Como pôde ser verificado na Figura 4-16, anteriormente citada, os dispositivos sem a presença do HALO possuem uma maior densidade de corrente de lacunas nesta região, sendo assim as lacunas injetadas no canal através das junções contribuem com o mecanismo de geração decrescendo o tempo de transitório em relação aos dispositivos com HALO, com pode ser observado Figura 4-17. 


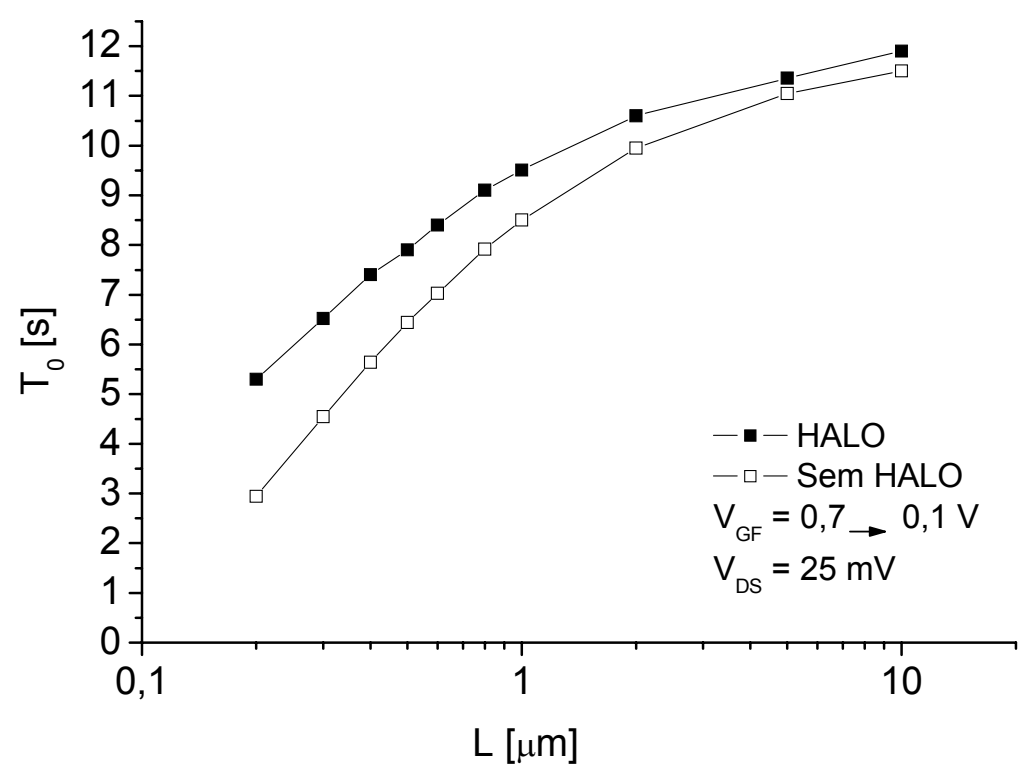

Figura 4-17 - Tempo de transitório $T_{0}$ em função do comprimento de canal (L).

Nesta seção, foi analisado o comportamento do transitório da corrente de dreno em função do comprimento de canal em dispositivos SOI MOSFETs parcialmente depletados, com e sem a presença da região de implantação de HALO.

Quando o comprimento de canal é reduzido, o maior acoplamento capacitivo das junções de fonte/dreno e o corpo provocam a redução do potencial interno da junção, desta forma, diminuindo o efeito de corpo flutuante. Este fato causa um aumento no valor inicial do transitório do potencial de corpo em dispositivos com e sem HALO. Na região de equilíbrio, o potencial de corpo não é influenciado pelo comprimento de canal.

Nos dispositivos sem HALO e com comprimento de canal reduzido é observado o efeito de canal curto. A redução significativa da tensão de limiar no instante inicial é observada e conseqüentemente um aumento na corrente do dreno durante todo transitório. Nos dispositivos com HALO, quando o comprimento de canal diminui, o aumento da concentração efetiva de dopantes, devido à presença do HALO, causa um aumento da tensão de limiar no estado de equilíbrio.

Nos dispositivos com HALO, a influência da junção é limitada somente ao acoplamento capacitivo das junções e o corpo, de modo que neste caso o tempo de transitório sofre uma redução de $56 \%$ dentro da faixa de comprimento de canal 
estudados (10 a 0,2 $\mu \mathrm{m}$ ). Entretanto, nos dispositivos sem HALO, além do acoplamento capacitivo há um aumento significativo na densidade de corrente de lacunas através da junção que causa uma redução no tempo de transitório de $74 \%$, para a mesma faixa de valores de comprimento de canal.

GALETI, M.; MARTINO, J. A.; SIMOEN, E.; CLAEYS, C.; Impact of Halo Implantation on the Lifetime Assessment in Partially Depleted SOI Transistors. High Purity Silicon 9 - 210th ECS Meeting. v.3, n.4, p.351, 2006. 


\subsection{NOVO MODELO PARA DETERMINAÇÃO DO TEMPO DE VIDA DE GERAÇÃO EM DISPOSITIVOS SOI NMOSFET COM CANAL CURTO.}

Nesta seção é reportada uma melhoria do modelo analítico unidimensional para extração do tempo de vida de geração. Este modelo pode quantificar o impacto do efeito do corpo flutuante no transitório da corrente de dreno, conforme descrito anteriormente na seção 3.3.1, e através da melhoria proposta passa a considerar também a influência da região de implantação de halo e a redução do comprimento de canal.

O método apresentado na seção 3.3.1 consiste na aplicação de um degrau negativo de tensão na porta de um dispositivo SOI nMOSFET parcialmente depletado, levando o dispositivo da inversão forte ( $\mathrm{V}_{\mathrm{GF}}$ acima da tensão de limiar) para inversão fraca ( $V_{G F}$ abaixo da tensão de limiar). Após a aplicação do degrau negativo de tensão é observado um transitório na corrente de dreno devido ao decréscimo do potencial do corpo flutuante, causando um aumento na tensão de limiar. Enquanto a geração de portadores preenche a região de depleção localizada entre a máxima depleção $\left(x_{d m a x}\right)$ e a depleção no estado de equilíbrio $\left(\mathrm{x}_{\mathrm{d} \infty}\right)$ o potencial do corpo retorna para zero e a tensão de limiar para seu valor de equilíbrio fazendo com que a corrente de dreno gradualmente aumente atingindo também seu valor de equilíbrio.

A principal contribuição deste novo modelo é quantificar separadamente as cargas que agem na superfície das que agem no corpo flutuante durante o transitório. $O$ impacto da lateralidade não uniforme da dopagem do canal no efeito de corpo flutuante, devido a presença das regiões de HALO, foi representada neste modelo através da média das dopagens no interior do canal, na superfície $\left(N_{\text {eff }}\right)$ e no corpo $\left(N_{Q D}\right)$, considerando um perfil uniforme dentro de cada uma das regiões do canal $\left(N_{h} \text { e } N_{a}\right)^{84}$.

Para o cálculo do potencial de superfície a influência das regiões de depleção controladas pelas junções de fonte e dreno não são significativas. Neste caso, a média das dopagens $\left(\mathrm{N}_{\text {eff }}\right)$ pode ser descrita conforme a equação $(96)$.

$$
N_{\text {eff }}=\frac{N_{a}\left(L-2 L_{h}\right)}{L}+\frac{2 N_{h}\left(L_{h}\right)}{L}
$$


Onde $L_{h}, N_{h}$ e $N_{a}$ são a largura da região de implantação de HALO, e as concentrações da região de implantação de HALO e da região de canal, respectivamente, conforme mostra a Figura 4-18.

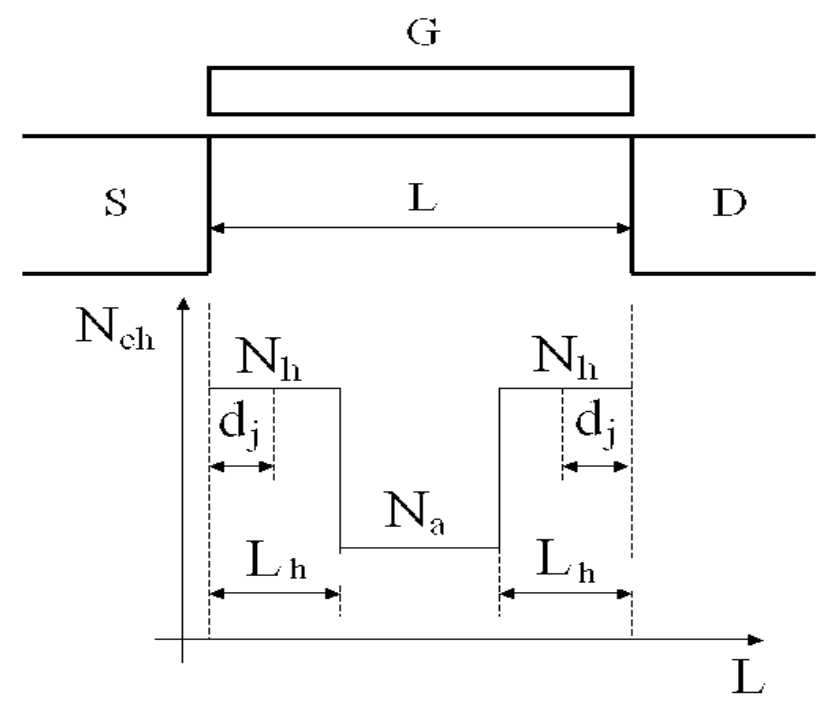

Figura 4-18 - Seção transversal do dispositivo com o perfil de dopagem ao longo do canal.

Contudo, na região do corpo do dispositivo a média das dopagens foi calculada considerando somente as cargas de depleção controladas pela porta, ou seja, sem a contribuição das cargas controladas pelas junções de fonte e dreno. De acordo com a equação (97), onde $d_{j}$ é a largura da região de depleção controlada pelas junções de fonte e dreno.

$$
N_{Q D}=\frac{N_{a}\left(L-2 L_{h}\right)}{L}+\frac{2 N_{h}\left(L_{h}-d_{j}\right)}{L}
$$

Desta forma, a variação das cargas de depleção em função do tempo $\left(Q_{D}(t)\right)$, devido a geração de portadores dentro da região de cargas espaciais no corpo do dispositivo, podem ser escritas conforme a equação (98) ${ }^{84}$.

$$
-q N_{Q D} \frac{d x_{d}}{d t}=q \frac{n_{i}}{\tau_{g}}\left[x_{d}(t)-x_{d \infty}\right]
$$

Sendo $x_{d}(t)$ a variação da região de depleção em função do tempo.

Resolvendo a equação (98), conforme citado anteriormente na seção (3.3.1), porém sem considerar as cargas controladas pelas junções de fonte e dreno tem-se que: 


$$
x_{d}(t)=\left[x_{d \max }-x_{d \infty}\right] \exp \left(-\frac{t}{\frac{\tau_{g} N_{Q D}}{n_{i}}}\right)+x_{d \infty}
$$

O equacionamento da tensão aplicada na porta após o degrau negativo de tensão é dado pela equação (100). O segundo termo desta equação se refere ao potencial de superfície, onde são consideradas a totalidade de cargas da região de

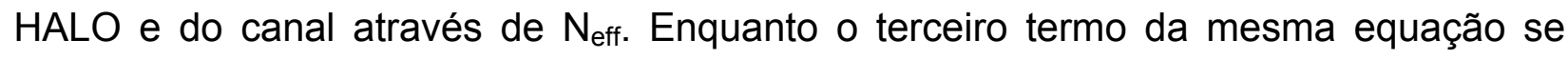
refere apenas as cargas de depleção controladas pela porta, sem considerar a influência das junções de fonte e dreno, sendo este termo dependente de $\mathrm{N}_{\mathrm{QD}}$.

$$
V_{G_{-} \text {low }}=V_{F B}+\frac{q \cdot N_{e f f} \cdot x_{d \infty}^{2}}{2 \cdot \varepsilon_{s i}}+\frac{q \cdot N_{Q D} \cdot X_{d \infty}}{C_{o x}}
$$

Através da equação (100) pode-se isolar $x_{d \infty}$, resultando na equação (101) apresentada a seguir.

$$
x_{d \infty}=\frac{-3 N_{Q D} t_{o x}+\sqrt{9\left(N_{Q D} t_{o x}\right)^{2}+\frac{2 \varepsilon_{s i} N_{\text {eff }}}{q}\left(V_{G_{-} \text {low }}-V_{F B}\right)}}{N_{\text {eff }}}
$$

Conforme já elucidado anteriormente, na seção 4.2, o efeito de corpo flutuante é menor em dispositivos com comprimento de canal reduzido devido ao maior acoplamento capacitivo das junções com o corpo nestes dispositivos. Logo, a excursão da região de depleção durante o transitório também é reduzida com a diminuição do comprimento de canal.

De posse das considerações incluídas no novo modelo foi possível calcular, através da equação (99), o comportamento da região de depleção na região do canal em função do tempo, para diferentes comprimentos de canal. Normalizando estes resultados pela profundidade máxima de depleção, foi possível observar, na Figura 4-19, a redução prevista da excursão da região de depleção em dispositivos cujos comprimentos de canal são menores. 


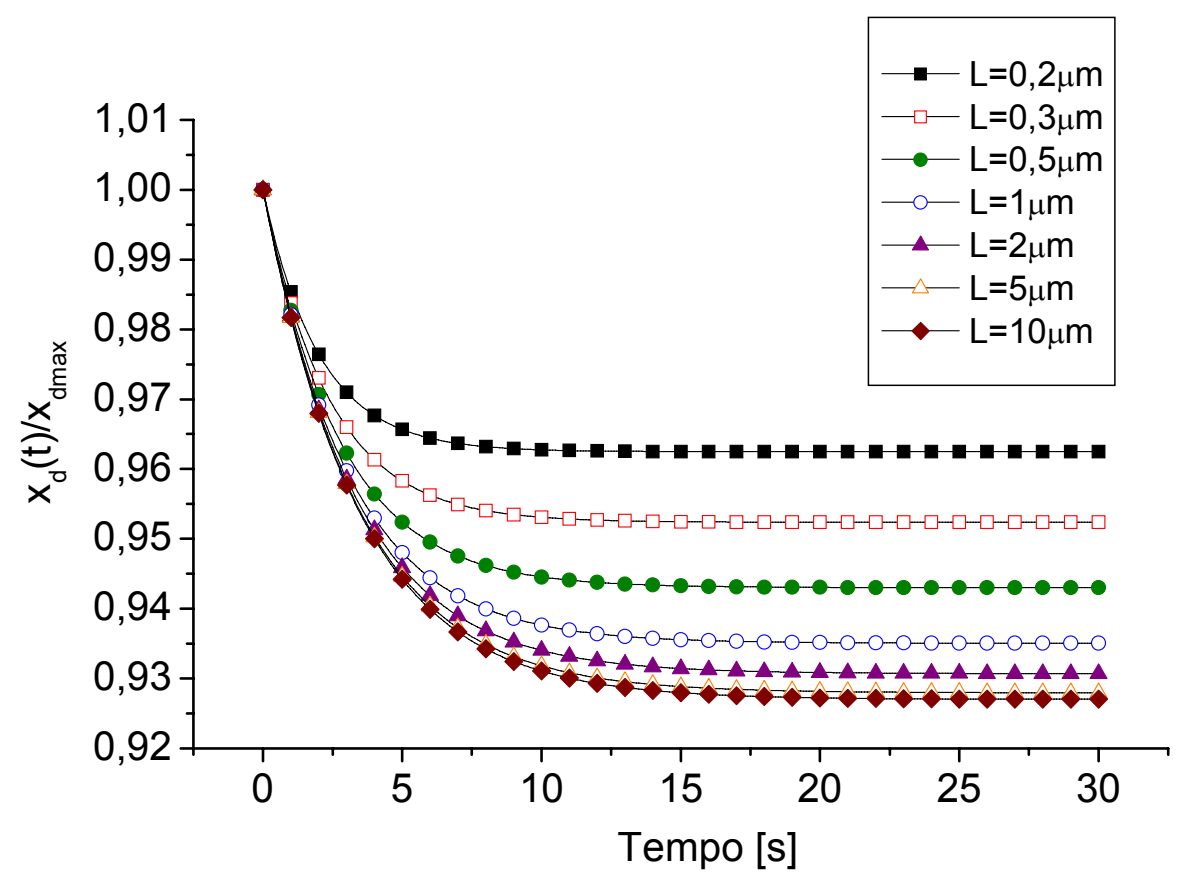

Figura 4-19 - O comportamento da largura da região de depleção normalizada pela largura da região de depleção máxima em função do tempo.

O Aumento da concentração de dopantes, causado pela presença da região de implantação de HALO, não influencia somente na capacitância de acoplamento das junções mas também na injeção de lacunas no corpo. Conseqüentemente, este fato induz uma polarização dinâmica do corpo que esta flutuando. Esta influência da injeção de lacunas esta empiricamente representado através do segundo termo da exponencial na equação (102), que descreve o transitório da corrente de dreno $\left(I_{D S}(t)\right)$ normalizado pela corrente de equilíbrio $\left(\mathrm{I}_{\mathrm{DS} \infty}\right)^{84}$.

$$
\frac{I_{D S}(t)}{I_{D S \infty}}=\exp \left\{\frac{q}{\xi k T}\left[\gamma\left(\sqrt{2 \phi_{F}}-\sqrt{2 \phi_{F}-V_{B S}(t)}\right)+\frac{\xi V_{B S}(t)}{2}\right]\right\}
$$

onde

$$
V_{B S}(t)=-\frac{q N_{Q D}}{2 \varepsilon_{s i}}\left\{\left[x_{d}(t)\right]^{2}-\left[x_{\mathrm{d} \infty}\right]^{2}\right\} \quad \text { e } \quad \xi=1+\left[C_{D}(t) / C_{o x}\right]
$$

A Figura 4-20 mostra o transitório da corrente de dreno $I_{D S}(t)$ (curvas experimentais e o novo modelo) normalizadas pelo nível de corrente no estado de 
equilíbrio $\mathrm{IDS}_{\infty}$, para dispositivos SOI nMOSFETs com comprimento de canal variando de 0,2 à $5 \mu \mathrm{m}$, após a variação da tensão na porta de $\mathrm{V}_{\mathrm{G}_{-} \text {high }}=0,7 \mathrm{~V}$ para $\mathrm{V}_{\mathrm{G}_{-} \text {low }}=0,1 \mathrm{~V}$. Nesta figura pode ser observado o aumento gradual da corrente de dreno em função do tempo, após ser aplicado na porta o degrau negativo de tensão, este fato se deve a geração térmica de portadores que ocorre dentro da região de depleção, conforme citado anteriormente.

A diminuição de cargas controladas pela porta, que ocorre para dispositivos com comprimento de canal menor, causa a redução do efeito de corpo flutuante nestes dispositivos e ao mesmo tempo no transitório da corrente de dreno, conforme observado experimentalmente. Este novo modelo demonstrou um bom ajuste quando comparado com dados experimentais, principalmente na região de maior interesse, em $90 \%$, usada para extração do tempo de vida de geração.

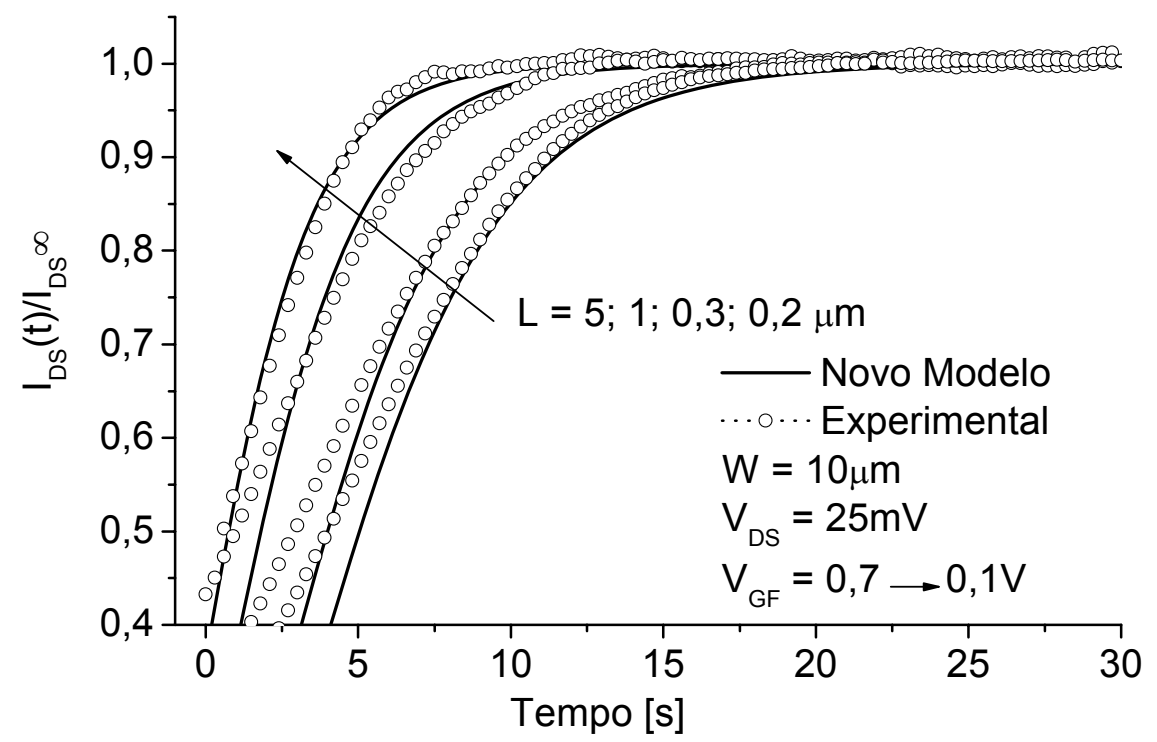

Figura 4-20 - Transitório da corrente de dreno para transistores PD SOI nMOSFETs com diferentes comprimentos de canal.

Conforme elucidado na seção 3.3.1, o tempo de transitório $\left(T_{0}\right)$ é definido como o tempo necessário para corrente de dreno atingir $90 \%$ do valor da corrente de equilíbrio. A Figura 4-21 compara o tempo de transitório obtido experimentalmente com dados obtidos através das simulações numéricas, do modelo descrito na literatura ${ }^{77}$ e do novo modelo com as considerações das equações (96) e (98). É possível observar que, após 
a contribuição deste trabalho, o tempo de transitório obtido através desta nova técnica acompanha o decréscimo verificado nos dados experimentais quando o comprimento de canal é reduzido.

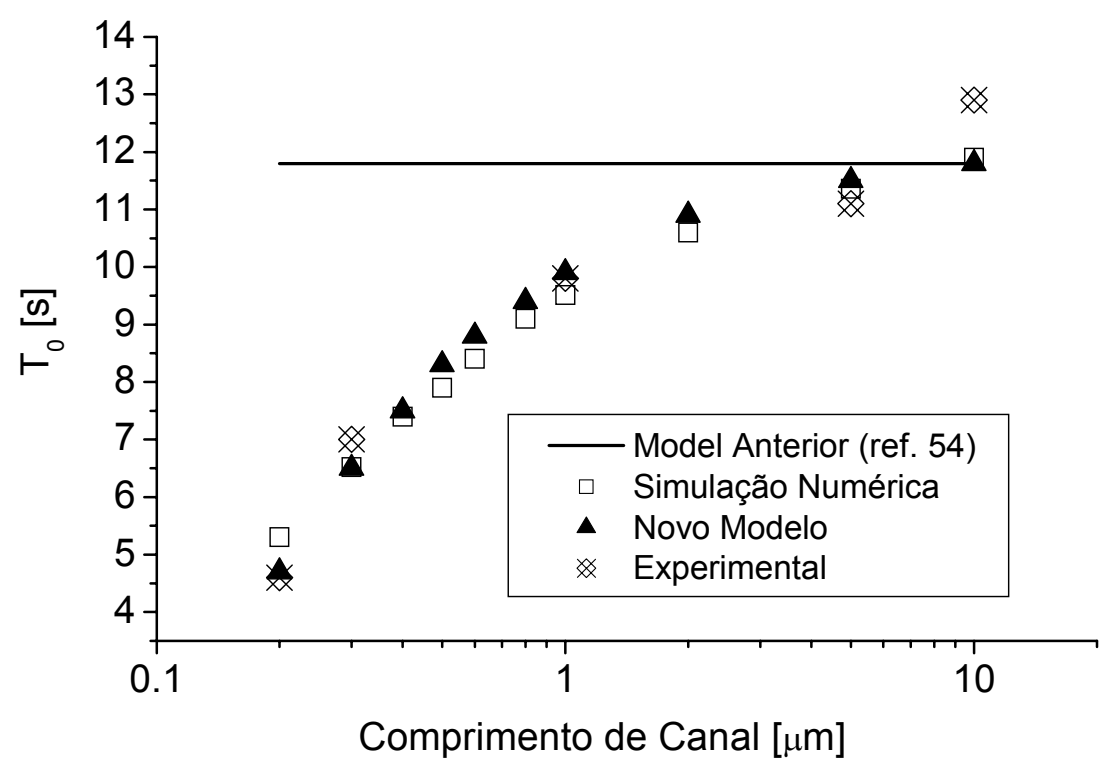

Figura 4-21 - Tempo de transitório em função do comprimento de canal.

A Tabela 5 mostra os valores do tempo de transitório, com a variação do comprimento de canal, obtidos a partir das simulações numéricas bidimensionais, dados experimentais e através do modelo proposto neste trabalho. Tomando como referência as simulações numéricas pode-se observar, através da porcentagem de erro, que o modelo proposto acompanha de forma satisfatória tanto os resultados simulados como os experimentais. 
Tabela 5 - Tempo de transitório extraídos a partir de simulação numérica, do modelo proposto e dados experimentais em função do comprimento de canal.

\begin{tabular}{ccccc}
\hline \multirow{2}{*}[\mu\mathrm{m}]{} & \multicolumn{3}{c}{$\mathrm{T}_{0}[\mathrm{~s}]$} & \multirow{2}{*}{ Erro [\%] } \\
\cline { 2 - 4 } & $\begin{array}{c}\text { Simul. } \\
\text { Numérica }\end{array}$ & $\begin{array}{c}\text { Modelo } \\
\text { Proposto }\end{array}$ & $\begin{array}{c}\text { Dados } \\
\text { Experimentais }\end{array}$ & \\
\hline 10 & 11,9 & 11,8 & 12,9 & 0,8 \\
5 & 11,4 & 11,5 & 11,1 & 1,2 \\
2 & 10,6 & 10,9 & -- & 2,8 \\
1 & 9,5 & 9,9 & 9,8 & 4,2 \\
0,8 & 9,1 & 9,4 & -- & 3,3 \\
0,6 & 8,4 & 8,8 & -- & 4,7 \\
0,5 & 7,9 & 8,3 & -- & 5,0 \\
0,4 & 7,4 & 7,5 & -- & 1,4 \\
0,3 & 6,5 & 6,5 & 7 & 0 \\
0,2 & 5,3 & 4,7 & 4.6 & 11,3 \\
\hline
\end{tabular}

A Tabela 6 compara os valores do tempo de transitório $\left(T_{0}\right)$ extraídos a partir das simulações numéricas e do novo modelo proveniente da equação (102) para um dispositivo de comprimento de canal igual a $0,3 \mu \mathrm{m}$, variando as concentrações da região de canal (mantendo $\mathrm{N}_{\mathrm{h}}=1 \quad 10^{18} \mathrm{~cm}^{-3}$ ) e de implantação de HALO (mantendo $\mathrm{N}_{a}=5.510^{17} \mathrm{~cm}^{-3}$ ) de $\pm 20 \%$. O máximo erro obtido dentro desta faixa de variação de $\mathrm{N}_{a}$ e $N_{h}$ foi de $9,2 \%$, adotando como referência os valores obtidos através das simulações numéricas.

Tabela 6 - Tempo de transitório extraídos a partir de simulação numérica e do modelo proposto para diferentes concentrações no canal e na região de HALO.

\begin{tabular}{cccc}
\hline \multirow{2}{*}{$\mathrm{N}_{\mathrm{a}}\left[10^{17} \mathrm{~cm}^{-3}\right]$} & Simul. Numérica $^{\mathrm{T}_{0}[\mathrm{~s}]}$ & Modelo Proposto & Erro[\%] \\
\hline 4,5 & 5,9 & 5,4 & 8,5 \\
5 & 6,2 & 5,9 & 4,8 \\
5,5 & 6,5 & 6,4 & 1,5 \\
6 & 6,8 & 6,8 & 0 \\
6,5 & 7,1 & 7,1 & 0 \\
\hline $\mathrm{N}_{\mathrm{n}}\left[10^{18} \mathrm{~cm}^{-3}\right]$ & & & \\
\hline 0,8 & 5,6 & 5,7 & 1,8 \\
0,9 & 6 & 6 & 0 \\
1 & 6,5 & 6,4 & 1,5 \\
1,1 & 7,1 & 6,6 & 7,0 \\
1,2 & 7,6 & 6,9 & 9,2
\end{tabular}

A Figura 4-22 apresenta as curvas do transitório da corrente de dreno normalizada pela corrente no estado de equilíbrio em um dispositivo SOI nMOSFET, operando em temperaturas de 20 à $60^{\circ} \mathrm{C}$, com comprimento de canal de $0,3 \mu \mathrm{m}$ e 
concentração do canal e da região de HALO de $5,510^{17} \mathrm{~cm}^{-3}$ e $1.10^{18} \mathrm{~cm}^{-3}$, respectivamente. As curvas apresentadas nesta figura mostram que mesmo com a variação da temperatura o novo modelo acompanha satisfatoriamente os dados experimentais.

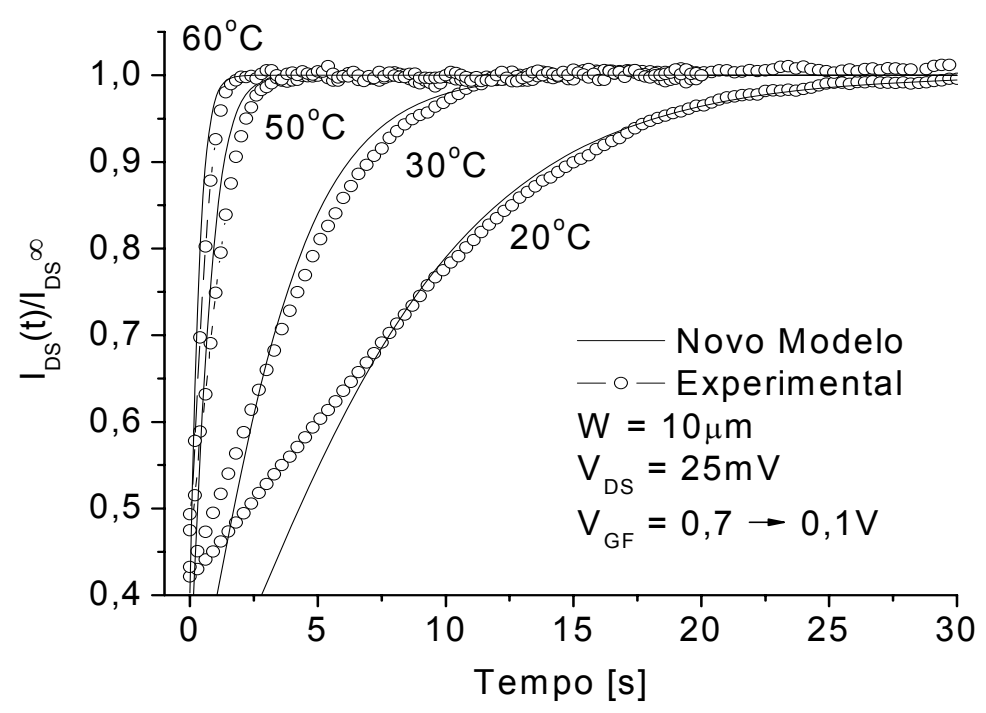

Figura 4-22 - Transitório da corrente de dreno, para um PD SOI nMOSFET de $L=0,3 \mu \mathrm{m}, \mathrm{N}_{\mathrm{a}}=5,510^{17} \mathrm{~cm}^{-3}$ e $\mathrm{N}_{\mathrm{h}}=110^{18} \mathrm{~cm}^{-3}$, com a variação da temperatura.

O tempo de vida de geração $\left(\tau_{g}\right)$ pode ser calculado usando as equações (99) e (102) que resultará na equação (103), onde o valor de $x_{d}$ será extraído a partir do valor de $V_{B S}$ à $90 \%$ de sua excursão.

$$
\tau_{g}=\frac{T_{0} n_{i}}{N_{Q D} \ln \left(\frac{x_{d \max }-x_{d \infty}}{x_{d}(90 \%)-x_{d \infty}}\right)}
$$

A Figura 4-23 compara o tempo de vida de geração $\left(\tau_{g}\right)$ obtidos através das curvas experimentais e das simulações numéricas com dados obtidos a partir do modelo aperfeiçoado. Conforme esperado, o tempo de vida de geração decresce com a diminuição do comprimento de canal devido ao aumento da concentração de dopantes efetiva causada pela proximidade das regiões de fonte e dreno ${ }^{84}$. 


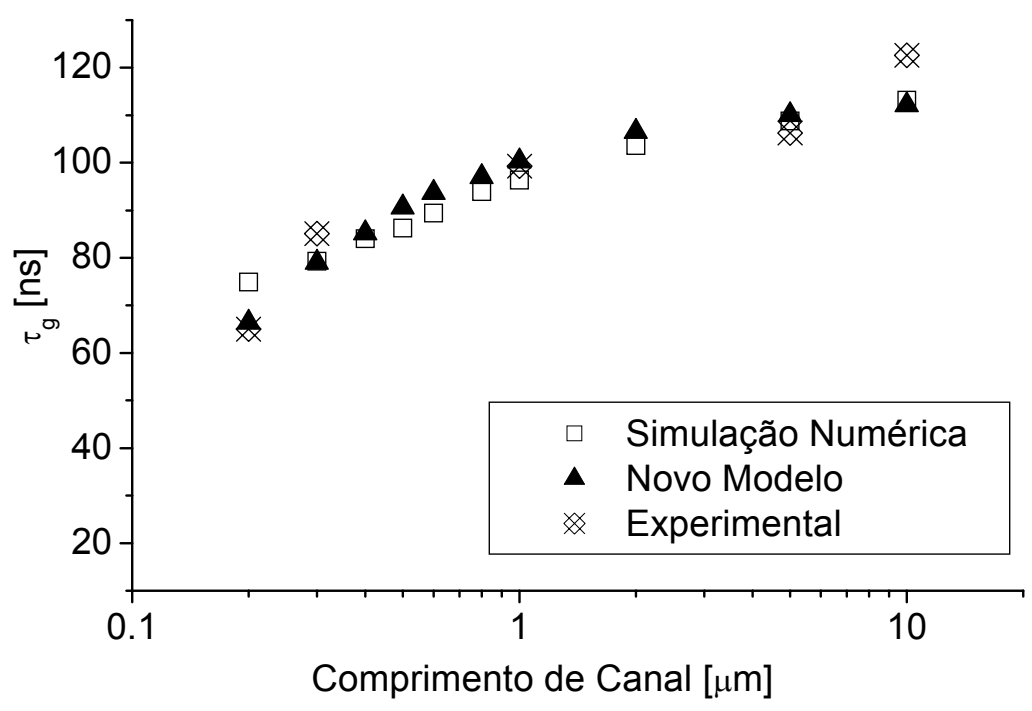

Figura 4-23 - Tempo de vida de geração $\left(\tau_{g}\right)$ em função do comprimento de canal.

Alimentando a equação (99) com três diferentes valores de tempo de vida de geração $\left(\tau_{g}\right.$ (alim) $)$, foram obtidos valores de tempo de transitório $\left(T_{0}\right)$ que se ajustaram perfeitamente com os valores simulados numericamente. Estes valores de $T_{0}$ serviram de alimentação na equação (103) para extrair novamente os tempos de vida de geração $\left(\tau_{g}\right.$ (extraído) $)$, conforme é mostrado na Tabela 7 , com a variação do comprimento de canal. Os resultados obtidos demonstraram que o modelo, com as novas considerações implementadas, acompanhou de forma satisfatória a variação em três décadas no tempo de vida, apresentando um erro de $17 \%$ no pior caso ${ }^{84}$.

Tabela 7 - Tempo de vida de geração extraído para três diferentes tempos de vida de alimentação da equação (99), com a variação do comprimento de canal.

\begin{tabular}{cccc}
\hline \multirow{2}{*}{$\begin{array}{c}\text { Comprimento } \\
\text { de Canal }[\mu \mathrm{m}]\end{array}$} & \multicolumn{3}{c}{$\tau_{\mathrm{g} \text { (alim) }}[\mathrm{ns}]$} \\
\cline { 2 - 4 } & & 100 & 1000 \\
\hline 0,2 & 8,48 & $\tau_{\mathrm{g} \text { (extraido) }}[\mathrm{ns}]$ \\
0,3 & 8,87 & 82,6 & 825 \\
1 & 9,83 & 86,3 & 862 \\
5 & 9,76 & 96,3 & 956 \\
\hline
\end{tabular}

Nesta seção foi proposto um novo modelo, a partir de um modelo já existente na literatura, que considera o impacto do perfil não uniforme da concentração de dopantes na região do canal devido à presença da região de implantação de HALO, assim como a influência das cargas de depleção controladas pelas junções de fonte e dreno no 
efeito de corpo flutuante. Com as novas considerações tornou-se possível a análise do transitório da corrente de dreno com a redução do comprimento de canal.

Os resultados obtidos, para os dispositivos de porta simples, foram comparados com dados experimentais e com simulações numéricas bidimensionais e apresentaram um bom ajuste com a variação do comprimento de canal, temperatura e com a variação das concentrações de dopantes da região de canal e da região de implantação de HALO.

GALETI, M.; MARTINO, J. A.; SIMOEN, E.; CLAEYS, C.; Improved Model to Determine the Generation Lifetime in Short Channel SOI nMOSFETs. Silicon-on-Insulator Technology and Devices 13 - 211th ECS Meeting. v.6, n.4, p.387, 2007. 


\subsection{ADAPTAÇÃO DO NOVO MODELO PARA DETERMINAÇÃO DO TEMPO DE VIDA DE GERAÇÃO EM DISPOSITIVOS SOI NMOSFET DE PORTA DUPLA.}

O processo de fabricação dos dispositivos de porta dupla (DG) SOI MOSFETs tem sido foco de grande interesse na comunidade cientifica, este fato se deve à superioridade das características elétricas destes dispositivos quando comparados com dispositivos de porta simples (SG). Os dispositivos DG aparecem na literatura como fortes candidatos às futuras gerações da tecnologia CMOS, devido à sua excelente escalabilidade ${ }^{85,86}$ e ao seu inerente potencial à supressão do efeito de canal curto. Além das vantagens já citadas, há outras descritas em publicações recentes ${ }^{87}$, como o aumento da corrente de dreno e da transcondutância, a redução das correntes de fuga e a inclinação de sublimiar próxima a ideal. Para conseguir alta performance nestes dispositivos, a alta qualidade da lâmina de silício e uma boa avaliação das etapas de processo são de fundamental importância, sendo que o tempo de vida de geração contribui de forma significativa para esta avaliação.

Os dispositivos dos quais foram extraídos os dados apresentados nesta seção tem seus parâmetros de processo listados no início da seção 4.1. Para as simulações das estruturas de porta dupla, o óxido enterrado foi substituído por uma camada de óxido fino com espessura ( $\left.t_{\text {oxb }}\right)$ de $2,5 \mathrm{~nm}$ conforme mostra a Figura 4-24. As concentrações de dopantes da fonte/dreno $\left(N_{S, D}\right)$, halo $\left(N_{h}\right)$ e do canal $\left(N_{a}\right)$ permaneceram as mesmas da estrutura de porta simples apresentada na seção 4.3. 

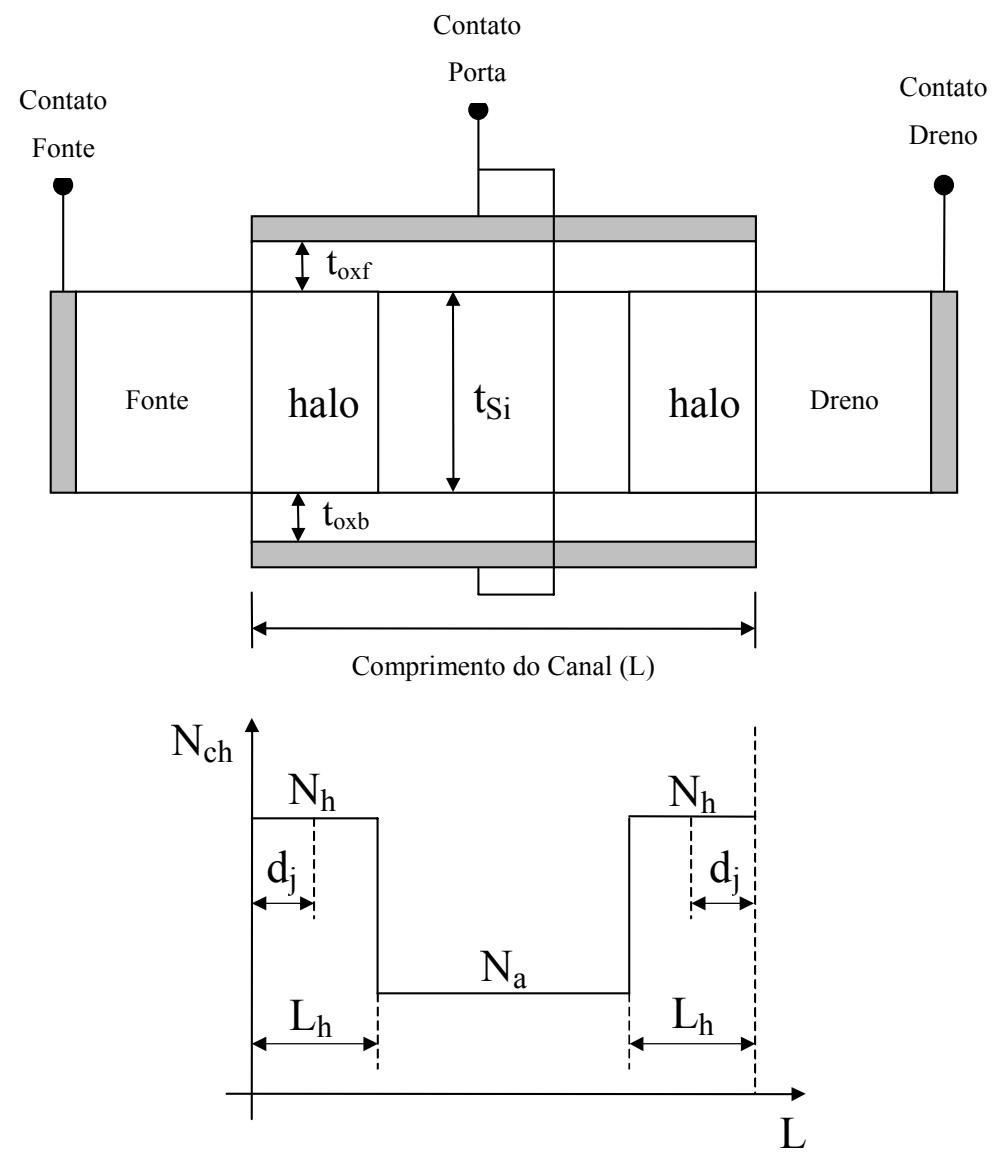

Figura 4-24 - Secção transversal do dispositivo de porta dupla com o perfil de dopagem ao longo do canal.

Para os dispositivos de porta dupla a influência das junções de fonte e dreno é menor devido à maior eficiência da porta no controle da variação das cargas de depleção. Com a redução da espessura do filme de silício o controle das duas portas torna-se ainda melhor sobre a região do canal. Esta menor influência das junções nos dispositivos de porta dupla foi incluída na equação (98) através da inserção de um parâmetro empírico de ajuste $\left(t_{\text {rel }}\right)$, conforme mostrado na equação (104). $O$ termo $\left(t_{\text {rel }}\right)$ possibilitou adaptar o novo modelo apresentado na seção 4.3 aos dispositivos de porta dupla, contabilizando o maior acoplamento capacitivo entre as portas e a região de corpo não somente através da dependência da espessura da camada silício, mas incluindo também a dependência com da concentração de dopantes através de $x_{\text {dmáx. }}$.

$$
N_{Q D(D G)}=\frac{N_{a}\left(L-2 L_{h}\right)}{L}+\frac{2 N_{h}\left(L_{h}-d_{j} \cdot t_{\text {rel }}\right)}{L}
$$


onde $t_{r e l}=\left(t_{s i}-x_{d \max }\right) / t_{s i}$.

Todo equacionamento descrito na seção 4.3, para dispositivos de porta simples, se mantém para os dispositivos de porta dupla, apenas com a substituição do termo $N_{Q D}$ por $N_{Q D(D G)}$.

A Figura 4-25 descreve o comportamento do potencial de corpo através da profundidade do filme de silício, para dispositivos de porta simples e dupla com $L=0,2 \mu \mathrm{m}$ e $L=5 \mu \mathrm{m}$, antes $(t<0 \mathrm{~s})$ e depois $\left(t=0^{+} \mathrm{s}\right)$ da aplicação do degrau negativo de tensão. A maior variação do potencial em $\left(t=0^{+} s\right)$ observada no dispositivo de porta dupla com $L=0,2 \mu \mathrm{m}$ se deve ao maior controle das portas sobre o filme de silício que ocorre nestes dispositivos ${ }^{88}$.

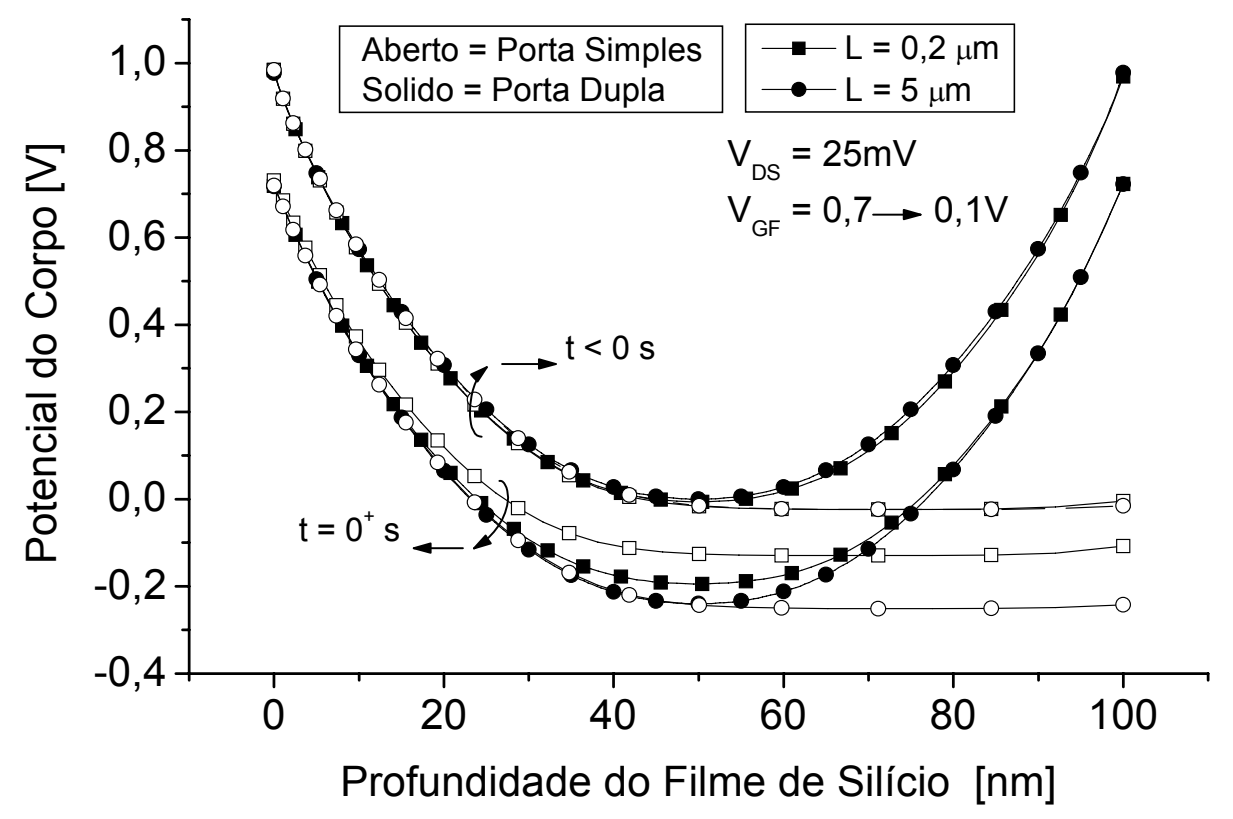

Figura 4-25 - Simulações numéricas da distribuição do potencial de corpo através do filme de silício, para $\mathrm{L}=0,2 \mu \mathrm{m}$ e $\mathrm{L}=5 \mu \mathrm{m}$ em dispositivos de porta simples e dupla, antes $(\mathrm{t}<0 \mathrm{~s})$ e depois $\left(\mathrm{t}=0^{+} \mathrm{s}\right)$ da aplicação do degrau negativo de tensão.

A Figura 4-26 mostra as curvas do transitório da corrente de dreno $I_{D}(t)$ (experimental e simuladas) normalizadas pelo valor da corrente de dreno no estado de equilíbrio ( $\left.\mathrm{I}_{\mathrm{D}_{\infty}}\right)$ para dispositivos SG e DG SOI nMOSFET, após a mudança da tensão 
na porta de $V_{G_{-} \text {high }}=0,7 \mathrm{~V}$ para $V_{G_{-} \text {low }}=0,1 \mathrm{~V}$, para diferentes comprimentos de canal variando entre 0,2 e $5 \mu \mathrm{m}$. A Figura 4-26A tem como objetivo mostrar o bom ajuste obtido entre as simulações e os dados experimentais nos dispositivos SG, porque a partir destas simulações foram geradas as simulações para os dispositivos DG, que podem ser observadas na Figura 4-26B. Para obtenção das simulações dos dispositivos DG, todos os parâmetros de processo usados nas simulações SG se mantiveram integralmente os mesmos, exceto o óxido enterrado que foi substituído por um óxido fino de $2,5 \mathrm{~nm}$. Nesta figura é possíveis observar uma menor variação do tempo de transitório com a redução do comprimento de canal nos dispositivos DG quando comparados aos dispositivos SG. 

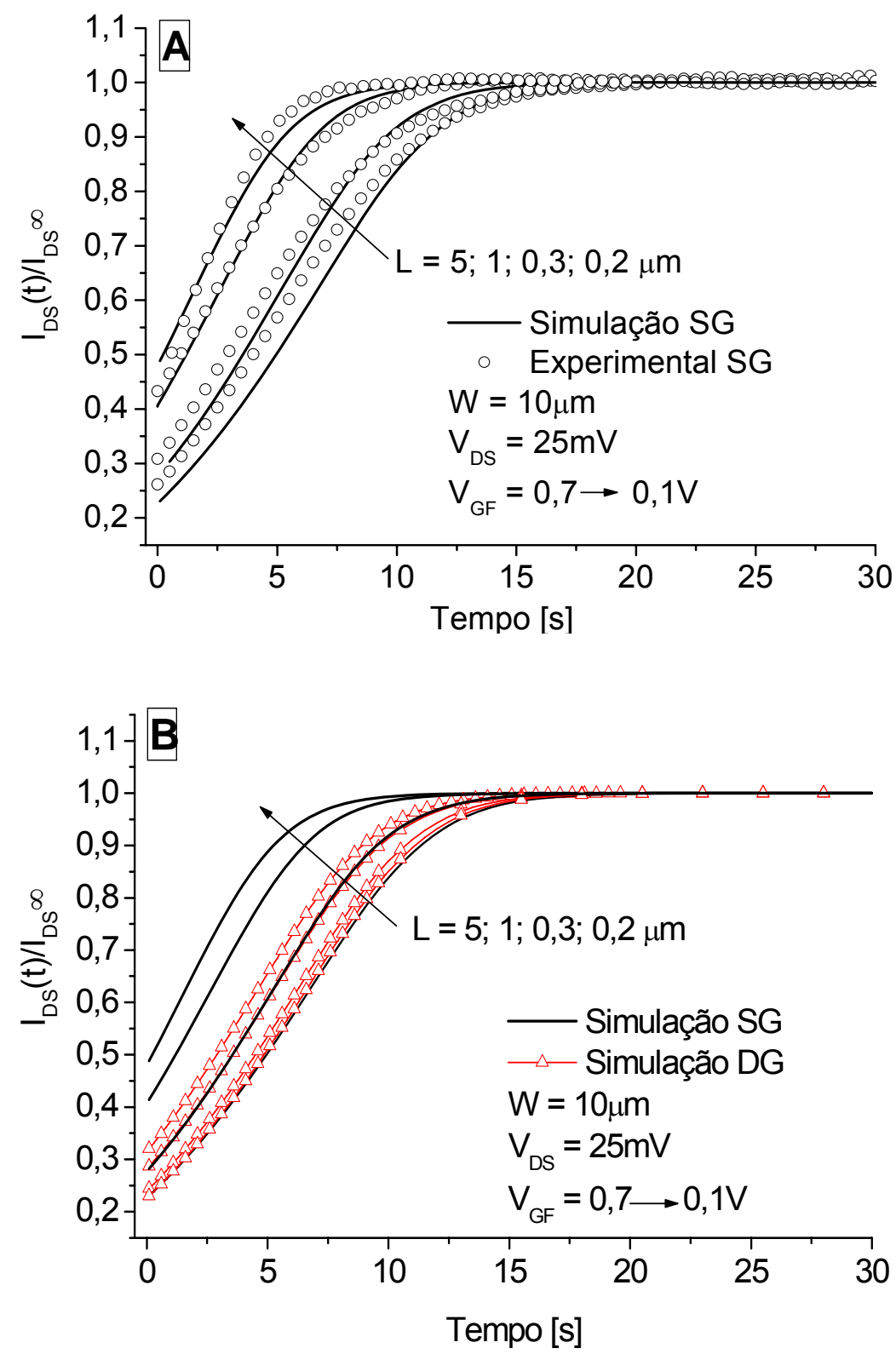

Figura 4-26 - Transitório da corrente de dreno de um PD SOI nMOSFET com diferentes comprimentos de canal. (A) Comparação entre as curvas experimentais e simuladas de dispositivos SG. (B) Comparação entre as curvas simuladas de dispositivos SG e DG

A Figura 4-27 apresenta o comportamento do transitório da corrente de dreno, em dispositivos de porta simples e dupla, normalizado pelo comprimento de canal em função do tempo, com comprimento de canal variando entre $5,1,0,5$ e $0,3 \mu \mathrm{m}$. $\mathrm{O}$ aumento na tensão de limiar causado pelo aumento na concentração efetiva de dopantes no canal, devido a presença da região de HALO, provoca o decréscimo da 
corrente de dreno no estado de equilíbrio quando é diminuído o comprimento de canal em ambas estruturas. Este fato resulta na diminuição do transitório ${ }^{83}$, como explicado anteriormente na seção 4.2 .

Para dispositivos com menores comprimentos de canal a capacitância de acoplamento entre fonte/corpo e corpo/dreno torna-se maior, levando a uma redução no potencial interno das junções após a aplicação do degrau negativo de tensão ${ }^{88}$. Este fenômeno justifica o maior nível de corrente de dreno no início do transitório dos dispositivos SG. Este fenômeno é atenuado nos dispositivos DG devido à menor influência das junções.

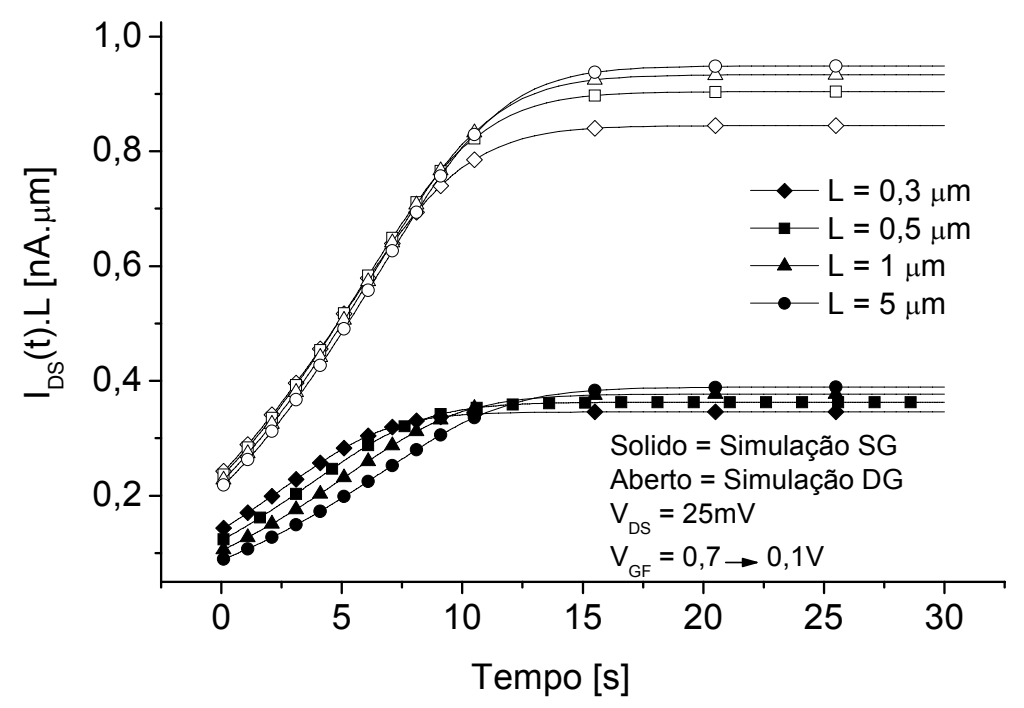

Figura 4-27- Transitório da corrente de dreno normalizado pelo comprimento de canal em função do tempo, para dispositivos SG e DG PD SOI nMOSFET com diferentes comprimentos de canal ${ }^{89}$.

A Figura 4-28 ilustra o comportamento do tempo de transitório $\left(T_{0}\right)$ em função do comprimento de canal para dispositivos SG e DG, ambos com a espessura do filme de silício de $100 \mathrm{~nm}$. Os valores do tempo de transitório foram extraídos a partir das curvas geradas pela equação (102) considerando a aproximação descrita na equação (104) e comparados com os valores obtidos a partir das simulações numéricas e dados experimentais ${ }^{89}$. Além do ajuste satisfatório entre os dados simulados e os obtidos através do modelo para dispositivos de porta dupla, usando o parâmetro ( $\left.\mathrm{t}_{\text {rel }}\right)$, é possível também observar claramente a menor sensibilidade destes dispositivos com a redução do comprimento de canal. 


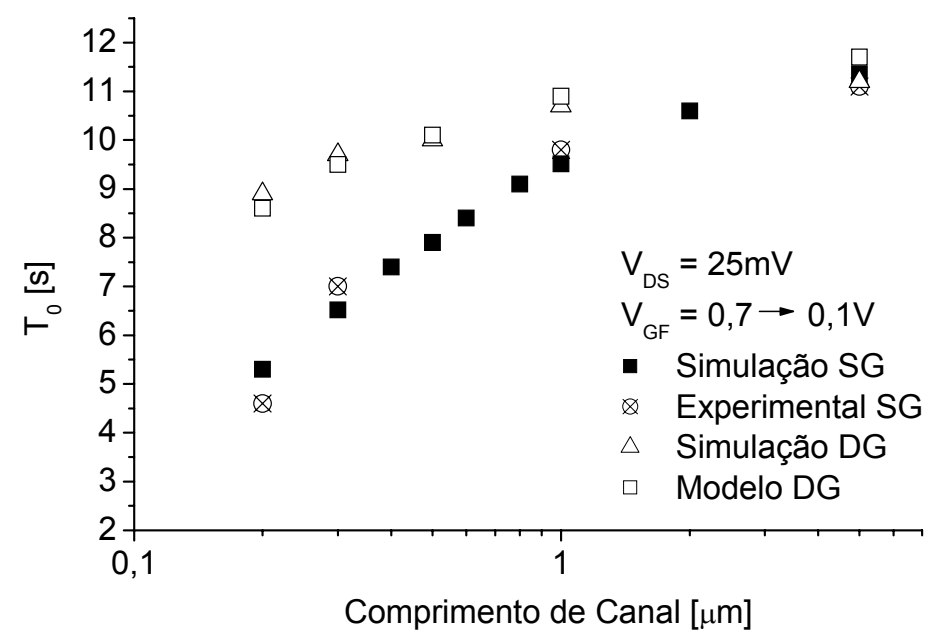

Figura 4-28 - Tempo de transitório em função do comprimento de canal.

A Figura 4-29 mostra o tempo de transitório do DG PD SOI nMOSFET em função do comprimento de canal, com a variação da espessura do filme de silício. Nesta figura, é possível observar que os valores obtidos através da aproximação proposta para os dispositivos de porta dupla acompanham a mesma tendência dos resultados simulados, apresentando um erro máximo de $16 \%{ }^{89}$.

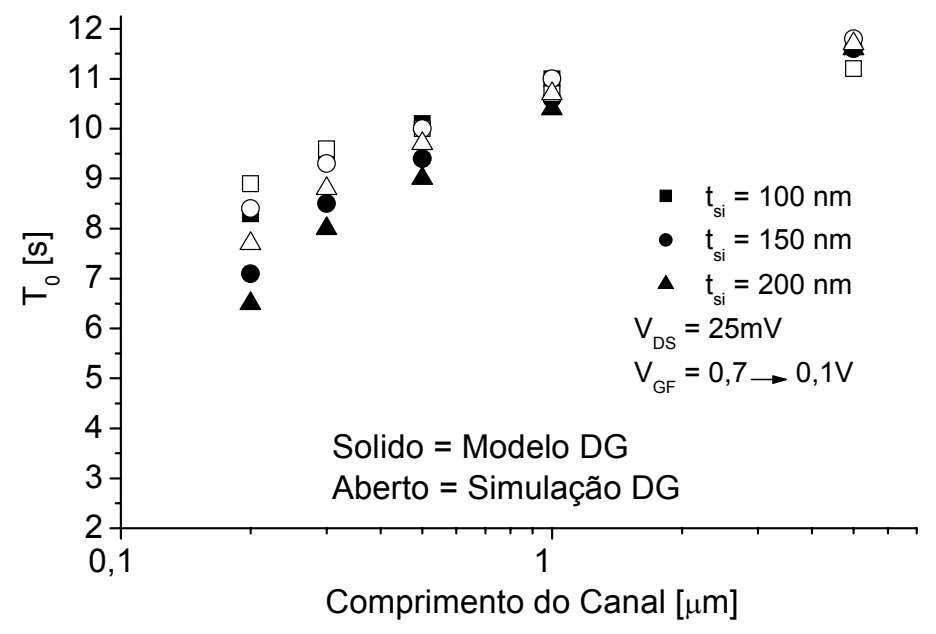

Figura 4-29 - Tempo de transitório do DG PD SOI nMOSFET em função do comprimento de canal, com a variação da espessura do filme de silício.

A comparação entre os valores do tempo de vida de geração $\left(\tau_{g}\right)$ obtidos pelo aperfeiçoamento do modelo para dispositivos de porta dupla com dados experimentais 
e simulados de dispositivos de porta simples, ambos com espessura do filme de silício de $100 \mathrm{~nm}$, pode ser observada na Figura 4-30. Apesar de obtida uma maior variação do tempo de transitório com a redução do comprimento de canal nos dispositivos SG em relação ao DG, o tempo de vida de geração $\left(\tau_{g}\right)$ obtido para dois dispositivos permaneceram bem próximos mesmo com a variação do comprimento de canal. Estes resultados já eram esperados, visto que, as propriedades do filme de silício se mantiveram as mesmas em ambas estruturas.

O aumento da concentração efetiva do canal ocasionada pela proximidade das regiões de HALO junto à fonte e ao dreno, em dispositivos com menores comprimentos de canal, causam a redução de $\tau_{\mathrm{g}}$ tanto nos dispositivos SG com nos DG. Esta dependência inversa de $\tau_{\mathrm{g}}$ com a concentração efetiva de dopantes, já reportada previamente na literatura ${ }^{90}$, pode ser quantificada através da equação (103).

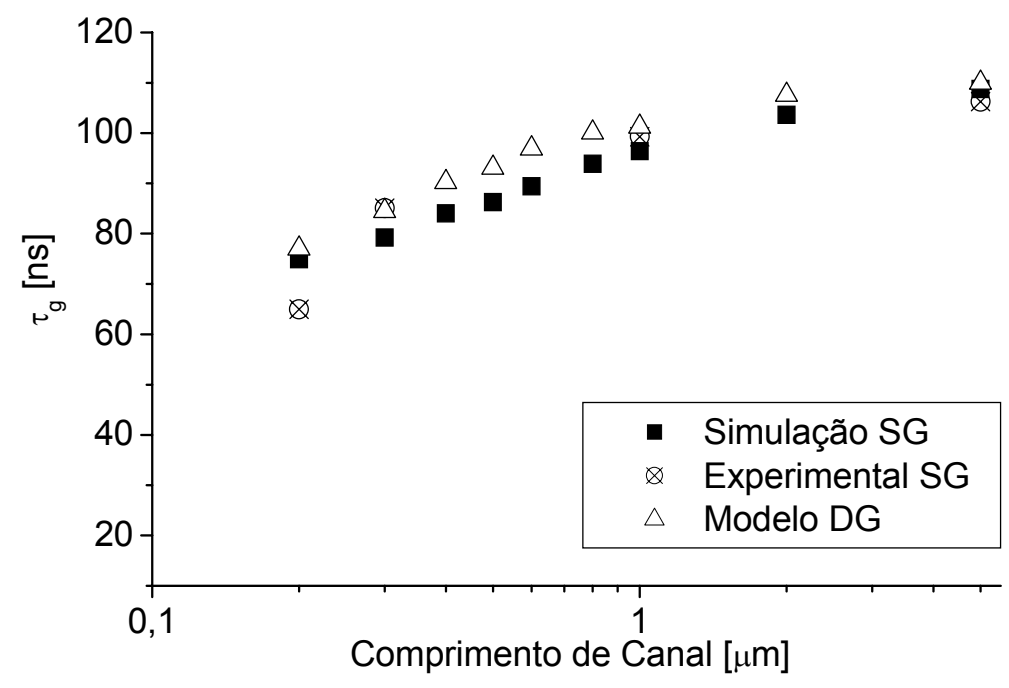

Figura 4-30 - Tempo de vida de geração $\left(\tau_{g}\right)$ em função do comprimento de canal.

Com o propósito de validar a equação (103) para os dispositivos de porta dupla, três diferentes valores do tempo de vida de geração $\left(\tau_{g}\right)$ foram inseridos na equação (99) com objetivo de extrair o valor do tempo de transitório $\left(T_{0}\right)$. Estes valores de $T_{0}$ serviram para alimentar a equação (103) com o propósito de extrair novamente os valores de $\tau_{g}$, para os comprimentos de canal de 0,3 e $5 \mu \mathrm{m}$ com diversas espessuras 
do filme de silício. Estes dados foram sumarizados na Tabela 8. Os valores dos tempos de vida extraídos apresentaram um erro máximo de $4 \%$ na faixa de valores estudada.

Tabela 8 - Tempo de vida de geração extraído para diferentes espessuras do filme de silício e comprimentos de canal.

\begin{tabular}{ccccc}
\hline \multirow{2}{*}{$\begin{array}{c}\text { Comprimento de } \\
\text { Canal }[\mu \mathrm{m}]\end{array}$} & & \multicolumn{3}{c}{$\tau_{\mathrm{g} \text { (input) }}[\mathrm{ns}]$} \\
\cline { 2 - 4 } & $\mathrm{t}_{\mathrm{si}}[\mathrm{nm}]$ & 10 & 100 & 1000 \\
\cline { 2 - 4 } 0,3 & 100 & 9,58 & 95,8 & 958 \\
& 150 & 9,73 & 97,2 & 973 \\
& 200 & 9,87 & 97,5 & 976 \\
\hline \multirow{2}{*}{5} & 100 & 9,78 & 95,9 & 968 \\
& 150 & 9,77 & 97,7 & 977 \\
& 200 & 10,0 & 97,2 & 971 \\
\hline
\end{tabular}

A maior eficiência da capacitância de acoplamento da porta nos dispositivos de porta dupla pode ser observada através do estudo do comportamento do potencial de corpo nestas estruturas. Com esta análise, a menor influência das cargas controladas pelas junções de fonte e dreno nos dispositivos de porta dupla foram consideradas através da inserção de um parâmetro de ajuste dependente da espessura do filme de silício, possibilitando a extrapolação do novo modelo proposto também para os dispositivos de porta dupla.

Nesta seção, os resultados obtidos através do modelo ajustado para os dispositivos de porta dupla foram comparados com as simulações numéricas bidimensionais, também apresentando um excelente ajuste com a redução do comprimento de canal. A sensibilidade do modelo proposto com a variação da espessura do filme de silício mostrou a mesma tendência das simulações numéricas, apresentando um erro máximo de $16 \%$. O tempo de vida de geração extraído a partir do modelo proposto foi comparado com os dados experimentais e simulado dos dispositivos de porta simples, apresentando valores numéricos bem próximos e a mesma tendência com a redução do comprimento de canal.

GALETI, M.; MARTINO, J.A.; SIMOEN, E.; CLAEYS, C.; Improved Model to Determine the Generation Lifetime in Double Gate SOI nMOSFETs, Microelectronics Technology and Devices - SBMicro 2007, ECS Trans., v.9, n.1, p.343, 2007. 


\subsection{ANÁLISE DO TRANSITÓRIO DA CORRENTE DE DRENO EM DISPOSITIVOS FinFETs DE PORTA TRIPLA.}

A diminuição do controle da porta sobre a região do canal tem sido a principal limitação da redução das geometrias na tecnologia SOI MOSFET. Para solucionar esta limitação foram propostas novas arquiteturas de múltiplas portas para melhorar o controle da porta sobre o canal, minimizando os efeitos de canal curto (SCE) e conseqüentemente aumentando a capacidade de fornecimento de corrente destes dispositivos.

Dentro das alternativas propostas na estrutura de múltiplas portas, os dispositivos FinFETs de porta tripla vêm se destacando como fortes candidatos a sucessão da tecnologia SOI planar ${ }^{91}$. Nestes dispositivos a porta envolve a ilha de silício, também conhecida como "fin". Desta forma, a corrente flui através das camadas de inversão formadas acima e nas laterais da ilha de silício. Devido ao maior acoplamento capacitivo que a porta exerce sobre o volume de silício do canal, é significativa a redução dos efeitos de canal curto, assim como o aumento da corrente ${ }^{91}$. Dependendo das dimensões dos "fins" a corrente fluirá predominantemente por cima ou pelas laterais.

A Figura 4-31 mostra esquematicamente um dispositivo FinFET de porta tripla, destacando seus parâmetros geométricos, onde a largura é representada por $W_{\text {fin }}$, a altura por $\mathrm{H}_{\text {fin }}$ e o comprimento de canal por $\mathrm{L}$.

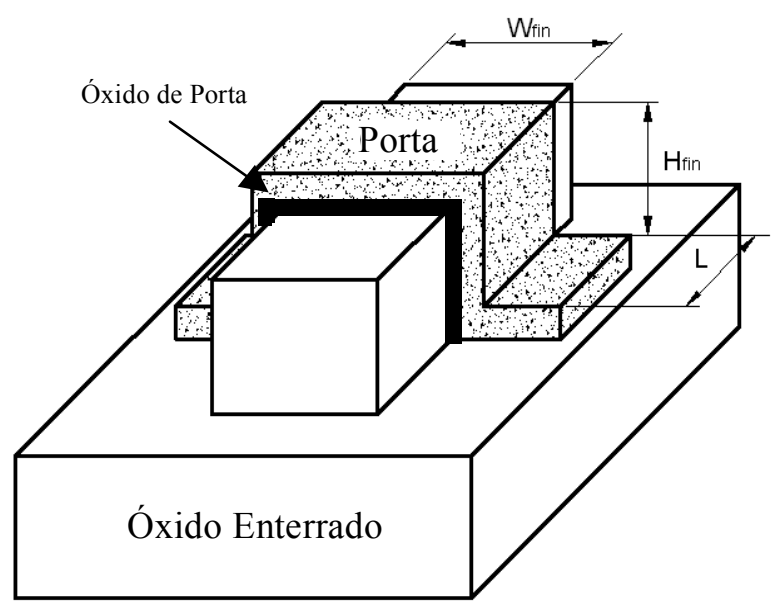

Figura 4-31 - Esquema de um dispositivo FinFET de porta tripla, destacando seus parâmetros geométricos. 
Trabalhos reportados na literatura demonstraram a dependência de diversos parâmetros elétricos com a largura do canal $\left(W_{\text {fin }}\right)$. Dentre outros, pode ser citado o aumento da resistência série de fonte/dreno ${ }^{92}$ com a redução de $W_{\text {fin }}$, o impacto na condutância de saída, no ganho de tensão ${ }^{93}$ e a sua influência no desempenho de circuitos analógicos ${ }^{94,95}$.

Com a crescente integração dos circuitos na tecnologia SOI, os contatos com a região de corpo dos dispositivos vêem freqüentemente sendo eliminados com o objetivo de otimização de área. Se a região de corpo não esta polarizada, então o fenômeno chamado efeito de corpo flutuante (FBEs - Floating Boby Effects) aumenta significativamente prejudicando a performance destes dispositivos ${ }^{96}$.

Normalmente os FBEs são mais pronunciados em dispositivos parcialmente depletados, mas também podem ser observados em dispositivos totalmente depletados quando a segunda interface esta operando na região de acumulação ${ }^{29}$. Um dos FBEs é o transitório da corrente de dreno que acontece quando ocorre uma mudança de estado lógico na porta do transistor ("on" para "off" ou "off" para "on"). Este fenômeno se deve a variação da região de depleção que acompanha a variação do potencial do corpo, que ocorre no momento da mudança de polarização da porta. $O$ equilíbrio do potencial no corpo e conseqüentemente da corrente de dreno é obtido devido ao processo de geração-recombinação que restabelece o equilíbrio da densidade de portadores majoritários na região de corpo do dispositivo ${ }^{29,78,96}$.

No caso de dispositivos com canal $n$, quando a polarização na porta varia da inversão forte para inversão fraca ("on" para "off"), lacunas são geradas para reduzir a região de depleção, fazendo com que esta atinja a espessura correspondente à nova condição de polarização da porta. Enquanto este processo de geração ocorre, a tensão de limiar que inicialmente sofreu um aumento volta a decrescer atingindo o equilíbrio correspondente a condição da porta. O caso inverso ocorre quando a porta varia da inversão fraca para inversão forte ("off" para "on"), neste caso as lacunas se recombinam para aumentar a região de depleção e atingir um maior valor da tensão de limiar correspondente a condição de equilíbrio. 
A dependência do transitório da corrente de dreno com a temperatura, geometria e com a presença da região de implantação de HALO em transistores PD SOI nMOSFETs planares já foi largamente estudada nas seções anteriores. Esta seção tem como objetivo estudar os fenômenos de FBEs nos transistores FinFETs de porta tripla, sendo estes particularmente importantes devido a impossibilidade do uso do contato de corpo nestes dispositivos, por limitações construtivas desta tecnologia.

O interesse particular neste trabalho foi estudar a influência da presença da região de implantação de HALO com a variação da geometria destes dispositivos. Para evitar-se efeitos de canal curto ou estreito as análises foram realizadas em dispositivos com comprimento de canal $(L)$ igual à $10 \mu \mathrm{m}$ e largura $\left(\mathrm{W}_{\text {fin }}\right)$ variando de 1 à $20 \mu \mathrm{m}$.

Os dispositivos foram fabricados sobre lâminas SOI com $N_{a}=1 \times 10^{15} \mathrm{~cm}^{-3}$, espessura do óxido enterrado de $t_{\mathrm{oxb}}=145 \mathrm{~nm}$ e a altura do "fin" $H_{\text {fin }}=60 \mathrm{~nm}$. Após a definição do filme de silício, óxido térmico é crescido com uma espessura de $1 \mathrm{~nm}$, seguido por uma deposição de camada atômica (ALD) de $2 \mathrm{~nm}$ de óxido de hafino $\left(\mathrm{HfO}_{2}\right)$, resultando em uma espessura equivalente de óxido de porta de EOT=2nm. No eletrodo da porta uma camada de $5 \mathrm{~nm}$ de Nitreto de Titânio (TiN) seguida por $100 \mathrm{~nm}$ de silício policristalino foram depositadas.

Primeiramente, foi observado que com $V_{G B}=0 V$ não foi possível observar 0 transitório da corrente de dreno devido à total depleção da região do canal destes dispositivos, ocasionada pela baixa dopagem na região do corpo $\left(\mathrm{N}_{\mathrm{a}}\right)$ juntamente com a pequena altura dos dedos $\left(\mathrm{H}_{\mathrm{fin}}\right)$. Para a obtenção do transitório da corrente de dreno, foi necessário levar a segunda interface a condição de forte acumulação em ambos dispositivos, com e sem a região de HALO. Para conhecer o valor de tensão a partir do qual a segunda interface estaria certamente acumulada foi analisada a segunda derivada das curvas $I_{D S} \times V_{G F}$ com a variação do potencial no substrato, conforme ilustra a Figura 4-32 (A) nos dispositivos com a presença da região de implantação de HALO e (B) sem a região de implantação de HALO. 

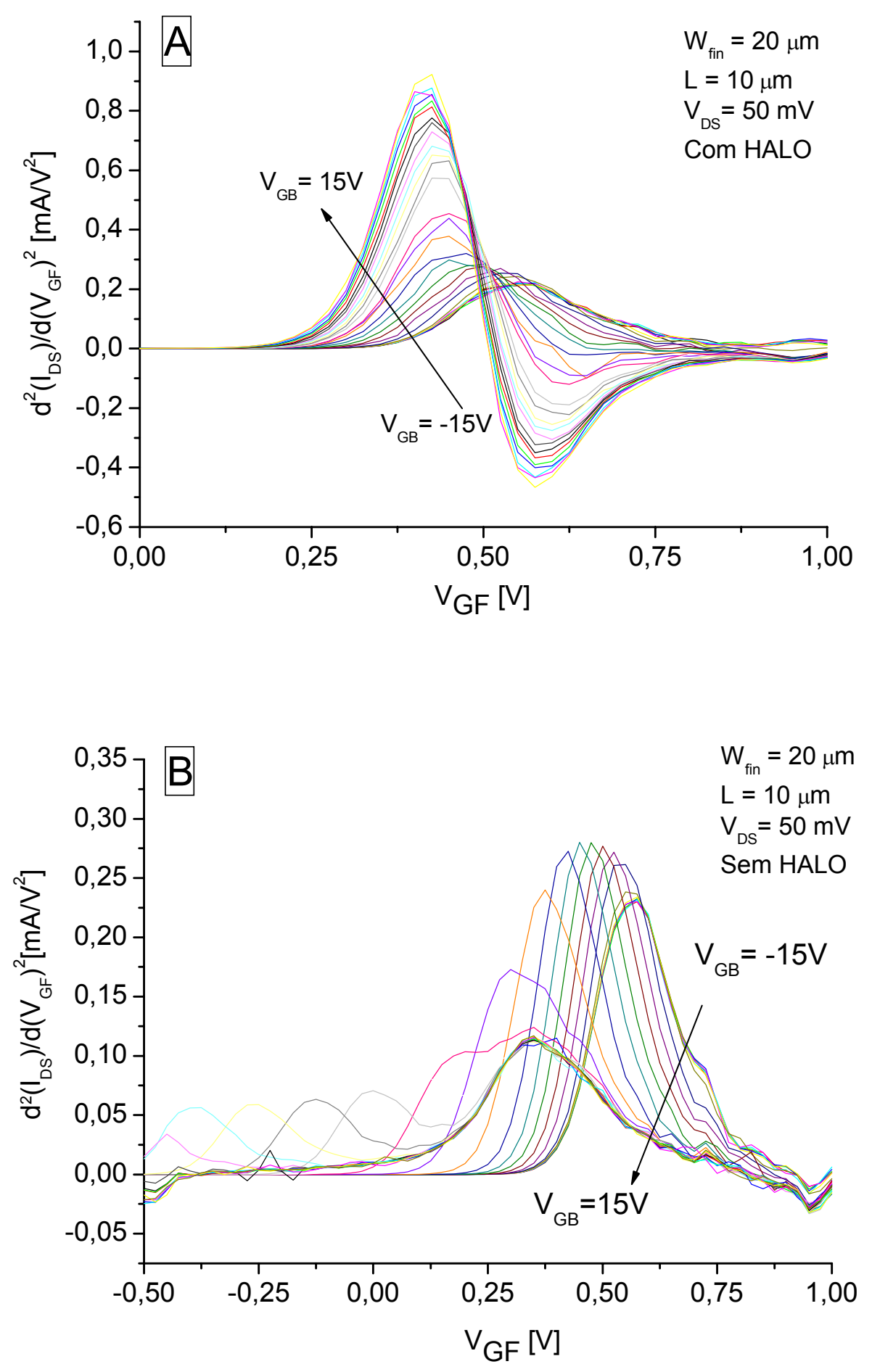

Figura 4-32 - Segunda derivada da corrente de dreno em função da tensão na porta com a variação do potencial no substrato, em dispositivos com (A) e sem (B) HALO. 
A partir das curvas apresentadas na Figura 4-32 foi possível obter a tensão de limiar em função da polarização aplicada ao substrato, para um dispositivo com $L=10 \mu \mathrm{m}$ e $W_{\text {fin }}=20 \mu \mathrm{m}$, conforme a Figura 4-33. A tensão de acumulação da segunda interface com a primeira interface invertida é o valor negativo de tensão a partir do qual não obtêm-se mais variação na tensão de limiar da primeira interface com a variação do potencial no substrato. No caso dos dispositivos sem HALO, a tensão de acumulação da segunda interface se manteve próxima a dos dispositivos com HALO. Contudo, pode-se observar que nos dispositivos sem HALO, para tensão no substrato igual a OV, a segunda interface já esta invertida, este fato também pode ser observado através do segundo pico (à esquerda) que apareceu na segunda derivada das curvas $I_{D S} \times V_{G F}$ apresentadas na Figura 4-32 (B).

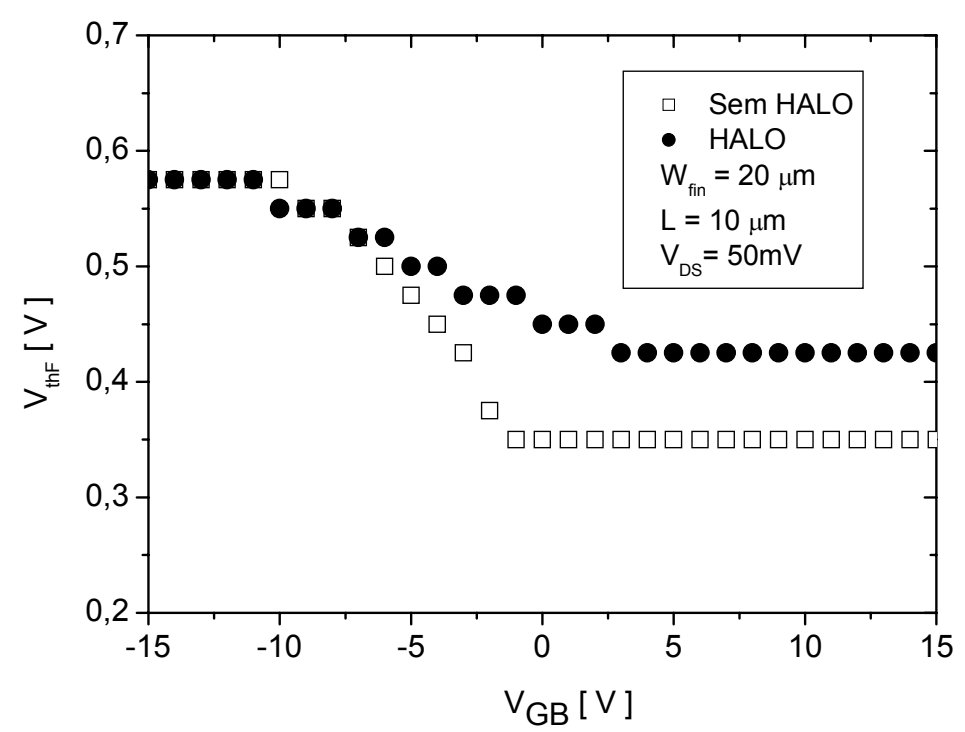

Figura 4-33 - Tensão de limiar em função da polarização aplicada ao substrato, para dispositivos com e sem HALO.

A Figura 4-34 apresenta o valor da tensão de limiar em função da largura do canal $\left(W_{\text {fin }}\right)$, com polarização do substrato de 0 e $-20 \mathrm{~V}$, em dispositivos FinFETs com e sem região de implantação de HALO. O fato da segunda interface dos dispositivos sem HALO estar próxima da inversão com $V_{G B}=0 V$ faz com que haja uma redução na tensão de limiar para todas as larguras de canal analisadas. Já com $-20 \mathrm{~V}$ aplicados ao substrato é garantido que ambos dispositivos estão com a segunda interface operando no regime de acumulação. Sendo assim, com $V_{G B}=-20 V$, é possível estabelecer a 
mesma variação de tensão na porta $\left(\mathrm{V}_{\mathrm{G}_{-} \text {high }} \mathrm{e} \mathrm{V}_{\mathrm{G}_{-} \text {low }}\right)$ para os dois dispositivos e garantir que permaneçam sob as mesmas condições de polarização.

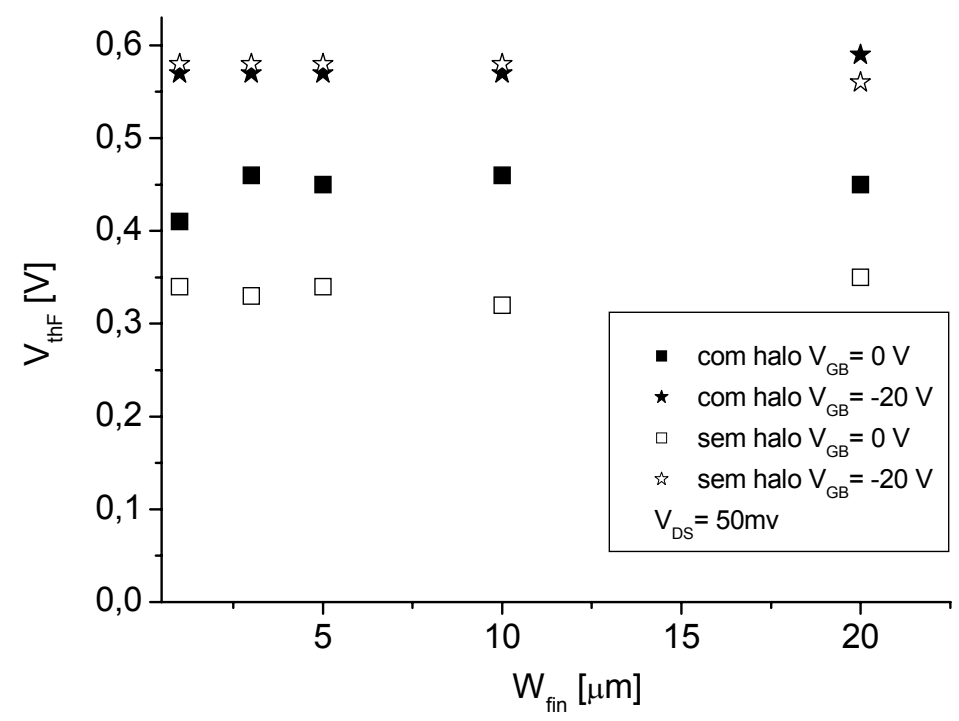

Figura 4-34 - Tensão de limiar em função da largura do canal $\left(W_{\text {fin }}\right)$, com polarização do substrato de 0 e $-20 \mathrm{~V}$, em dispositivos FinFETs com e sem região de implantação de HALO.

Dispositivos com reduzidas espessuras de óxido de porta estão sujeitos a outro $\mathrm{FBE}$, que está associado com o tunelamento direto através do óxido de porta ${ }^{51,97}$. Este fenômeno pode ser explicado através do tunelamento de elétron da banda de valência (EVB) do silício no canal, que ocorre para tensões de porta suficientemente altas, deixando uma quantidade significativa de portadores majoritários (lacunas no caso de SOI nMOSFET) na região de corpo, elevando assim o seu potencial. Com o aumento do potencial no corpo há um decréscimo na tensão de limiar que pode ser observado através de uma inflexão na curva $I_{D S} \times V_{G F}$ e conseqüentemente, por um segundo pico na curva de transcondutância (gm).

A Figura 4-35 apresenta as curvas da transcondutância de dreno normalizadas pela largura de canal $\left(\mathrm{W}_{\text {fin }}+2 \mathrm{H}_{\text {fin }}\right)$ em função da polarização de porta, para dispositivos com e sem a região de HALO e diferentes $W_{\text {fin }}$. $O$ maior valor da transcondutância máxima observado nos dispositivos de maior $W_{\text {fin }}$, se deve ao fato de termos uma mobilidade maior na orientação cristalográfica da parte superior (100) do que na lateral do canal (110). 
Uma redução da amplitude do segundo pico de gm em dispositivos com canal mais estreito também é observada nos dispositivos com e sem a presença da região de implantação de HALO. Esta redução pode ser justificada pelo maior acoplamento das portas laterais dos dispositivos FinFETs ${ }^{98}$ que minimiza a variação do potencial no corpo. Porém, comparando dispositivos com e sem a região de HALO e de mesmo $W_{\text {fin }}$, observa-se uma redução da amplitude do segundo pico de gm nos dispositivos com HALO. Este fato se deve a menor variação do potencial no corpo destes dispositivos e conseqüentemente uma menor variação na tensão de limiar no instante em que ocorre o segundo pico de gm.

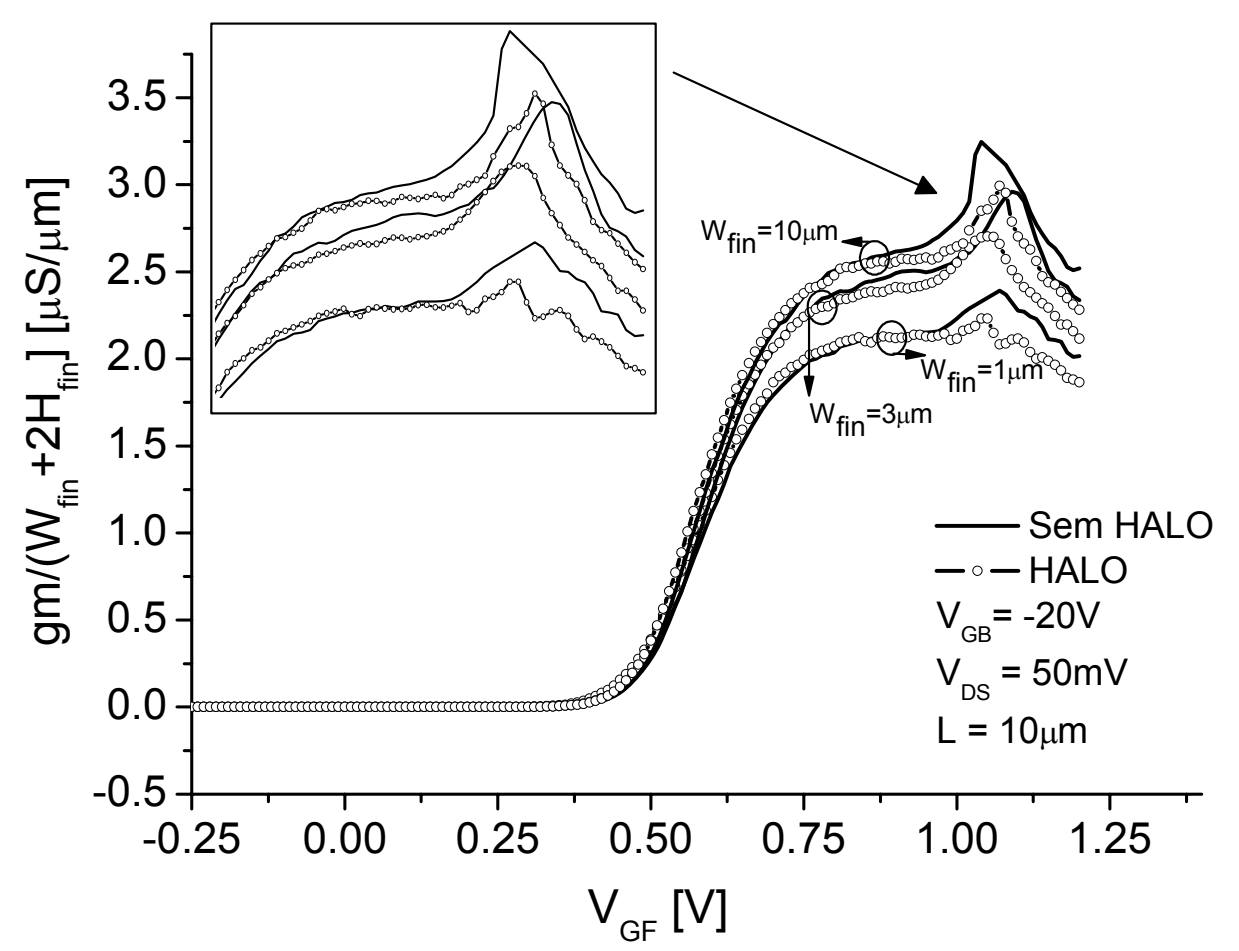

Figura 4-35- Transcondutância de dreno normalizada pela largura de canal em função da polarização de porta, para dispositivos com e sem a região de HALO, variando $\mathrm{W}_{\text {fin }}$.

Através da análise da tensão de limiar juntamente com as curvas de transcondutância, foi possível definir as condições de polarização dos dispositivos FinFETs, possibilitando uma melhor observação do transitório da corrente de dreno. Da mesma forma que o caso do segundo pico da transcondutância, o transitório da corrente de dreno só pode ser observado na condição de acumulação da segunda 
interface. Deste modo, foi usado $\mathrm{V}_{\mathrm{GB}}=-20 \mathrm{~V}$, tensão esta, que não apresentou variação na tensão de limiar na faixa de $W_{\text {fin }}$ estudada.

Na Figura 4-36 pode-se observar o transitório da corrente de dreno normalizado pela corrente no estado de equilíbrio, em um dispositivo com $L=10 \mu \mathrm{m}$ e $W_{\text {fin }}=3 \mu \mathrm{m}$, variando o nível superior $\left(V_{G_{-} \text {high }}\right)$ do degrau de tensão aplicado à porta. Conforme observado previamente em dispositivos PD SOI nMOSFET planares, para valores de $V_{G_{\text {_high }}}$ acima da tensão de limiar obtêm-se uma maior variação na corrente de dreno após a aplicação do degrau negativo de tensão na porta. Para valores de $\mathrm{V}_{\mathrm{G}_{-} \text {high }}$ que se aproximam da região onde acontece o segundo pico na curva da transcondutância de dreno, o transitório gradualmente diminui até inverter o comportamento, quando $\mathrm{V}_{\mathrm{G}_{-} \text {high }}$ atinge a tensão onde ocorre o segundo pico de gm $^{99}$.

Esta inversão no comportamento do transitório se deve ao excesso de portadores majoritários (neste caso lacunas) injetados no corpo através do tunelamento direto pela porta. $\mathrm{O}$ acumulo de lacunas na região de corpo causa um aumento no potencial desta região e conseqüentemente uma redução da tensão de limiar neste momento. Neste caso, o potencial do corpo e conseqüentemente a corrente de dreno atingem o equilíbrio através do processo de recombinação.

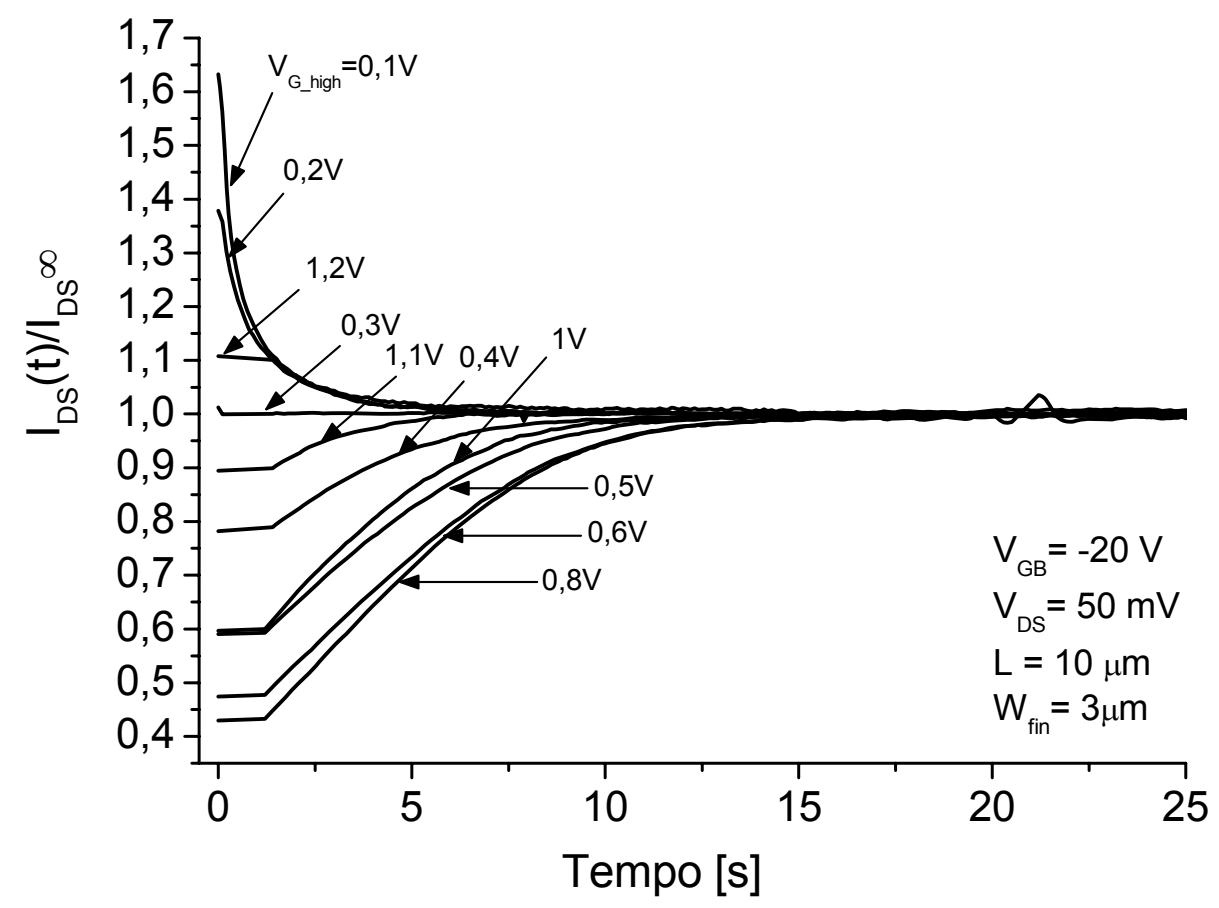

Figura 4-36 - Transitório da corrente de dreno normalizado pela corrente de dreno no estado de equilíbrio, com a variação de $\mathrm{V}_{\mathrm{G}_{-} \text {high }}$. 
Através da análise da tensão de acumulação da segunda interface, da tensão de limiar e do comportamento do transitório da corrente de dreno nos dispositivos de porta tripla foi possível definir $V_{G_{-} H i g h} e V_{G \_L o w}$ garantindo que ambos os dispositivos, com e sem HALO, permaneçam sob as mesmas condições de polarização, e de forma a melhor observar o transitório de corrente. Com $-20 \mathrm{~V}$ aplicado ao substrato, o degrau negativo de tensão aplicado na porta foi estabelecido com $V_{G_{-} \text {High }}=0,8 \mathrm{~V}$ e $V_{G_{-} \text {Low }}=0,3 \mathrm{~V}$.

A Figura 4-37 compara o comportamento da corrente de dreno normalizada por $\left(\mathrm{W}_{\text {fin }}+2 \mathrm{H}_{\text {fin }}\right)$ em função da tensão aplicada à porta, em dispositivos com e sem a presença da região de HALO, para diferentes larguras $W_{\text {fin }}$. É possível observar o aumento da corrente de dreno com a redução de $W_{\text {fin }}$, que se deve ao maior acoplamento das portas laterais em dispositivos mais estreitos. Quando são comparados os dispositivos com e sem HALO, constata-se que os dispositivos que não possuem HALO apresentam menor nível de corrente na região de sublimiar e maior nível na região de fuga $\left(\mathrm{V}_{\mathrm{GF}}=0 \mathrm{~V}\right)$. Na região de fuga o maior nível de corrente observado em dispositivos sem HALO pode ser justificado pela menor barreira de potencial nas junções devido a ausência da região de maior concentração de dopantes proveniente da região do HALO.

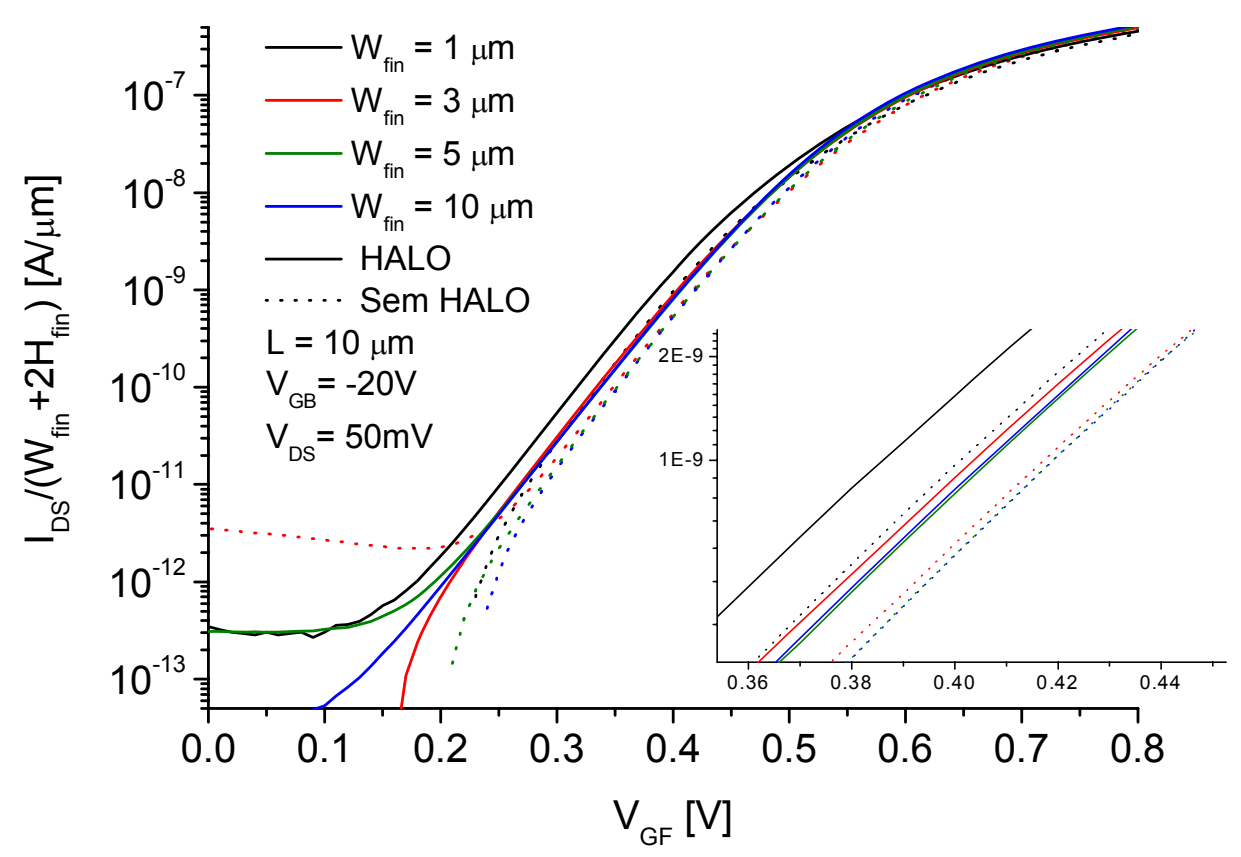

Figura 4-37- Corrente de dreno normalizada por $\mathrm{W}_{\text {fin }}+2 \mathrm{H}_{\text {fin }}$ em função da tensão aplicada à porta, com a variação de $W_{\text {fin }}$, em dispositivos com e sem HALO. 
Após a aplicação do degrau negativo de tensão na porta do transistor é observado o transitório da corrente de dreno, que normalizado por $\left(\mathrm{W}_{\text {fin }}+2 \mathrm{H}_{\text {fin }}\right)$ está apresentado na Figura 4-38. A menor influência da região de acumulação da segunda interface na variação do potencial do corpo, devido ao maior acoplamento das portas gerado com diminuição de $\mathrm{W}_{\text {fin }}$, também pode ser observada através dos menores níveis da corrente de transitório nos dispositivos com $W_{\text {fin }}$ maiores.

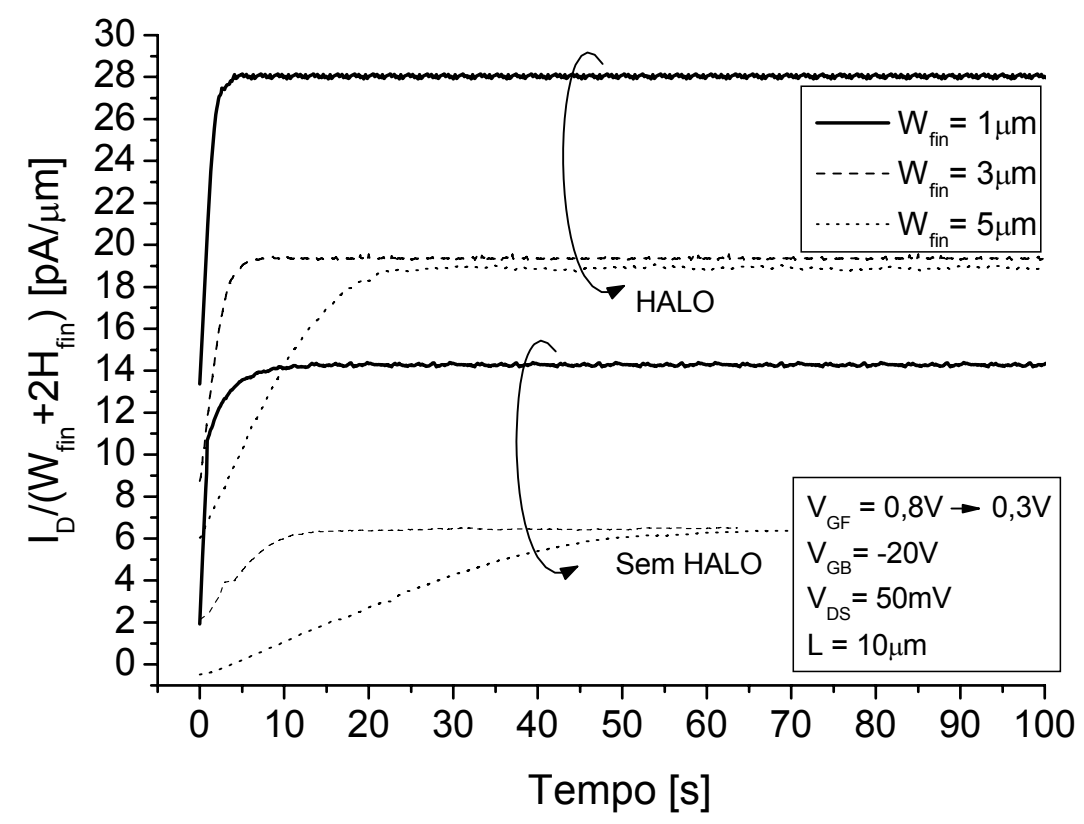

Figura 4-38 - Transitório da corrente de dreno normalizado por $\mathrm{W}_{\text {fin }}+2 \mathrm{H}_{\text {fin }}$.

Através da analise da corrente de dreno durante o transitório normalizada pela corrente no estado de equilíbrio (Figura 4-39) obtêm-se o tempo de transitório. O tempo de transitório, conforme já mencionado anteriormente, é definido como o tempo necessário para a corrente de dreno atingir $90 \%$ do seu valor de equilíbrio. Para avaliar o comportamento dos dispositivos FinFETs com a redução de $W_{\text {fin }}$ é importante observar a dependência do tempo de transitório com a redução desta dimensão. Em ambos dispositivos, com HALO (Figura 4-39 A) e sem HALO (Figura 4-39 B), o tempo de transitório reduz gradualmente com a redução de $W_{\text {fin }}$. Este fato sugere que nos dispositivos mais largos o potencial do corpo esteja assumindo valores mais baixos e conseqüentemente um transitório de corrente maior. Mas quando compara-se dispositivos com e sem HALO, de mesmo $W_{\text {fin }}$, pode-se observar que o tempo de 
transitório aumenta significativamente no caso dos dispositivos sem a região de HALO, mostrando que estes dispositivos estão mais sujeitos aos FBEs.
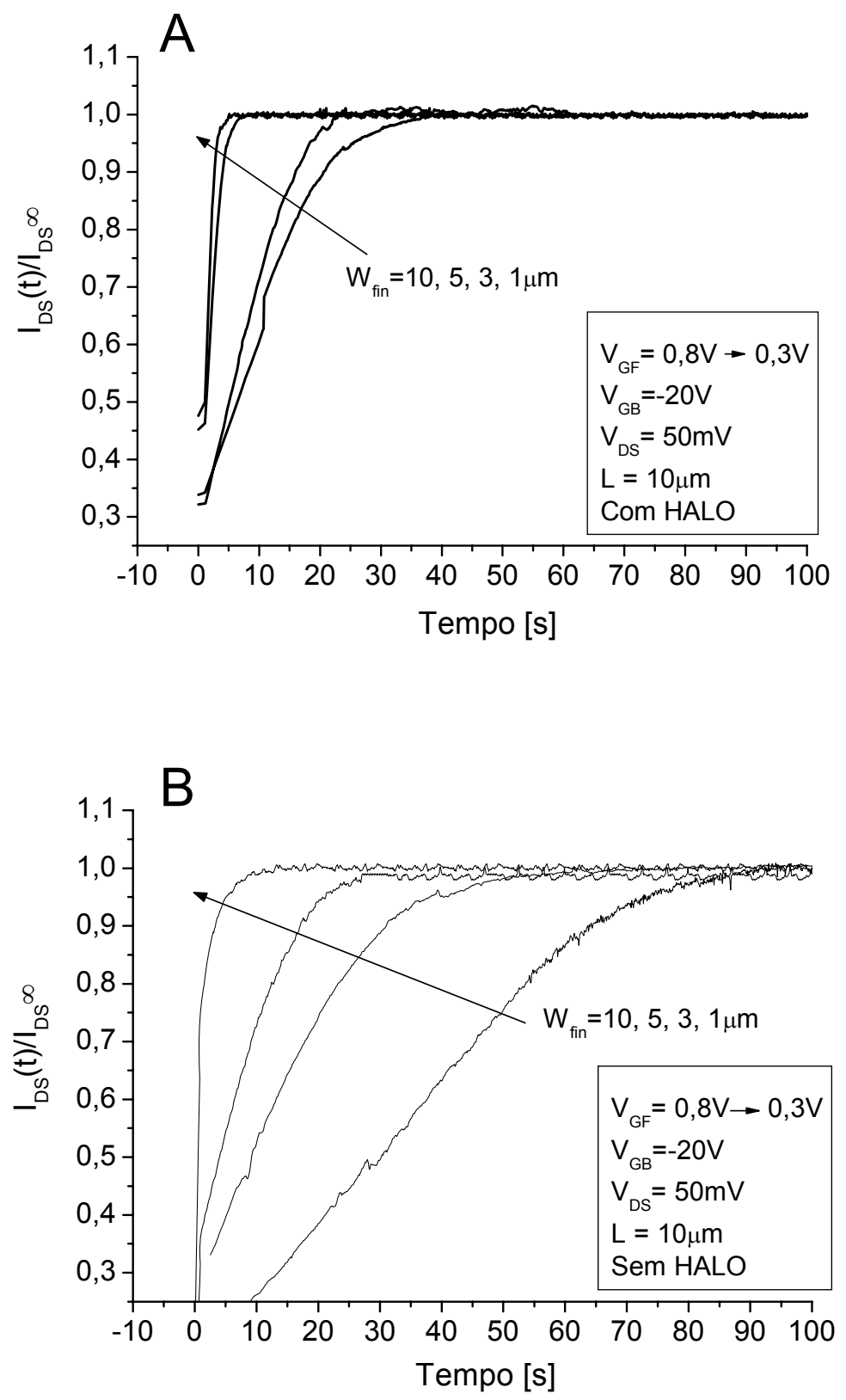

Figura 4-39 - Transitório da corrente de dreno normalizado pela corrente no estado de equilíbrio,com a variação de $W_{\text {fin }},(A)$ com HALO e (B) sem HALO. 
Nesta seção foi estudado o impacto da região de implantação de HALO no efeito de corpo flutuante em dispositivos FinFETs de porta tripla. Os dispositivos com e sem HALO apresentaram uma redução na amplitude do segundo pico da transcondutância com a redução da largura dos dedos $\left(\mathrm{W}_{\text {fin }}\right)$. Comparando dispositivos com o mesmo $W_{\text {fin }}$, com e sem HALO, foi possível ainda observar uma redução na amplitude do segundo pico nos dispositivos com HALO.

Finalmente, o transitório da corrente de dreno foi analisado para ambos os dispositivos, com a variação de $W_{\text {fin }}$, onde foi possível observar a redução do tempo de transitório com a redução deste parâmetro. Contudo, quando os dispositivos com o mesmo $W_{\text {fin }}$ foram comparados pôde-se observar que o tempo de transitório aumenta substancialmente nos dispositivos sem região do HALO. Este fato sugere que a variação do potencial do corpo nos dispositivos sem a presença da região de HALO é maior, tornando estes dispositivos mais susceptíveis aos efeitos de corpo flutuante estudados. 


\section{CONCLUSÕES}

Este trabalho teve como objetivo apresentar uma análise detalhada, teórica e experimental, do transitório da corrente de dreno em transistores SOI nMOSFET de porta simples, dupla e tripla, assim como a proposta de um novo modelo para extração do tempo de vida de portadores com aplicação em dispositivos de canal reduzido.

Primeiramente, através de simulações numéricas bidimensionais e dados experimentais foram realizados estudos sobre a influência da espessura do óxido de porta no potencial de superfície e na energia de ativação, para uma variação de temperatura de 20 a $80{ }^{\circ} \mathrm{C}$, em dispositivos SOI nMOSFET parcialmente depletados de porta simples. A expressão para o cálculo do tempo de vida de geração foi simplificada de forma a se utilizar apenas três termos: $F, n_{i}$ e $T_{0}$. Na mesma faixa de temperatura, a máxima variação observada no fator $\mathrm{F}$ foi de $11 \%$. A sensibilidade deste termo com uma variação de $\pm 10 \%$ na espessura do óxido de porta e na concentração de dopantes da região do canal também foi analisada, e como resultado foi obtida uma variação máxima de $13 \%$ no fator $F$. Negligenciando-se a variação do fator $F$ com a temperatura foi possível propor um modelo simples para estimar o tempo de vida de geração em função da temperatura. O modelo proposto foi experimentalmente aplicado para a tecnologia de $0,13 \mu \mathrm{m}$ em dispositivos SOI nMOSFETs parcialmente depletados de porta simples e comparados com resultados obtidos através de simulações numéricas bidimensionais e o máximo erro encontrado na determinação deste parâmetro foi por volta de $5 \%$.

Neste trabalho também foi analisado, nos dispositivos parcialmente depletados de porta simples, o impacto da presença da região de implantação de HALO no transitório da corrente de dreno com a redução do comprimento de canal. Com a redução do comprimento de canal ocorre um maior acoplamento capacitivo entre as junções de fonte/dreno e o corpo do dispositivo provocando assim a redução do efeito de corpo flutuante. Desta forma, após a variação do potencial na porta, os dispositivos de comprimento de canal reduzido, com e sem HALO, apresentaram um aumento no valor inicial do transitório do potencial de corpo. Já, na região de equilíbrio o potencial de corpo não foi influenciado pelo comprimento de canal. 
Em dispositivos sem HALO e de menores comprimentos de canal foi observado uma redução significativa da tensão de limiar no instante inicial, devido ao efeito de canal curto, e conseqüentemente um aumento na corrente do dreno durante todo transitório. Nos dispositivos com HALO, com a redução do comprimento de canal há um aumento na concentração efetiva de dopantes, devido a presença da região de implantação de HALO, ocasionando um aumento da tensão de limiar no estado de equilíbrio.

Através da analise detalhada da influência da região de implantação de HALO no efeito de corpo flutuante foi possível, partir de um modelo já existente na literatura, propor um novo modelo para transistores parcialmente depletados de porta simples que considera o impacto do perfil não uniforme da concentração de dopantes na região do canal, bem como a influência das cargas de depleção controladas pelas junções de fonte e dreno. Com a implementação destas novas considerações tornou-se viável a análise do transitório da corrente de dreno e o cálculo do tempo de vida de geração nestes dispositivos, em função da redução do comprimento de canal.

Dados experimentais e simulações numéricas bidimensionais foram comparados com os resultados obtidos através do novo modelo e apresentaram um ajuste satisfatório, tanto com a variação do comprimento de canal e concentrações de dopantes da região de canal e da região de implantação de HALO como com a variação da temperatura. Com a variação de $\pm 20 \%$ nas concentrações da região de canal e de implantação de HALO foi obtido um erro máximo de $9,2 \%$ na extração do tempo de transitório através do modelo proposto, adotando como referência os valores obtidos através das simulações numéricas.

O estudo do comportamento do potencial de corpo nas estruturas de porta dupla demonstrou a maior eficiência da capacitância de acoplamento entre a porta e o corpo nestes dispositivos. Através desta análise foi possível inserir no modelo proposto um parâmetro de ajuste dependente da espessura do filme de silício. Este parâmetro tem como finalidade contabilizar a menor influência das cargas controladas pelas junções de fonte e dreno nestes dispositivos, possibilitando a extrapolação do modelo proposto também para os dispositivos de porta dupla. 
Os resultados obtidos através do modelo proposto, para os dispositivos de porta dupla, foram validados através de simulações numéricas bidimensionais e da mesma forma que os resultados obtidos para os de porta simples apresentaram um excelente ajuste do transitório da corrente de dreno com a redução do comprimento de canal. Quando comparados com as simulações numéricas, o método proposto aplicado em dispositivos de porta dupla com a variação da espessura do filme de silício apresentou a mesma tendência com um erro máximo de $16 \%$ no tempo de transitório. Os tempos de vida de geração extraídos a partir das curvas geradas pelo modelo proposto foram comparados com resultados obtidos dos dados experimentais e simulados dos dispositivos de porta simples, apresentando valores numéricos bem próximos. Estes resultados eram esperados, visto que, os parâmetros do filme de silício não foram variados entre as duas estruturas.

Por fim, foi estudado neste trabalho o efeito de corpo flutuante com a variação da geometria em dispositivos FinFET de porta tripla, com e sem a região de implantação de HALO. Em dispositivos mais estreitos observa-se uma redução na transcondutância máxima e uma redução na amplitude do segundo pico da transcondutância. A redução na transcondutância máxima pode ocorrer pelo fato de termos uma mobilidade maior na orientação cristalográfica superficial (100) do que na lateral (110) e a redução na amplitude do segundo pico foi justificada pelo maior acoplamento das portas laterais que ocorre em dispositivos com menor largura de canal.

A análise do transitório da corrente de dreno nos transistores FinFETs de porta tripla demonstrou em ambos dispositivos, com e sem HALO, a redução do tempo de transitório com a diminuição da largura do canal. Através da comparação entre ambos dispositivos, com e sem HALO, de mesma largura de canal foi possível observar que o tempo de transitório aumenta significativamente no caso dos dispositivos sem a região de HALO.

Como seqüência deste trabalho pretende-se obter o tempo de vida de portadores em transistores de múltiplas portas (como o FinFET) a partir do estudo do transitório da corrente de dreno realizado neste trabalho. 


\section{REFERÊNCIAS}

1. FRANK, D. J.; et al. Devices scaling limits of Si MOSFETs and their application dependencies. Proceedings of the IEEE, v. 89, n.3, p. 259, 2001.

2. DOYLE, B.; et al. Transistor elements for $30 \mathrm{~nm}$ physical gate lengths and beyond. Intel Technologic journal. v. 6, n.2, p. 42, 2002.

3. IZUMI, K.; Proceedings of the Fourth International Symposium on Silicon-OnInsulator Technology and Advices, v. 90, n.6, p.3, 1990.

4. COLINGE, J. P.; Thin-film SOI technology: the solution to many submicron CMOS problems. Technical Digest International Electron Devices Meeting, 1989. IEDM. p. 817, 1989.

5 FOSSUM, J. G.; TRIVEDI, V. P.; WU, K. Extremely scale fully depleted SOI CMOS. Proceedings IEEE Int. SOI Conference. p. 135, 2002.

6. COLINGE, J. P.; Novel gate concepts for MOS devices. Proceedings $34^{\text {th }}$ ESSDERC, p.45, 2004.

7. DAVIS, G. E.; et al. IEEE Trans. on Nuclear Science, v. 32, p. 4432, 1985.

8. LERAY, J. L.; et al. From substrate to VLSI: investigation of hardened SIMOX without epitaxy, for dose, dose rate and SEU phenomena. IEEE Transaction on Nuclear Science, v. 35, n.6, p.1355, 1988.

9. KRULL, W. A.; LEE, J. C.; Demonstration of the benefits of SOI for high temperature operation. Proceedings of SOS/SOI Technology Workshop IEEE. p. 69, 1988.

10. MASZARA, W. P.; Proceedings of the Fourth International Symposium on Silicon-On-Insulator Technology and Devices. v. 90, n.6, p.199, 1990.

11. LEMNIOS, Z. J.;RADACK, D. J.; ZOLPER, J. C.; The future of silicon-on-insulator (SOI) technology in microelectronic systems. Proceedings IEEE Int. SOI Conference. p. 9, 2004.

12. CRISTOLOVEANU, S.; FERLET-CAVROIS, V.; Introduction to SOI MOSFETs: Context, radiation effects, and future trends, Int. Journal High Speed Electron. Syst. v.14, n.2, p.465, 2004. 
13. SHAHIDI, G. G.; SOI technology for the GHz era. IBM J. Res. Develop., v. 46, n.2, p. 121, 2002.

14. PARK, S. B.; et al. ; A $0.25 \mu \mathrm{m}, 600-\mathrm{MHz}, 1.5 \mathrm{~V}$, fully depleted SOI CMOS 64-bit microprocessor. IEEE Journal Solid-State circuits, v. 34, n.11, p.1436, 1999.

15. FIORENZA, J. G.; DEL ALAMO, J. A.; Experimental comparison of RF power LDMOSFETs on thin-film SOI and bulk silicon. IEEE Transaction on Electron Devices. v. 49, n.4, p. 687, 2002.

16. WEI, L.; et al.; Vertically integrated SOI circuits for low-power and high-performance applications. IEEE Transaction Very Large Scale Integration System. v.10, n.3, p.351, 2002.

17. AJMERA, A.; et al.; A $0.22 \mu \mathrm{m}$ CMOS-SOI technology with a Cu BEOL. VLSI Symp. Tech. Dig. p.15, 1999.

18. FRANCK, D.; LAUX, S.; FISCHETTI, M.; Monte Carlo simulation of a $30 \mathrm{~nm}$ dualgate MOSFET: how short can $\mathrm{Si}$ go?. Technical Digest International Electron Devices Meeting, 1992. IEDM. p. 553, 1992.

19. WONG, H-S.; FRANK, D. J.; SOLOMON P.; Device design considerations for double-gate, ground-plane, and single-gated ultra-thin SOI MOSFET's at the $25 \mathrm{~nm}$ channel length generation. Technical Digest International Electron Devices Meeting, 1998. IEDM. p. 407, 1998.

20. HISAMOTO, D.; KAGA, T.; TAKEDA, E.; Impact of the vertical SOI 'DELTA' structure on planar device technology. IEEE Transaction on Electron Devices. v.38, n.1, p.1419, 1991.

21. HISAMOTO, D.; et al.; A folded-channel MOSFET for deep-sub-tenth micron era.Technical Digest International Electron Devices Meeting, 1998. IEDM. p. 1032, 1998.

22. CHAU, R.; et al.; ISSDMC Nagoya Japan 68, 2002.

23. DAUGÉ, F.; et al.; Coupling effects and channel separation in FinFETs. Solid-State Electronics, v.48, n.4, p.535, 2004.

24. HALL, R. N.; Electron-hole recombination in germanium. Physical Review. v.87, p.387, 1952. 
25 SHOCKLEY, W.; READ, W. T.; Statistics of the recombination of holes and electrons. Physical Review. v.87, p. 835, 1952.

26 Hall, R. N.; Recombination processes in semiconductors. Proc. IEE. v.106B, p. 923, 1960.

27. MASZARA, W. P.; et al.; Quality of SOI film after surface smoothing with hydrogen annealing, touch-polishing; in SOI Conference/1997, Proceedings IEEE International, p.130, 1997.

28. SHAHIDI, G.G.; et al.; A room temperature $0.1 \mu \mathrm{m}$ CMOS on SOI. IEEE Transaction on Electron Devices. v. 41, n.12, p.2405, 1994.

29. COLINGE, J. P.; Silicon-On-Insulator Technology: Materials to VLSI, $3^{\text {nd }}$ Edition, Boston, Kluwer Academic Publishers, 2004.

30. HARRIS, E.P.; et al., 1997 GOMAC, Digest of Papers, p. 329, 1997.

31 LIM, H. K.; FOSSUM, J. G.; Transient Drain Current and Propagation Delay in SOI CMOS. IEEE Transaction on Electron Devices. v.31, n.9, p.1251-1258, 1984.

32 RUDENKO, T; et al.; Determination of film and surface recombination in thin-film SOI devices using gated-diode technique. Solid-State Electronics, v.48, n.3, p.389, 2004.

33. LIM, H. K.; FOSSUM, J. G.; Threshold voltage of thin-film silicon-on-insulator (SOI) MOSFETs. IEEE Transaction on Electron Devices. v.30, n.10, p.1244, 1983.

34. MULLER, R. S.; KAMINS, T. I.; Devices Electronics for Integrated Circuits, , New York, J. Wiley \& Sons, 1986.

35. WEI, A.; SHERONY, M.J.; ANTONIADIS, D.A.; Effect of floating-body charge on SOI MOSFET design. IEEE Transaction on Electron Devices. v.45, n.2, p.430, 1998.

36. SHEPARD, K.L.; KIM, DAE-JIN; Body-voltage estimation in digital PD-SOI circuits and its application to static timing analysis. IEEE Transactions on Computer-Aided Design of Integrated Circuits and Systems. v.20, n.7, p.888, 2001.

37. FUNG, S.K.H.; MANSUN, CHAN; KO, P.K.; Experimental characterization of transient floating body effect in non-fully depleted SOI MOSFET. IEEE International SOI Conference Proceedings. p.80, 1997. 
38. DONGWOOK, SUH; FOSSUM, J.G.; Dynamic floating-body instabilities in partially depleted SOI CMOS circuits. Electron Devices Meeting, 1994. Technical Digest., International. p.661, 1994.

39. VEERARAGHAVAN, S.; FOSSUM, J. G.; A physical short-channel model for the thin-film SOI MOSFET applicable to device and circuit CAD. IEEE Transaction on Electron Devices. v.35, n.11, p.1866, 1988.

40. FRANK, D. J.; et al.; Device scaling limits of Si MOSFETs and their application dependencies, Proceedings of the IEEE, v.89, n.3, p.259, 2001.

41. IWAI, H.; CMOS technology-year 2010 and beyond. IEEE Journal of Solid-State Circuits. v.34, n.3, p.357, 1999.

42. KANYU, M. C.; et al.; Modeling of pocket implanted MOSFETs for anomalous analog behavior, Electron Devices Meeting, 1999. IEDM Technical Digest. International. p.171, 1999.

43. MII, Y., et al.; Experimental high performance sub-0.1 $\mu \mathrm{m}$ channel nMOSFET's. IEEE Electron Devices Letters. v.15, n.1, p.28, 1994.

44. BIN, YU; et al.; Short-channel effect improved by lateral channel-engineering in deep-submicronmeter MOSFET's. IEEE Transaction on Electron Devices. v.44, n.4, p.627, 1997.

45. KHANNA, MANOJ K.; et al.; An analytical model for anomalous threshold voltage behavior of short channel MOSFETs. Solid-State Electronics, v.41, n.9, p.1386, 1997.

46. GWOZIECKI, R.; et al.; Optimization of $V_{\text {th }}$ roll-off in MOSFET's with advanced channel architecture-retrograde doping and pockets, IEEE Transaction on Electron Devices. v.46, n.7, p.1551, 1999.

47. UENO, H.; et al.; Impurity-profile-based threshold-voltage model of pocket-implanted MOSFETs for circuit simulation. IEEE Transaction on Electron Devices. v.49, n.10, p.1783, 2002.

48. GROVE, A. S.; Physics and Technology of Semiconductor Devices, New York, J. Wiley \& Sons, p. 326, 1967. 
49. STURM, J. C.; TOKUNAGA, K.; Dependence of transconductance on substrate bias in ultrathin silicon-on-insulator MOS transistors. Electronics Letters. v.25, n.18, p.1233, 1989.

50. YANG, J-W.; FOSSUM, J. G.; WORKMAN, G. O.; HUANG, C-L; A physical model for gate-to-body tunneling current and its effects on floating-body PD/SOI CMOS devices and circuits. Solid-State Electronics. v.48, n.2, p.259, 2004.

51. MERCHA, A.; et al.; "Linear kink effect" induced by electron valence band tunneling in ultra thin gate oxide bulk and SOI MOSFETS. IEEE Transaction on Electron Devices. v.50, n.7, p.1675, 2003.

52. RAFÍ, J. M.; et al.; Impact of gate tunneling floating-body charging on drain current transients of $0.10 \mu \mathrm{m}$-CMOS partially depleted SOI MOSFETs, Solid-State Electronics, v.48, n.7, p.1211, 2004.

53. LIM, H. K.; FOSSUM, J. H.; Current-voltage characteristics of thin-film SOI MOSFET's in strong inversion. IEEE Transaction on Electron Devices. v.31, n.4, p.401, 1984.

54. SUM, S. C.; PLUMMER, J. D.; Electron mobility in inversion and accumulation layers on thermally oxidized silicon surfaces. IEEE Transaction on Electron Devices. v.27, n.8, p.1497, 1980.

55. SZE, S. M.; Physics of Semiconductor Devices, $2^{\text {nd }}$ edition, New York: J. Wiley \& Sons, 1981.

56. JOACHIM, H. O.; et al.; Simulation and two-dimensional analytical modeling of subthreshold slope in ultrathin-film SOI MOSFETs down to $0.1 \mu \mathrm{m}$ gate length. IEEE Transaction on Electron Devices. v.40, n.10, p.1812, 1993.

57. SHIN, H. S.; et al; Channel Length Independent Subthreshold Characteristics in Submicron MOSFET's. IEEE Electron Devices Letters, v.19, n.4, p.137, 1998.

58. GENTINNE, B.; et al.; Measurement and two-dimensional simulation of thin-film SOI MOSFETs: intrinsic gate capacitances at elevated temperatures. Solid-State Electronics, v.39, n.11, p.1613, 1996.

59. RUDENKO, T.; On the high-temperature subthreshold slope of thin-film SOI MOSFETs. IEEE Electron Devices Letters. v.23, n.3, p.148, 2002. 
60. GENTINE, B.; Fully depleted SOI-CMOS technology for high temperature IC applications. Solid-State Electronics. v.46, n.1-3, p.1, 1997.

61. VU, D. P., BODEN, M. J.; HENDERSON, W. R.; et al; High temperature operation of ISE devices and circuits. IEEE SOS/SOI Technology Conference, p.165, 1989.

62. GENTINE, B.; A Study of the Potencial of SOI Technology for Analog Applications, Tese (Doutorado). UCL-Bélgica, 1996.

63. Avant! MEDICl, Two-Dimensional Devices Simulator, vers. 4.1 .0 (1998).

64. CAUGHEY, D. M.; THOMAS, R. E.; Carrier Mobilities in Silicon Empirically Related to Doping and Field. Proceedings of the IEEE, v.55, n.12, p. 2192, 1967.

65. SELBERHERR, S.; Process and Device Modeling for VLSI, Microelectron. Reliab., v. 24, n.2, p. 225, 1984.

66 YAMAGUCHI, K.; Field-Dependent Mobility Model for Two-Dimensional Numerical Analysis of MOSFET's. IEEE Transaction on Electron Devices. v.26, n.7, p.1068, 1979.

67. YAMAGUCHI, K.; A Mobility Model for Carriers in the MOS Inversion Layer. IEEE Transaction on Electron Devices. v. 30, n.6, p. 658, 1983.

68. SLOTBOOM, J. W.; The pn Product in Silicon. Solid-State Electronics. v.20, n.4, p.279, 1977.

69. VENKATESAN, S.; PIERRET, R.; NEUDECK, G.; A Linear Sweep Technique for Determining Generation Lifetime in SOI MOSFETS. IEEE Transaction on Electron Devices. v.41, n.4, p.567, 1994.

70. IZUMI, K.; DOKEN, M.; ARIYOSHI, H.; C.M.O.S. devices fabricated on buried $\mathrm{SiO} 2$ layers formed by oxygen implantation into silicon. IEEE Electron Devices Letters. v.14, n.18, p.593, 1978.

71. BRUEL, M.; Silicon on insulator material technology. IEE Electronics letters. v.31, n.14, p.1201, 1995. 
72. PENNISE, C.A.; BOESCH, H.E., JR.; Photoconduction measurements of the charge trapping and transport in bond-and-etch-back buried oxides. IEEE Transactions on Nuclear Science. v.39, n.6, p.2139, 1992.

73. IONESCU, A. M.; A New Lifetime Characterization Technique Using Drain Current Transients in SOI Material. Solid-State Electronics. v.39, n.12, p.1753, 1996.

74. SCHRODER, D. K.; Semiconductor Material and Device Characterization, New York, John Wiley \& Sons.

75 SCHRODER, D. K.; The Concept of Generation and Recombination Lfetimes in Semiconductors. IEEE Transaction on Electron Devices. v.29, n.8, p.1336, 1982.

76. YASUDA, N., et al.; New Carrier Lifetime Measurement Method for Fully Depleted SOI MOSFET's. IEEE Transaction on Electron Devices. v.39, n.5, p.1197, 1992.

77. H. SHIN, et al.; Measurement of Carrier Generation Lifetime in SOI Devices. SolidState Electronics. v. 43, n.2, p.349, 1999.

78. IOANNOU, D. E.; et al.; Characterization of Carrier Generation in EnhancementMode SOI MOSFET's. IEEE Electron Device Letters, v.11, n.9, p.409, 1990.

79. ZERBST, M.; Relaxationseffekte and Halbleiter Isolator Grenzflachen, Z. Angew. Phys., v. 22, n.12, p.30, 1966.

80. MARTINO, J. A.; GALETI, M.; RAFÍ, J. M.; et al.; Simple Model to Estimate the Temperature Dependence of the Generation Lifetime Extracted from Drain Current Transients in Partially Depleted SOI nMOSFETs. Journal of The Electrochemical Society. v.153, n.5, p.502, 2006.

81. GALETI, M.; MARTINO, J. A.; SIMOEN, E.; CLAEYS, C.; Temperature and Oxide Thickness Influence on the Generation Lifetime Determination in Partially Depleted SOI nMOSFETs. Microelectronics Technology and Devices - SBMicro 2005, ECS Trans., v.8, n.8, p.538, 2005.

82. SHIN, H. C.; et al.; Analysis of Floating Body Induced Transient Behaviors in Partially Depleted Thin Film SOI Devices. IEEE Transaction on Electron Devices. v.43, n.2, p.318, 1996. 
83. GALETI, M.; MARTINO, J. A.; SIMOEN, E.; CLAEYS, C.; Impact of Halo Implantation on the Lifetime Assessment in Partially Depleted SOI Transistors. High Purity Silicon 9 - 210th ECS Meeting. v.3, n.4, p.351, 2006.

84. GALETI, M.; MARTINO, J. A.; SIMOEN, E.; CLAEYS, C.; Improved Model to Determine the Generation Lifetime in Short Channel SOI nMOSFETs. Silicon-onInsulator Technology and Devices 13 - 211th ECS Meeting. v.6, n.4, p.387, 2007.

85. BALESTRA, F.; et al.; Double-Gate Silicon-On-Insulator Transistor with Volume Inversion: A New Device with Greatly Enhanced Performance. IEEE Electron Device Letters. v.8, n.9, p.410, 1987.

86. KRANTI, A.; et al.; Laterally Asymmetric Channel Engineering in Fully Depleted Double Gate SOI MOSFETs for High Performance Analog Applications, Solid-State Electronics. v.48, n.6, p.947, 2004.

87. COLINGE, J.P.; Multi-Gate SOI MOSFETs. Microelectronic Engineering. v.84, n.9, p.2071, 2007.

88. LEE, C. W. ; et al. ; Device Design Guidelines for Nano-Scale MuGFETs, SolidState Electronics, v.51, n.3, p.505, 2007.

89. GALETI, M.; MARTINO, J.A.; SIMOEN, E.; CLAEYS, C.; Improved Model to Determine the Generation Lifetime in Double Gate SOI nMOSFETs, Microelectronics Technology and Devices - SBMicro 2007, ECS Trans., v.9, n.1, p.343, 2007.

90. GAUBAS, E.; VANHELLEMONT, J.; Comparative Study of Carrier Lifetime Variations with Doping in $\mathrm{Si}$ and Ge, High Purity Silicon 9 - 210th ECS Meeting. v.3, n.4, p. 339, 2006.

91. HISAMOTO, D.; FinFET-a Self-Aligned Double-Gate MOSFET Scalable to $20 \mathrm{~nm}$. IEEE Transaction on Electron Devices. v.47, n.12, p.2320, 2000.

92. Rudenko, T.; et al.; Substrate Bias Effect Linked to Parasitic Series Resistance in Multiple-Gate SOI MOSFETs. IEEE Electron Device Letters. v.28, n.9, p.834, 2007.

93. KILCHYTSKA, V.;et al.; Perspective of FinFETs for Analog Applications. Solid-State Device Research conference, 2004. ESSDERC 2004. Proceeding of the 34th European. p. 65, 2004. 
94. RASKIN, J.-P.; et al.; Analog/RF Performance of Multiple Gate SOI Devices: Wideband Simulations and Characterization. IEEE Transaction on Electron Devices. v.53, n.5, p.1088, 2006.

95. LEDERER, D.; et al.; FinFET Analogue Characterization from DC to $110 \mathrm{GHz}$. Solid-State Electronics. v. 49, n. 9, p.1488, 2005.

96. CRISTOLOVEANU, S.; LI, S.S.; "Eletrical Characterization of Silicon-OnInsulator Materials and Devices", $1^{\text {nd }}$ Edition, Boston: Kluwer Academic Publishers, 1995.

97. PRETET, J.; et al.; New Mechanism of Body Charging in Partially Depleted SOIMOSFETs with Ultra-thin Gate Oxides. Proceeding of the 32nd European Solid-State Device Research Conference, 2002. p.515, 2002.

98. AKARVARDAR, K.; et al.; A Two-Dimensional Model for Interface Coupling in TripleGate Transistors. IEEE Transaction on Electron Devices. v.54, n.4, p.767, 2007.

99. RAFÍ, J. M.; et al.; Gate Induced Floating Body Effects in TiN/SiON and TiN/HfO Gate Stack Triple Gate SOI nFinFETs. Solid-State Electronics. v. 51, n. 9, p.1201, 2007. 